\title{
LILIA DE SOUZA NOGUEIRA
}

\section{VÍTIMAS DE TRAUMA ADMITIDAS EM UNIDADE DE TERAPIA INTENSIVA: CARACTERÍSTICAS E FATORES ASSOCIADOS À CARGA DE TRABALHO DE ENFERMAGEM}

Tese apresentada ao Programa de Pós-

Graduação em Enfermagem na Saúde do Adulto para obtenção do título de Doutor em Ciências

Orientadora: $\operatorname{Prof}^{\mathrm{a}} \mathrm{Dr}^{\mathrm{a}}$ Regina Marcia Cardoso de Sousa

\section{SÃO PAULO}




\section{FOLHA DE APROVAÇÃO}

Nome: Lilia de Souza Nogueira

Título: Vítimas de trauma admitidas em Unidade de Terapia Intensiva: características e fatores associados à carga de trabalho de enfermagem

Tese apresentada à Escola de Enfermagem da Universidade de São Paulo para obtenção do título de Doutor em Ciências

Aprovada em:

\section{Banca examinadora}

Prof. Dr. Instituição:

Julgamento: Assinatura:

Prof. Dr. Instituição:

Julgamento: Assinatura:

Prof. Dr. Instituição:

Julgamento: Assinatura:

Prof. Dr. Instituição:

Julgamento: Assinatura:

Prof. Dr. Instituição:

Julgamento: Assinatura: 


\section{DEDICATÓRIA}

À minha mãe, exemplo de vida, perseverança, caráter $e$ sabedoria, minha gratidão pelos ensinamentos que formaram os alicerces da minha história de vida.

Ao meu irmão, pelo incentivo e apoio incondicional.

Ao meu afilhado, que esta vitória seja um estímulo para que siga em frente nos estudos e almeje sempre grandes conquistas. 


\section{AGRADECIMENTOS}

À Professora Doutora Regina Marcia Cardoso de Sousa, meu reconhecimento pela oportunidade de realizar este trabalho ao lado de alguém tão especial; meu respeito e admiração pela sua serenidade, competência e sabedoria.

À Fundação de Amparo à Pesquisa do Estado de São Paulo (FAPESP), pela concessão da bolsa de doutorado e apoio financeiro para a realização desta pesquisa.

Às Professoras Doutoras Katia Grillo Padilha e Iveth Yamaguchi Whitaker, pelas sugestões no Exame de Qualificação.

Às Professoras Doutoras Hilaire Thompson e Margaret Heitkemper, pelo acolhimento na Universidade de Washington e as valiosas contribuições ao estudo.

Ao Professor Doutor Renato Sérgio Poggetti, pelo apoio e auxílio junto ao Hospital das Clínicas.

Às Doutorandas Cristiane de Alencar Domingues, Cristina Helena Constanti Settervall e Rita de Cássia Almeida Vieira, amigas especiais, pela ajuda, disponibilidade e companhia ao longo desta trajetória.

Às Enfermeiras Amanda de Oliveira Fernandes, Fernanda Araújo José e Karina Mitie Koike, pelo auxílio e dedicação especial na etapa de coleta de dados.

À equipe da UTI do Trauma do Hospital das Clínicas, pela colaboração e acolhimento durante a fase de coleta de dados.

Aos meus padrinhos, que sempre me incentivaram e torceram pela minha vitória. 
À família Cintra Neves, pelo incentivo e oportunidade de convívio.

À Professora Doutora Maria do Rosário Dias de Oliveira Latorre e ao Doutorando Marcio José de Medeiros, pela valiosa contribuição na orientação estatística.

Ao Queni Winters, pela prontidão e competência na revisão do texto.

Às funcionárias da Secretaria da Pós-Graduação, pela prontidão e apoio administrativo.

Aos funcionários da biblioteca, que sempre me atenderam de forma gentil e acolhedora.

A todos os meus amigos, que sempre estiveram ao meu lado nesta trajetória.

A todos aqueles que, direta ou indiretamente, colaboraram para a concretização deste sonho.

Meu sincero reconhecimento e gratidão! 
Nogueira LS. Vítimas de trauma admitidas em Unidade de Terapia Intensiva: características e fatores associados à carga de trabalho de enfermagem. São Paulo: Escola de Enfermagem, Universidade de São Paulo; 2012.

\section{RESUMO}

A complexidade da assistência à vítima de trauma na Unidade de Terapia Intensiva (UTI) repercute na carga de trabalho de enfermagem, sendo fundamental à equipe o conhecimento de aspectos que a influenciam para o planejamento de sua atuação. Diante disso, foram objetivos deste estudo caracterizar as vítimas de trauma admitidas na UTI, identificar um possível padrão de intervenções realizadas nos pacientes e os fatores associados à alta carga de trabalho no primeiro dia de internação, além de elaborar um modelo de estimativa da carga de trabalho de enfermagem requerida pelos sobreviventes na alta da unidade. Trata-se de um estudo quantitativo, do tipo coorte prospectivo, realizado em UTI especializada para assistência de vítima de trauma em hospital de referência para esse atendimento. A carga de trabalho de enfermagem, variável dependente, foi mensurada pelo Nursing Activities Score (NAS). Estatísticas descritivas, testes de associação e correlação e análises multivariadas foram realizados no tratamento dos dados. A casuística compôs-se de 200 vítimas, a maioria do sexo masculino (82,0\%), com idade média de 40,7 anos $(\mathrm{dp}=18,6)$, procedente do Centro Cirúrgico $(70,0 \%)$ e submetida à cirurgia não programada (66,5\%). A média do índice de comorbidade de Charlson foi $0,6(\mathrm{dp}=1,4)$. Os acidentes de transportes $(57,5 \%)$ prevaleceram na amostra, assim como o trauma contuso $(94,5 \%)$. Na análise da gravidade do trauma, a média do Injury Severity Score foi 19,3 (dp=9,1) e do New Injury Severity Score (NISS), $27,1(\mathrm{dp}=9,9)$. O número médio de lesões Abbreviated Injury Scale (AIS) $\geq 3$ foi 3,1 $(\mathrm{dp}=1,8)$ e de regiões corpóreas acometidas, $2,7(\mathrm{dp}=1,3)$. Cabeça ou pescoço foi a região mais gravemente lesada $(64,0 \%)$ e que apresentou maior frequência de lesões AIS $\geq 3(65,5 \%)$. Quanto à gravidade do paciente, a média do risco de morte variou de $21,1 \%$ a $25,6 \%$, segundo diferentes índices, e as insuficiências pulmonar (76,5\%) e neurológica $(69,0 \%)$ prevaleceram na casuística. A média do NAS na admissão da UTI foi 71,3\% (dp=16,9) e dos sobreviventes, na alta da unidade, 45,2\% ( $\mathrm{dp}=9,1)$. O tempo médio de permanência na UTI foi de 13,6 dias $(\mathrm{dp}=14,6)$ e a taxa de mortalidade na unidade crítica, 19,0\%. Foi identificado um grupo de 136 pacientes que apresentavam similaridade de intervenções na admissão da UTI. Destacou-se, nesse grupo, monitorização/controles e mobilização/posicionamento como atividades que requereram maior complexidade e ocuparam mais tempo que a rotina normal das unidades críticas. Gênero, insuficiência pulmonar, número de regiões corpóreas acometidas e risco de morte pelo Simplified Acute Physiology Score (SAPS II) foram fatores associados à alta carga de trabalho de enfermagem na admissão da UTI. O modelo de estimativa da carga de trabalho de enfermagem requerida pelos sobreviventes na alta da UTI foi expresso pela seguinte fórmula: NAS alta $=37,171+$ 0,188 (risco de morte SAPS II) $+0,193$ (NISS). Os resultados obtidos nesta investigação fornecem subsídios às equipes de enfermagem que prestam assistência à vítima de trauma, durante ou após a alta da UTI, que facilitarão o planejamento dos cuidados, adequação do quantitativo de pessoal e distribuição de tarefas, com enfoque na excelência da assistência ao traumatizado.

PALAVRAS-CHAVE: Carga de trabalho. Enfermagem. Ferimentos e lesões. Unidades de Terapia Intensiva. 
Nogueira L.S. Trauma victims admitted to the Intensive Care Unit: characteristics and factors associated with nursing workload [thesis]. Sao Paulo: Nursing School, University of Sao Paulo; 2012.

\begin{abstract}
The complexity posed by the assistance offered to trauma victims at Intensive Care Units (ICU) affects the nursing workload and, for this reason, information on the aspects impacting the workload and its planning is crucial. This study aimed to characterize trauma victims admitted to ICU, to identify a possible pattern of procedures performed in those patients, and the factors associated with high workload on the first hospitalization day, as well as to elaborate an estimate model of nursing workload required by the survivors on ICU discharge. This cohort quantitative study was prospective and carried out at an ICU specialized in assistance to trauma victims in a reference hospital for this service. The nursing workload, the dependent variable, was measured using the Nursing Activities Score (NAS). Descriptive statistics, association and correlation tests as well as multivariate analyses were performed. The sample consisted of 200 victims, mainly male $(82.0 \%)$, with an average age of 40.7 years $(\mathrm{SD}=18.6)$, transferred from the surgery room $(70.0 \%)$ and submitted to unscheduled surgery $(66.5 \%)$. The Charlson comorbidity index average was $0.6(\mathrm{SD}=1.4)$. Traffic accidents $(57.5 \%)$ and blunt trauma $(94.5 \%)$ prevailed in the sample. As regards the analysis of trauma severity, the average of Injury Severity Score was 19.3 (SD=9.1) and 27.1 (SD=9.9) for the New Injury Severity Score (NISS). The average number of injuries according to the Abbreviated Injury Scale (AIS) $\geq 3$ was 3.1 ( $\mathrm{SD}=1.8$ ), and of the body region affected, $2.7(\mathrm{SD}=1.3)$. Head or neck had the most severe injuries (64.0\%) and showed a higher frequency of injuries AIS $\geq 3(65.5 \%)$. With respect to patient severity, the average death risk ranged from $21.1 \%$ to $25.6 \%$, according to different indexes. Pulmonary (76.5\%) and neurological (69.0\%) insufficiency were predominant in the sample. The average NAS on ICU admission was $71.3 \%$ $(\mathrm{SD}=16.9)$, and $45.2 \%(\mathrm{SD}=9.1)$ among survivors on the unit discharge. The mean ICU length of stay was 13.6 days $(\mathrm{SD}=14.6)$ and the mortality rate at the critical unit, $19.0 \%$. A group of 136 patients submitted to similar procedures on ICU admission was identified. In this group, monitoring/titration and mobilization/positioning were regarded as the most complex activities, requiring longer than normal routine time of critical units. Gender, pulmonary insufficiency, number of body region injured and death risk by Simplified Acute Physiology Score (SAPS II) were factors associated with high nursing workload on ICU admission. The estimate model of nursing workload required by survivors on ICU discharge was expressed by the following formula: NAS discharge $=37.171+0.188$ (death risk SAPS II) +0.193 (NISS). The results obtained from this investigation provide information to the nursing teams offering assistance to trauma victims, during or post ICU discharge, with data which contributes to better care and quantitative staff planning, as well as task distribution, aiming for excellence in trauma patient assistance.
\end{abstract}

KEYWORDS: Workload. Nursing. Wounds and Injuries. Intensive Care Units. 


\section{LISTA DE TABELAS}

Tabela 1 - Estatística descritiva das variáveis idade e presença de comorbidade. São Paulo, 2010-2011

Tabela 2 - Número $\left(\mathrm{n}^{\circ}\right)$ e percentual $(\%)$ de pacientes segundo causa externa e tipo de trauma. São Paulo, 2010-2011

Tabela 3 - Estatística descritiva das variáveis relacionadas à gravidade do trauma. São Paulo, 2010-2011

Tabela 4 - Número $\left(n^{\circ}\right)$ e percentual $(\%)$ de pacientes segundo valor do MAIS. São Paulo, 2010-2011

Tabela 5 - Análise por região corpórea do $\mathrm{n}^{\circ}$ e $\%$ de pacientes segundo a presença de lesões AIS $\geq 3$ e indicação de região corpórea mais gravemente lesada. São Paulo, 2010-2011

Tabela 6 - Número $\left(\mathrm{n}^{\circ}\right)$ e percentual $(\%)$ de pacientes segundo procedência, tipo de admissão e destino após saída da UTI. São Paulo, 2010-2011

Tabela 7 - Estatística descritiva das variáveis relacionadas aos intervalos de tempo durante a internação hospitalar. São Paulo, 2010-2011 .46

Tabela 8 - Estatística descritiva do risco de morte na admissão ( $1^{\text {as }} 24$ horas) na UTI, segundo índices de gravidade dos pacientes dessa unidade. São Paulo, 2010-2011.46 Tabela 9 - Número $\left(\mathrm{n}^{\circ}\right)$ e percentual $(\%)$ de pacientes segundo presença de insuficiências orgânicas na admissão na UTI, conforme o LODS. São Paulo, 20102011

Tabela 10 - Estatística descritiva dos valores do NAS na admissão e saída da UTI, considerando a casuística total, os sobreviventes e os não sobreviventes à internação nessa unidade. São Paulo, 2010-2011

Tabela 11 - Distribuição das vítimas de trauma ( $\mathrm{n}^{\circ}$ e \%) segundo grupos com intervenções de enfermagem similares. São Paulo, 2010-2011

Tabela 12 - Número $\left(\mathrm{n}^{\circ}\right)$ e percentual (\%) de pacientes do grupo $8(\mathrm{n}=136)$ segundo intervenções de enfermagem realizadas na admissão da UTI. São Paulo, 20102011 .55

Tabela 13 - Comparação entre os grupos de alta e média/baixa carga de trabalho de enfermagem na admissão na UTI em relação ao gênero, causa externa, procedência e tipo de admissão nessa unidade. São Paulo, 2010-2011 
Tabela 14 - Medidas descritivas e comparação entre os grupos de alta e média/baixa carga de trabalho de enfermagem na admissão na UTI em relação à idade, índice de Charlson e intervalo de tempo entre admissão hospitalar e UTI. São Paulo, 20102011

Tabela 15 - Medidas descritivas e comparação entre os grupos de alta e média/baixa carga de trabalho de enfermagem na admissão na UTI em relação ao ISS, NISS, número de regiões corpóreas acometidas e número de lesões AIS $\geq 3$. São Paulo, 2010-2011 .59

Tabela 16 - Comparação entre os grupos de alta e média/baixa carga de trabalho de enfermagem na admissão na UTI segundo valor do MAIS. São Paulo, 2010-2011 .60 Tabela 17 - Comparação entre os grupos de alta e média/baixa carga de trabalho de enfermagem na admissão na UTI em relação à localização das lesões AIS $\geq 3$. São Paulo, 2010-2011

Tabela 18 - Comparação entre os grupos de alta e média/baixa carga de trabalho de enfermagem na admissão na UTI em relação à região corpórea mais gravemente lesada. São Paulo, 2010-2011

Tabela 19 - Medidas descritivas e comparação entre os grupos de alta e média/baixa carga de trabalho de enfermagem na admissão na UTI em relação ao risco de morte calculado pelo APACHE II, SAPS II e LODS e número de sistemas comprometidos conforme o LODS. São Paulo, 2010-2011

Tabela 20 - Comparação entre os grupos de alta e média/baixa carga de trabalho de enfermagem na admissão na UTI em relação ao tipo de insuficiência orgânica apresentada conforme o LODS. São Paulo, 2010-2011

Tabela 21 - Modelo de regressão logística dos fatores associados à alta carga de trabalho de enfermagem. São Paulo, 2010-2011

Tabela 22 - Medidas descritivas e comparação das médias do NAS dos sobreviventes na alta da UTI segundo gênero, causa externa, procedência e tipo de admissão nessa unidade. São Paulo, 2010-2011 .68

Tabela 23 - Coeficientes de correlação entre valores do NAS dos sobreviventes na alta da UTI e as variáveis idade, índice de Charlson e intervalo entre admissão hospitalar e UTI. São Paulo, 2010-2011 
Tabela 24 - Coeficientes de correlação entre os valores do NAS dos sobreviventes na alta da UTI e ISS, NISS, número de regiões corpóreas acometidas e número de lesões AIS $\geq 3$. São Paulo, 2010-2011

Tabela 25 - Medidas descritivas e comparação das médias do NAS dos sobreviventes na alta da UTI segundo valor do MAIS. São Paulo, 2010-2011

Tabela 26 - Medidas descritivas e comparação das médias do valor do NAS dos sobreviventes na alta da UTI segundo localização das lesões AIS $\geq 3$. São Paulo, 2010-2011 .70

Tabela 27 - Medidas descritivas e comparação das médias do NAS dos sobreviventes na alta da UTI segundo região corpórea mais gravemente lesada. São Paulo, 20102011

Tabela 28 - Coeficientes de correlação entre os valores do NAS dos sobreviventes na alta da UTI e as variáveis número de sistemas comprometidos e risco de morte segundo APACHE II, SAPS II e LODS. São Paulo, 2010-2011 .72

Tabela 29 - Medidas descritivas e comparação das médias do NAS dos sobreviventes na alta da UTI segundo tipo de insuficiência orgânica apresentada conforme o LODS. São Paulo, 2010-2011

Tabela 30 - Regressão linear simples para carga de trabalho de enfermagem requerida pelos sobreviventes na alta da UTI. São Paulo, 2010-2011 


\section{LISTA DE FIGURAS}

Figura 1 - Dendograma das vítimas segundo intervenções de enfermagem realizadas nas primeiras 24 horas de admissão na UTI. São Paulo, 2010-2011 51 Figura 2 - Análise da capacidade preditiva do modelo de regressão logística relacionada aos fatores associados à alta carga de trabalho de enfermagem. São Paulo, 2010-2011 .66

Figura 3 - Análise da suposição de normalidade para o modelo de regressão linear da carga de trabalho de enfermagem. São Paulo, 2010-2011 .75 


\section{LISTA DE SIGLAS}

AIS - Abbreviated Injury Scale

APACHE - Acute Physiologic and Chronic Health Evaluation

CAPPesq - Comissão de Ética para Análise de Projetos de Pesquisa

CID - Classificação Estatística Internacional de Doenças e Problemas Relacionado à Saúde

Curva ROC - Receiver Operating Characteristics Curve

ECGI - Escala de Coma de Glasgow

FAPESP - Fundação de Amparo à Pesquisa do Estado de São Paulo

IC-HFMUSP - Instituto Central do Hospital das Clínicas da Faculdade de Medicina da Universidade de São Paulo

ISS - Injury Severity Score

LODS - Logistic Organ Dysfunction System

MPM - Mortality Predicition Model

MAIS - Maximum Abbreviated Injury Scale

NAS - Nursing Activities Score

NEMS - Nine Equivalents of Nursing Manpower Use Score

NISS - New Injury Severity Score

OMEGA - Omega Scoring System

PRN - Project of Research of Nursing

SAPS - Simplified Acute Physiologic Score

SUS - Sistema Único de Saúde

TCE - Traumatismo craniencefálico

TCLE - Termo de Consentimento Livre e Esclarecido

TISS - Therapeutic Intervention Scoring System

TOSS - Time Oriented Score System

TRISS - Trauma and Injury Severity Score

UTI - Unidade de Terapia Intensiva 


\section{SUMÁRIO}

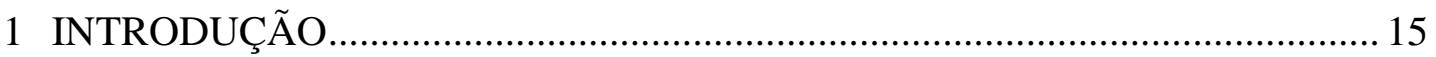

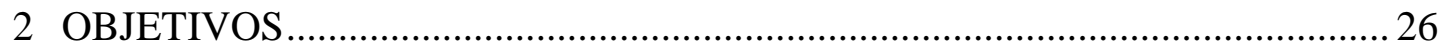

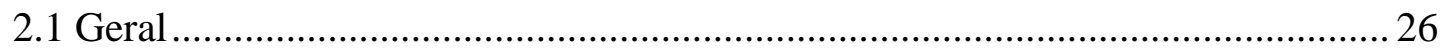

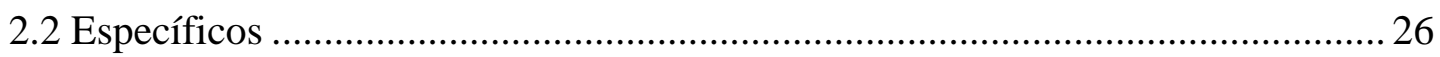

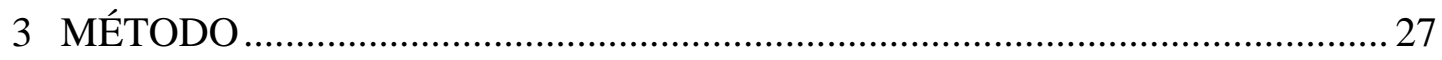

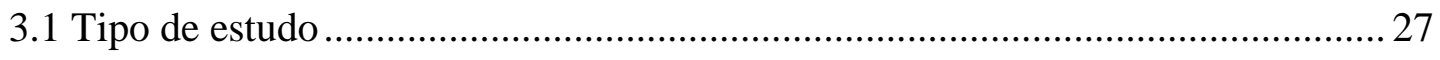

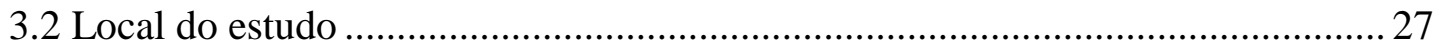

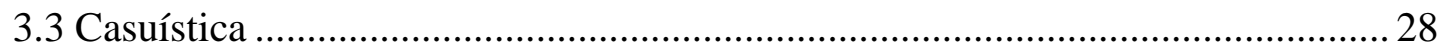

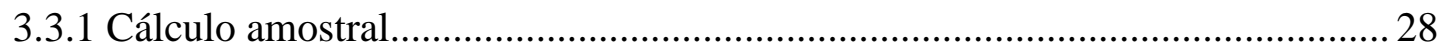

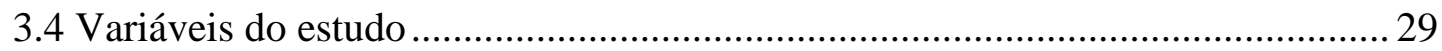

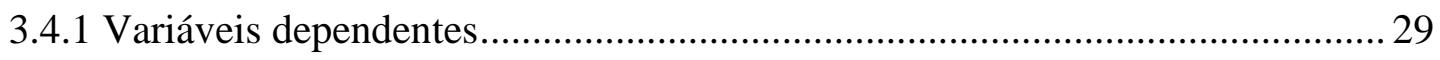

3.4.1.1 Análise dos fatores associados à alta carga de trabalho na admissão da UTI 29

3.4.1.2 Análise para identificar o modelo de estimativa da carga de trabalho na alta

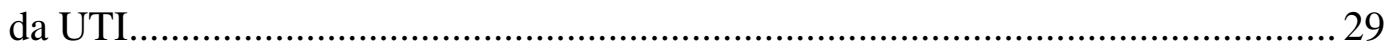

3.4.2 Variáveis independentes em ambas as análises inferenciais.............................. 29

3.4.2.1 Características demográficas e comorbidade ................................................. 29

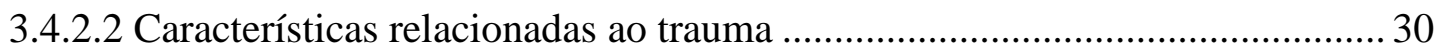

3.4.2.3 Características clínicas relacionadas à internação na UTI .............................. 32

3.4.3 Variáveis complementares à descrição da casuística do estudo.......................... 34

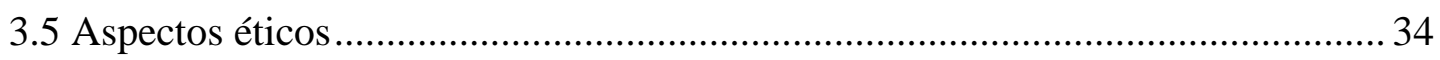

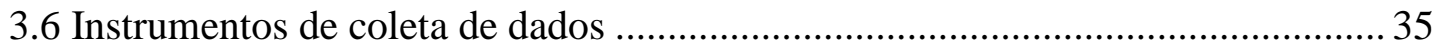

3.6.1 Ficha de levantamento de dados de identificação e da internação do paciente

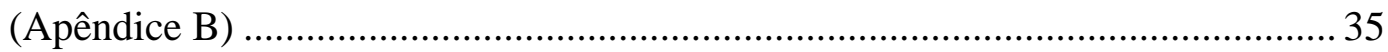

3.6.2 Ficha de levantamento das variáveis para o cálculo do APACHE II, SAPS II e

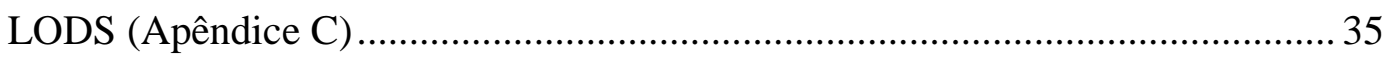

3.6.3 Formulário para aplicação do NAS (Apêndice D) ............................................... 36

3.6.4 Ficha para registro da descrição das lesões e cálculo do ISS e NISS (Apêndice

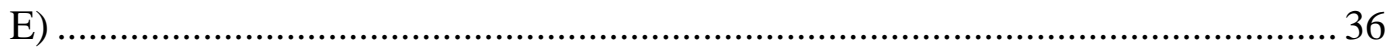

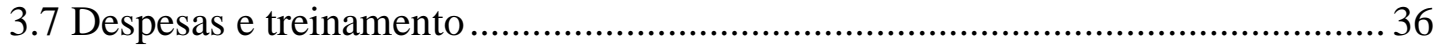

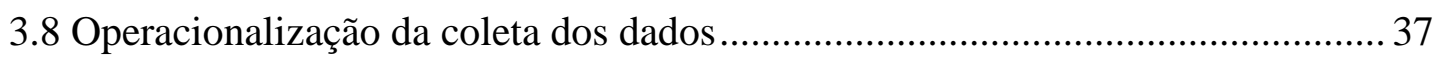

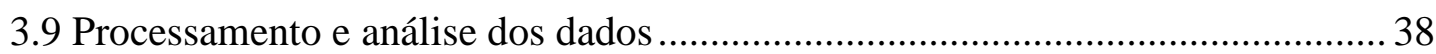




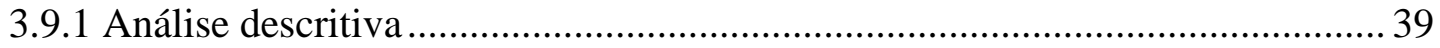

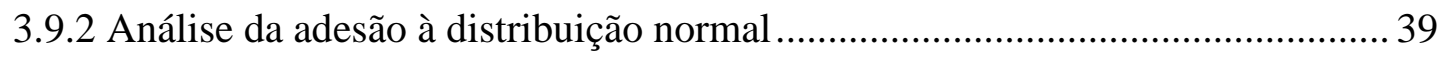

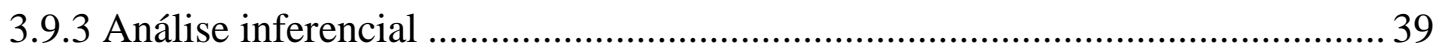

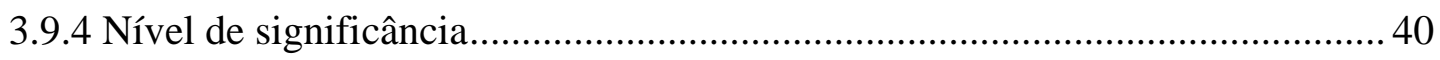

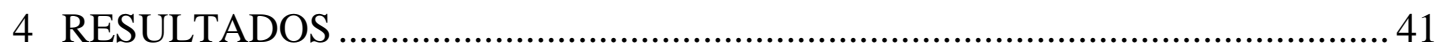

4.1 Caracterização das vítimas de trauma admitidas na UTI ..................................... 41

4.2 Identificação de um padrão de intervenções realizadas em vítimas de trauma na

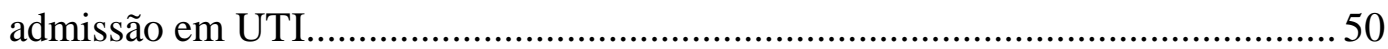

4.3 Fatores associados à alta carga de trabalho no primeiro dia de internação na UTI

4.4 Modelo para estimativa da carga de trabalho de enfermagem requerida pelos

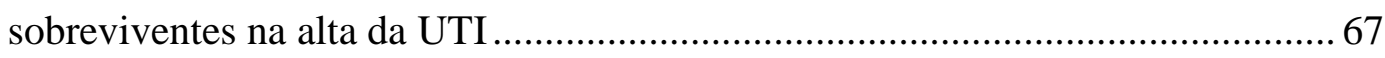

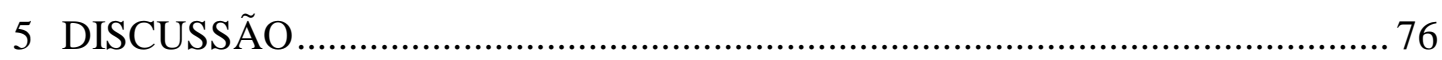

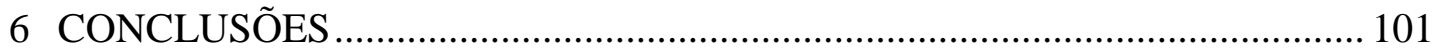

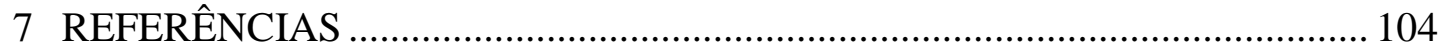

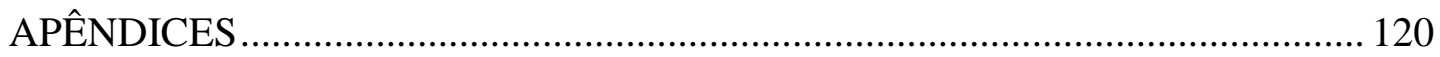

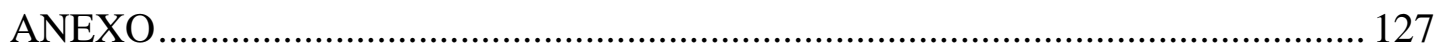




\section{INTRODUÇÃO}

A Organização Mundial da Saúde, por meio de dados da Classificação Estatística Internacional de Doenças e Problemas Relacionados à Saúde (CID-10) ${ }^{(1)}$, reconhece os acidentes e violências como causas externas, consideradas problemas de saúde pública e sinalizadas como a grande epidemia do século XXI.

Nos últimos anos, têm-se realizado esforços para controlar e minimizar esse problema com campanhas preventivas e exercícios de cidadania. Entretanto, as causas externas continuam provocando grande impacto na sociedade, tanto em número de fatalidades ${ }^{(2)}$ quanto em sequelas provocadas por lesões traumáticas ${ }^{(3-4)}$.

Estatísticas do Ministério da Saúde revelam a magnitude do problema com dados alarmantes: a mortalidade por causas externas no Brasil apresenta uma tendência crescente, com aumento de $18 \%$ no período de 2001 a 2010, ocupando atualmente o terceiro lugar como principal causa de morte no país, posição esta precedida apenas pelas doenças do aparelho circulatório e neoplasias ${ }^{(2)}$. Além disso, as causas externas são as principais responsáveis pelos óbitos ocorridos na ampla faixa etária de 1 a $39 \operatorname{anos}^{(5)}$.

Entre as lesões decorrentes de causas externas, o traumatismo craniencefálico (TCE) tem se destacado como um dos motivos mais comuns de morte ${ }^{(6)}$, alterações cognitivas, comportamentais e incapacidades ${ }^{(3,7)}$.

Do ponto de vista social, essas incapacidades temporárias ou sequelas físicas e cognitivas permanentes afetam negativamente a qualidade de vida da vítima e sua reinserção na sociedade ${ }^{(8-9)}$.

Do ponto de vista econômico, as causas externas produzem elevados custos indiretos e diretos à economia do país. Os custos indiretos referem-se à perda da produtividade gerada por limitações físicas oriundas do $\operatorname{trauma}^{(10)}$. Pesquisas mostram que apenas 49 a $60 \%$ das vítimas de trauma retornam ao trabalho após o tratamento das lesões ${ }^{(11-13)}$ e o número de desempregados é maior entre aqueles pacientes que permanecem por mais tempo internados em Unidade de Terapia Intensiva (UTI) ${ }^{(14)}$.

Os custos diretos são aqueles oriundos do diagnóstico, tratamento, recuperação, reabilitação e envolvimento familiar ${ }^{(10)}$. 
O percentual de vítimas de trauma que necessitam de cuidados intensivos apresenta grande variabilidade na literatura: $8,7 \%$ a $44,5 \%{ }^{(15-18)}$. Neste contexto, destaca-se o alto custo direto decorrente de internação em UTI, unidade que desempenha papel relevante na chance de sobrevida de pacientes gravemente traumatizados que necessitam de intervenções altamente específicas e tecnologia avançada de monitorização contínua para o manejo e tratamento das lesões ${ }^{(19-20)}$.

O Ministério da Saúde, por meio da Portaria 3.432/98, define UTI como unidades que atendem pacientes graves ou de risco, com equipamentos específicos adequados e recursos humanos especializados ${ }^{(21)}$.

A sofisticação tecnológica, a especialidade da unidade e as características e evolução dos pacientes interferem diretamente no custo oriundo do setor crítico ${ }^{(20,22)}$. Pesquisa que analisou a evolução clínica das vítimas de trauma na UTI e os custos despendidos no atendimento mostrou que os pacientes assistidos em UTI especializada em trauma apresentaram melhores resultados clínicos comparados àqueles tratados em UTI cirúrgica geral. Além disso, o custo da UTI do trauma foi menor $^{(20)}$, mostrando que o cuidado a essas vítimas é complexo e a assistência realizada por uma equipe especializada impacta positivamente no desfecho do paciente e nos gastos orçamentários da instituição.

Estudo que analisou e comparou o custo de 51 UTI localizadas na Alemanha identificou que os gastos foram significativamente maiores nos pacientes admitidos na unidade crítica em virtude de cirurgia não programada ou naqueles com maior gravidade, que apresentaram sepse ou morreram na UTI. Os autores salientaram que os recursos humanos consumiram $56 \%$ do total dos gastos das unidades, com destaque para o alto custo associado à equipe de enfermagem ${ }^{(22)}$.

Pesquisa realizada em UTI na Austrália mostrou forte correlação entre horas de enfermagem dispensadas no cuidado e custo total por paciente ${ }^{(23)}$. Outros estudos evidenciaram que o custo com pessoal de enfermagem na UTI é variável perante as diferenças na complexidade dos pacientes, sendo possível estabelecê-lo em conjunto com a aplicação de um índice de gravidade ou de carga de trabalho de enfermagem $^{(24-25)}$.

Neste contexto, observa-se a preocupação crescente dos profissionais em avaliar a carga de trabalho de enfermagem requerida pelos pacientes na unidade 
crítica, no intuito de assegurar a qualidade da assistência, satisfação profissional, otimização de recursos e redução de custos ${ }^{(26-30)}$.

A mensuração da carga de trabalho identifica as necessidades de cuidados do paciente e o tempo despendido pelo profissional de enfermagem para atendê-las, permitindo assim quantificar o número de profissionais necessários conforme a demanda da unidade. Uma vez que a adequação dos profissionais de enfermagem pode afetar financeiramente a instituição, a aplicação de um índice que possibilita mensurar a carga de trabalho de enfermagem fornece dados consistentes e argumentações aos enfermeiros para alcançar bem-sucedidos processos de negociação com administradores hospitalares a respeito do aumento ou manutenção de recursos humanos ${ }^{(25,31-33)}$.

Estudos sobre o dimensionamento de profissionais nas UTI brasileiras são essenciais para fornecer dados aos enfermeiros para que se atinja o equilíbrio entre recursos humanos, custo e qualidade. Pesquisa realizada em uma UTI neonatal identificou a necessidade de se aumentar o quadro médio dos profissionais de enfermagem na unidade e calculou que tal medida resultaria em um acréscimo de $30 \%$ sobre o montante financeiro do quadro já existente ${ }^{(25)}$. Outra investigação, realizada em UTI geral para adultos, mostrou que o número de profissionais na UTI estava superestimado, sugerindo que os custos com recursos humanos poderiam ser reduzidos sem prejudicar a qualidade da assistência ${ }^{(29)}$.

A avaliação da carga de trabalho de enfermagem é uma ferramenta indispensável na gestão do quadro de profissionais na UTI, visto que uma equipe superdimensionada representa alto custo e uso inadequado de recursos, ao passo que o subdimensionamento impacta negativamente na qualidade da assistência intensiva, além de gerar insatisfação profissional e burnout ${ }^{(27,34-35)}$.

Há também de se considerar que esse impacto negativo da equipe reduzida na qualidade da assistência de enfermagem geralmente resulta em aumento do tempo de permanência na UTI, eleva a morbidade e mortalidade, gerando, em outra perspectiva, maior custo do tratamento do paciente ${ }^{(34)}$.

Instrumentos de medida de carga de trabalho de enfermagem foram desenvolvidos em diferentes países com o intuito de facilitar a prática clínica do enfermeiro na determinação da real necessidade de assistência requerida pelo paciente e do correto dimensionamento da equipe. Entre eles, destaca-se o Project of 
Research of Nursing $(\mathrm{PRN})^{(36)}$, elaborado no Canadá em 1981; o Omega Scoring System (OMEGA) ${ }^{(37)}$, na França, em 1986; e o Time Oriented Score System (TOSS) $)^{(38)}$, na Itália, em 1991.

O sistema pioneiro de medida de carga de trabalho de enfermagem foi o Therapeutic Intervention Scoring System (TISS), criado em 1974 por Cullen e colaboradores. O TISS pressupunha que, quanto mais grave o paciente, maior o número de intervenções realizadas, independentemente do diagnóstico apresentado. Portanto, o índice quantificava a gravidade do paciente e a carga de trabalho de enfermagem com base no tipo de intervenção terapêutica e quantidade de tratamento recebido $^{(39)}$.

A versão original do TISS, com 57 itens, foi revista e ampliada em 1983, passando a quantificar a complexidade e o grau de invasividade do tratamento, além do tempo dispensado ao paciente, por meio da análise de 76 itens (TISS-76) ${ }^{(40)}$.

Decorridos 13 anos da criação do TISS-76, profissionais da Holanda reconheceram a necessidade de atualizar e simplificar o uso do índice, reduzindo para 28 o número de intervenções contempladas, passando esse instrumento a ser chamado TISS-28. Os 28 itens do instrumento são divididos em sete grupos: atividades básicas, suporte ventilatório, cardiovascular, renal, neurológico e metabólico, além de intervenções específicas ${ }^{(41)}$.

Miranda e colaboradores, autores do TISS-28, publicaram em 1997 uma versão reduzida desse instrumento, denominada Nine Equivalents of Nursing Manpower Use Score (NEMS), na qual 9 itens avaliados permitem quantificar a carga de trabalho de enfermagem em $\mathrm{UTI}^{(42)}$. Esta versão reduzida foi elaborada para aplicação em grandes grupos de pacientes de UTI, é de fácil uso e tem apresentado boa confiabilidade entre avaliadores ${ }^{(43)}$. Cada ponto do TISS- $28^{(41)}$ ou do NEMS ${ }^{(42)}$ corresponde a 10,6 minutos do tempo de trabalho de um profissional de enfermagem em um turno de 8 horas. Esta informação pode ser usada para planejar e avaliar a alocação dos recursos humanos e, objetivamente, classificar as UTI segundo quantidade de cuidado prestado sem, no entanto, considerar a complexidade na realização das atividades ${ }^{(43)}$.

A aplicação prática desses índices apresentou fragilidade, uma vez que atividades relacionadas ao cuidado indireto ao paciente, como tarefas administrativas e gerenciais e suporte a familiares, não eram abordadas. Além disso, um melhor 
detalhamento em relação a tempo, frequência e número de profissionais envolvidos em atividades específicas da enfermagem, como monitorização e controles, procedimentos de higiene e mobilização e posicionamento, tornou-se necessário para identificar a complexidade do cuidado.

Objetivando preencher as lacunas e deficiências encontradas, um novo ajuste do TISS-28 foi proposto em 2003, com mudança expressiva do índice. Essa nova versão, denominada Nursing Activities Score (NAS) ${ }^{(44)}$, passou a abranger um maior número de atividades realizadas pela equipe de enfermagem.

A lista de itens que compõe o NAS foi desenvolvida com a participação de profissionais de 15 países por meio da formação de consenso. A média de tempo consumida pelas atividades foi determinada pelo resultado de múltiplos momentos de observação durante o período de uma semana em uma amostra de 99 UTI desses países. Nesse período, o TISS-28 dos pacientes também foi registrado, permitindo assim analisar tanto o TISS-28 quanto o NAS, perante os registros realizados ${ }^{(43-45)}$.

Sete grandes categorias compuseram o novo instrumento: atividades básicas, suporte ventilatório, cardiovascular, renal, neurológico, metabólico e intervenções específicas. A categoria atividades básicas sofreu a alteração mais expressiva em relação ao TISS-28, criando mais cinco categorias: monitorização e controles, procedimentos de higiene, mobilização e posicionamento do paciente, suporte e cuidado aos familiares e pacientes e tarefas administrativas e gerenciais. Esses cinco novos itens apresentam subitens que são mutuamente excludentes, na medida em que representam diferentes níveis de complexidade de uma mesma atividade de enfermagem $^{(44)}$.

Um total de 23 atividades compõe o instrumento NAS. Cada uma delas possui um peso no escore final, traduzido por diferentes pontuações para cada item. O preenchimento do NAS é feito retrospectivamente (considera as atividades realizadas nas últimas 24 horas de permanência na UTI) e o escore obtido pelo somatório dos pontos expressa a porcentagem de tempo gasto por enfermeiro, por turno, na assistência direta ao paciente, podendo atingir no máximo $176,8 \%{ }^{(44)}$.

Com esta nova estrutura, o NAS contemplou $80,8 \%$ das atividades de enfermagem, ante 43,3\% identificadas pelo TISS-28, descrevendo, assim, duas vezes mais o tempo gasto pela enfermagem no cuidado ao doente crítico ${ }^{(44)}$. Neste sentido, o NAS passou a ser o índice mais abrangente para mensurar as atividades realizadas 
e, consequentemente, a carga de trabalho de enfermagem requerida pelos pacientes na UTI.

O NAS foi traduzido para o português por Queijo em 2003. A mesma pesquisadora validou o índice no país e mostrou confiabilidade do instrumento em mensurar a carga de trabalho na realidade brasileira ${ }^{(45)}$. Considerando-se os atributos positivos do NAS descritos anteriormente, julgou-se pertinente a sua escolha para análise da carga de trabalho de enfermagem nesta investigação.

Passada aproximadamente uma década da publicação do NAS, observa-se ainda um número reduzido de estudos internacionais que utilizam o instrumento para medir a carga de trabalho de enfermagem. Entretanto, no Brasil, nota-se aumento expressivo de pesquisadores que analisam o NAS em diferentes aspectos. Tal crescimento pode estar relacionado à necessidade de alertar os gestores que a qualidade do cuidado não está garantida apenas pela capacitação continuada e títulos adquiridos, mas também pelo dimensionamento dos profissionais pautado na real demanda de cuidados dos pacientes assistidos.

Outro aspecto que pode ter despertado o interesse dos enfermeiros brasileiros pelo NAS nos últimos dois anos é a publicação, em 24/02/2010, da Resolução RDC 07 no Diário Oficial da União, que, entre os requisitos mínimos necessários para o funcionamento de UTI, estabelece no artigo 49 a obrigatoriedade de se avaliar os pacientes internados em unidades críticas por meio de Sistemas de Classificação de Necessidades de Cuidados de Enfermagem, recomendado por literatura científica especializada. Este Sistema é definido na resolução como um índice de carga de trabalho de enfermagem que auxilia a avaliação quantitativa e qualitativa dos recursos humanos necessários para o cuidado ${ }^{(46)}$.

Estudos sobre dimensionamento de profissionais de enfermagem afirmam que o NAS tem mostrado eficiência na estimativa de pessoal necessário para desenvolver a assistência de enfermagem em $\mathrm{UTI}^{(29-30,32-33)}$.

Nas pesquisas nacionais, observa-se que o NAS vem sendo aplicado com o objetivo não só de verificar alocação de recursos humanos na UTI e auxiliar no correto dimensionamento de profissionais ${ }^{(29-30,32-33)}$, mas também para estabelecer relações diversas entre necessidades de cuidados de enfermagem e grupos etários ${ }^{(47-}$ 48), verificar a associação entre a carga de trabalho e variáveis clínicas e/ou demográficas $^{(28,49-52)}$, associar carga de trabalho com estilos de liderança do 
enfermeiro $^{(53)}$, identificar preditores de alta demanda de cuidados em populações geral $^{(54-55)}$ ou específica ${ }^{(56)}$ de pacientes de UTI, analisar fatores relacionados à alta do doente para unidade semi-intensiva ${ }^{(57)}$, além de verificar formas de aplicação do instrumento $^{(58)}$.

Entretanto, os resultados das investigações que calcularam o NAS do paciente nas primeiras 24 horas de internação na UTI mostram variabilidade nos valores médios do índice: 51,5 a 80,1\%(49-50,53-55,57,59).

$\mathrm{Na}$ literatura internacional, apenas três publicações foram encontradas com a utilização do NAS, sendo duas realizadas por um grupo espanhol ${ }^{(60-61)}$ e outra na Noruega ${ }^{(62)}$. Os estudos espanhóis revelam demanda de cuidados de enfermagem inferior à encontrada na população brasileira, tanto na pontuação média do NAS obtida no primeiro dia de internação na UTI $(41,42 \%)$ quanto nos valores médios do índice calculados durante toda a permanência na unidade crítica $(41,27 \%)^{(60-61)}$.

Resultado oposto foi mostrado na pesquisa realizada em quatro UTI localizadas em Oslo, Noruega, onde a média do NAS foi 96,24\%. As autoras explicam a alta demanda de cuidados como reflexo do tempo gasto com familiares, uma vez que a visita nas unidades não tem limitação de horário, além do longo tempo requerido durante os transportes intra-hospitalares realizados pelos enfermeiros das $\mathrm{UTI}^{(62)}$.

Tais discrepâncias dos valores médios do NAS evidenciadas nos estudos podem estar relacionadas às peculiaridades e características das necessidades dos pacientes das diferentes instituições e países. Ademais, regras locais de admissão e alta das UTI e protocolos de tratamento podem interferir nos escores obtidos ${ }^{(43)}$, assim como o impacto que a deficiência de recursos humanos de enfermagem pode gerar no cuidado alocado para o paciente, não permitindo atender plenamente suas necessidades.

Pesquisas mostraram que o NAS calculado na saída da UTI esteve diretamente relacionado com o desfecho da internação nessa unidade. Estudo que analisou 600 pacientes internados em quatro UTI mostrou que, a cada acréscimo de um ponto do NAS na saída da UTI, houve aumento de $8 \%$ na chance de morte dos doentes da casuística ${ }^{(52)}$. Outra análise relacionada a essa amostra evidenciou que o grupo de pacientes encaminhados para unidade semi-intensiva após alta da UTI 
apresentava valor médio do NAS 10,3\% maior do que aqueles que foram para unidades de internação: $64,5 \%$ ante $54,2 \%{ }^{(57)}$.

Considerando a importância da avaliação da demanda de trabalho de enfermagem, bem como das variáveis que a influenciam, como ferramentas indispensáveis na gestão da UTI, previsão das horas de cuidados de enfermagem e dos custos, foram identificadas na literatura três investigações que analisaram os fatores associados à alta carga de trabalho de enfermagem requerida por pacientes na unidade crítica mediante variáveis clínicas e demográficas ${ }^{(54-56)}$.

Nessas investigações, o tempo de permanência na UTI foi fator significante para alta carga de trabalho ${ }^{(54-55)}$, bem como a mortalidade na unidade crítica ${ }^{(55)}$. Escore superior a 23 pontos no TISS-28 ${ }^{(55)}$, admissão cirúrgica ${ }^{(56)}$, idade ${ }^{(56)}$ e gravidade do paciente segundo Simplified Acute Physiologic Score (SAPS II) ${ }^{(56-55)}$ também foram identificados como preditores de elevada demanda de cuidados de enfermagem.

Assim, nota-se que a gravidade do paciente exerce influência significativa na demanda de cuidados requerida. Neste contexto, é inquestionável a importância de se identificar a gravidade dos pacientes assistidos na UTI.

Toda complexidade tecnológica da unidade crítica e necessidade de capacitação e atualização profissional que incrementaram os gastos hospitalares, além do elevado índice de mortalidade observado durante décadas na unidade crítica, geraram a necessidade de se criar índices prognósticos, numa tentativa de quantificar a gravidade e estimar a sobrevida dos doentes, avaliar a qualidade da assistência prestada e, indiretamente, a relação custo/benefício da utilização de recursos, além de comparar o desempenho de UTI diversas ${ }^{(19,63)}$.

Esses índices de gravidade possibilitam quantificar o grau de disfunção orgânica de pacientes na unidade crítica, cuja gravidade é expressa em um valor numérico identificado a partir da análise de variáveis clínicas e laboratoriais ${ }^{(63)}$. Dentre os índices mais utilizados nas UTI que permitem calcular a probabilidade de óbito hospitalar, destacam-se as versões do Acute Physiologic and Chronic Health Evaluation (APACHE) ${ }^{(64-67)}$, do SAPS ${ }^{(68-70)}$ e do Mortality Predicition Model $(\mathrm{MPM})^{(71-72)}$, além do Logistic Organ Dysfunction System (LODS) ${ }^{(73)}$.

A maioria dos estudos que analisam especificamente vítimas de trauma admitidas em UTI aplica os índices APACHE II e SAPS II nesta população, com o 
objetivo de avaliar a capacidade discriminatória do índice em estimar a mortalidade ${ }^{(74-81)}$, identificar a performance de índices de gravidade do paciente de UTI combinados a indicadores de gravidade do trauma na predição de mortalidade ${ }^{(74,81-82)}$, realizar análise comparativa entre os grupos de sobreviventes e não sobreviventes ${ }^{(74,79,83-84)}$ ou daqueles que apresentaram sepse grave ${ }^{(85)}$, fibrilação atrial $^{(86)}$, lesão pulmonar aguda ${ }^{(85,87)}$, falência múltipla de órgãos ${ }^{(85,88)}$ ou infecção nosocomial $^{(89)}$.

Por outro lado, uma preocupação frequente da equipe que atende vítimas de acidentes ou violência é estimar a gravidade das lesões e do trauma, uma vez que a adequada definição desta gravidade infere no cálculo da probabilidade de sobrevida do paciente. Para tanto, foram criados índices de trauma que, por meio de uma linguagem uniforme, permitem quantificar e avaliar a gravidade das lesões anatômicas, analisar a qualidade do atendimento prestado, comparar os resultados dentro de um mesmo serviço ou entre outros hospitais, documentar características epidemiológicas, entre outros objetivos ${ }^{(90)}$. Dentre esses índices, destacam-se o Injury Severity Score (ISS) ${ }^{(91)}$ e o New Injury Severity Score (NISS) ${ }^{(92)}$.

$\mathrm{O} \mathrm{ISS}^{(91)}$ foi desenvolvido em 1974 por Baker e colaboradores pautado na fragilidade da Abbreviated Injury Scale (AIS) ${ }^{(93)}$, escala utilizada para descrever as lesões decorrentes de um trauma e identificar a gravidade da lesão de forma isolada. O ISS permite estabelecer uma medida prognóstica para pacientes com múltiplas lesões ao analisar seis regiões corpóreas e é considerado padrão ouro para a estratificação da gravidade do trauma ${ }^{(91)}$.

O NISS surgiu em 1997 a partir da identificação de falhas no cálculo do ISS que resultavam na subestimativa da gravidade global do paciente. A principal diferença desta nova proposta é que o NISS considera no cálculo a gravidade das lesões, independentemente da região corpórea acometida na vítima ${ }^{(92)}$.

Algumas pesquisas que analisam vítimas de trauma internadas em UTI vêm utilizando os índices de gravidade do trauma com o objetivo de caracterizar e analisar a gravidade dos pacientes da casuística, bem como identificar o melhor preditor, ISS ou NISS, para diferentes desfechos ${ }^{(15-16,78,94-96)}$.

Em síntese, observa-se que a gravidade da vítima, em consequência do evento traumático ou de alterações fisiológicas observadas na UTI, vem sendo analisada em comparação com diferentes variáveis. Porém, no que se refere à análise da carga de 
trabalho de enfermagem requerida por esses pacientes na UTI, encontra-se escassez de estudos sobre o tema e ausência de pesquisas que aplicam o NAS nessa população.

Foram encontrados apenas dois estudos que aplicaram o TISS-28 em vítimas de trauma na UTI. Investigação que analisou pacientes admitidos em uma UTI cirúrgica mostrou que os traumatizados representaram $12,4 \%$ da casuística e apresentaram os maiores valores da média (13,2 dias) e mediana (4 dias) quando analisado o tempo de permanência na unidade. Esta variável apresentou alta correlação com o TISS-28(97).

Estudo que analisou 11 UTI mostrou que os pacientes admitidos nas unidades de neurologia, nefrologia e do trauma eram mais jovens que aqueles admitidos em UTI que atendiam outras especialidades (transplante hepático, hematologia, emergência clínica, cirurgia, doenças infecciosas e queimados). As unidades que apresentaram maiores valores referentes à média do tempo de permanência foram a de queimados (17 dias), seguida da emergência clínica (12 dias) e das UTI de trauma e transplante hepático (11 dias cada). O valor médio do TISS-28 calculado nas vítimas de trauma foi de 28 pontos e a taxa de mortalidade nessa população, 35,2\%. Os pesquisadores observaram que a UTI que demandou maior carga de trabalho de enfermagem (maiores valores do TISS-28) foi a de transplante hepático, seguida pela unidade de trauma ${ }^{(98)}$.

Conhecer as particularidades e a demanda de cuidados de enfermagem requerida por pacientes admitidos em UTI especializadas, bem como os fatores associados a essa carga de trabalho, é fundamental para a adequação de recursos da unidade focada na qualidade da assistência.

Estudo comparativo realizado em unidades geral e especializadas mostrou que a carga de trabalho de enfermagem foi estatisticamente diferente entre as UTI cardiológica, geral e neurológica, tendo esta última apresentado a menor carga ${ }^{(59)}$.

Considerando que existem diferenças na demanda de cuidados de pacientes admitidos em unidade especializada e tendo em vista as lacunas de conhecimento sobre a carga de trabalho de enfermagem requerida pelas vítimas de trauma internadas em UTI, torna-se emergente a realização de estudos que descrevam esses pacientes e analisem variáveis relacionadas às atividades de enfermagem nessa população. 
Na prática clínica, muitos enfermeiros revelam dificuldades no atendimento a essas vítimas em razão da alta carga de trabalho dispensada na assistência direta. Suas experiências e percepções sugerem que a demanda de cuidados de enfermagem aumenta proporcionalmente conforme o número de regiões corpóreas acometidas e localização das lesões, e depende diretamente da gravidade do trauma e da instabilidade fisiológica do paciente.

Além disso, muitos profissionais consideram que a maioria das vítimas de trauma é submetida a um padrão de cuidados e intervenções de enfermagem similares no momento da admissão na UTI. Diariamente, tal percepção é considerada na distribuição empírica da equipe de enfermagem de acordo com o número de pacientes e leitos vagos na unidade crítica.

Diante dos vários aspectos expostos e considerando a ausência de estudos sobre a demanda de cuidados de enfermagem mensurada pelo NAS em vítimas de trauma, pretendeu-se por meio desta pesquisa mostrar as principais intervenções de enfermagem realizadas nesses pacientes na admissão na UTI, assim como evidenciar fatores associados à alta carga de trabalho de enfermagem.

O conhecimento dos fatores que influenciam a carga de trabalho é um recurso fundamental ao enfermeiro em sua prática na terapia intensiva, uma vez que permite estabelecer previamente estratégias para admissão do doente crítico e planejamento dos cuidados a serem prestados, bem como adequar o quantitativo de pessoal de acordo com a demanda, objetivando atingir a excelência na assistência.

Além disso, a preocupação da equipe de enfermagem que recebe o doente após a alta da UTI está centrada na satisfação das necessidades e demanda de cuidados da vítima, com o objetivo de manter a mesma qualidade da assistência intensiva. Para tanto, estimar a carga de trabalho requerida pelos sobreviventes na alta da UTI certamente auxiliará o enfermeiro e os gestores das instituições no planejamento de recursos humanos das unidades para onde as vítimas são encaminhadas.

Mediante as informações apresentadas e a escassez de pesquisas sobre o tema, além da necessidade constante de se garantir a segurança da assistência de enfermagem às vítimas de trauma, propôs-se a realização do presente estudo, cujos resultados contribuirão para fundamentar a prática clínica da equipe de enfermagem que presta assistência ao traumatizado. 


\section{OBJETIVOS}

\subsection{Geral}

Analisar aspectos da carga de trabalho de enfermagem requerida por vítimas de trauma internadas em UTI.

\subsection{Específicos}

2.2.1 Caracterizar as vítimas de trauma admitidas na UTI segundo dados clínicos e demográficos.

2.2.2 Identificar um possível padrão de intervenções realizadas nessas vítimas nas primeiras 24 horas de internação na UTI.

2.2.3 Identificar os fatores associados à alta carga de trabalho no primeiro dia de internação na UTI.

2.2.4 Elaborar, a partir de dados da admissão na UTI, um modelo para estimar a carga de trabalho de enfermagem requerida pelos sobreviventes na alta da unidade. 


\section{MÉTODO}

\subsection{Tipo de estudo}

Trata-se de uma pesquisa quantitativa, com análise descritiva e correlacional, do tipo coorte prospectivo, realizada em duas etapas. Na primeira, foram coletados dados clínicos e demográficos dos pacientes referentes às primeiras 24 horas de internação na UTI. Na segunda, identificou-se a condição de saída da vítima da UTI (sobrevivente ou não sobrevivente) e calculou-se a carga de trabalho de enfermagem demandada pelos sobreviventes nas últimas 24 horas de permanência na unidade, segundo NAS.

\subsection{Local do estudo}

O estudo foi desenvolvido na UTI de Emergências Cirúrgicas, conhecida como UTI do Trauma, localizada no Instituto Central do Hospital das Clínicas da Faculdade de Medicina da Universidade de São Paulo (IC-HCFMUSP), instituição situada na zona oeste da cidade de São Paulo e considerada centro de referência para o atendimento às vítimas de trauma.

O IC-HCFMUSP possui 10 UTI de diferentes especialidades: clínica, cirúrgica, moléstias infecciosas, neurologia, nefrologia, pneumologia, queimados, trauma, gastroenterologia e anestesiologia. A UTI do trauma tem 22 leitos ativos e uma taxa de ocupação próxima a 100\%.

O IC-HCFMUSP é um dos institutos do Complexo Hospitalar das Clínicas, uma autarquia do Governo do Estado de São Paulo vinculada à Secretaria de Estado da Saúde para fins de coordenação administrativa e associada à FMUSP para fins de ensino, pesquisa e prestação de ações e serviços de saúde destinados à comunidade.

$\mathrm{O}$ atendimento inicial à vítima de trauma dentro desse complexo hospitalar é realizado no Pronto-Socorro do IC-HCFMUSP e, quando há necessidade de tratamento intensivo, o paciente é, preferencialmente, encaminhado à UTI do Trauma dessa instituição. 


\subsection{Casuística}

A população alvo do estudo foi pacientes admitidos na UTI anteriormente especificada, no período de $1^{\circ}$ de maio de 2010 a 31 de janeiro de 2011, que preencheram os seguintes critérios de elegibilidade:

- Ter idade igual ou superior a 18 anos;

- Ser vítima de trauma, seja ele contuso, penetrante ou misto (contuso e penetrante);

- Permanecer por mais de 24 horas na UTI;

- Ser atendido no IC-HCFMUSP até 48 horas após a ocorrência do evento traumático.

A limitação da idade foi estabelecida tendo em vista a população base definida para a elaboração dos índices APACHE II, SAPS II e LODS que excluiu pacientes com idade inferior a $18 \operatorname{anos}^{(65,69,73)}$. A permanência mínima de 24 horas na UTI seguiu o critério de inclusão estabelecido na aplicação do $\mathrm{NAS}^{(44)}$.

O limite de 48 horas até o atendimento - entre o evento traumático e a chegada ao Pronto-Socorro do IC-HCFMUSP - foi fixado para evitar falhas na identificação de lesões originadas no trauma. A transferência ou a busca do atendimento hospitalar tardiamente, que pode decorrer de complicações póstraumáticas, minimiza, em geral, a importância das lesões causadas pelo trauma e favorece falhas em sua descrição.

Todos os pacientes readmitidos na UTI, incluídos ou não previamente na casuística, foram excluídos do estudo.

\subsubsection{Cálculo amostral}

O cálculo do tamanho da amostra foi realizado analisando-se os dados dos primeiros 20 pacientes distribuídos segundo índices de gravidade do trauma em três grupos: escore <16; escore de 16 a 24 e >24. Nessa avaliação, verificou-se que a diferença mínima das médias do NAS entre os três grupos formados segundo ISS ${ }^{(91)}$ e $\operatorname{NISS}^{(92)}$ foi de 8 pontos e que o desvio padrão médio foi 10 . Assumindo $\alpha=5 \%$ e poder $=90 \%$, estimou-se que seriam necessários ao menos 34 pacientes em cada uma das categorias, totalizando aproximadamente 100 vítimas. Optou-se por coletar o dobro desta amostra para garantir o poder e o nível de significância, mesmo com diferenças menores. 


\subsection{Variáveis do estudo}

\subsubsection{Variáveis dependentes}

Visando os objetivos da pesquisa, diferentes variáveis dependentes foram estabelecidas nas análises inferenciais deste estudo.

\subsubsection{Análise dos fatores associados à alta carga de trabalho na admissão da UTI}

Carga de trabalho de enfermagem na admissão da UTI: variável categórica que distinguiu os pacientes que requereram alta carga de trabalho de enfermagem na admissão na UTI (primeiras 24 horas) dos demais. Por meio da divisão dos pacientes segundo valores do NAS em tercis foram estabelecidos dois grupos: média/baixa carga $\left(1^{\circ}\right.$ e $2^{\circ}$ tercis) e alta carga ( $3^{\circ}$ tercil).

\subsubsection{Análise para identificar o modelo de estimativa da carga de trabalho na} alta da UTI

Carga de trabalho na alta da UTI (NAS alta): variável quantitativa contínua, avaliada por meio do cálculo do NAS referente às últimas 24 horas de permanência na UTI, considerando apenas os sobreviventes.

\subsubsection{Variáveis independentes em ambas as análises inferenciais}

\subsubsection{Características demográficas e comorbidade}

Gênero: variável nominal (feminino e masculino).

Idade: variável quantitativa contínua considerada em anos.

Índice de comorbidade de Charlson: variável quantitativa discreta. Neste índice, são analisadas 19 condições clínicas (infarto do miocárdio, insuficiência cardíaca congestiva, doença vascular periférica, doença cerebrovascular, demência, doença pulmonar crônica, doença do tecido conjuntivo, úlcera péptica, doença crônica do fígado ou cirrose, diabetes sem complicação, hemiplegia ou paraplegia, doença renal severa ou moderada, diabetes com complicação, tumor, leucemia, linfoma, doença do fígado severa ou moderada, tumor maligno metastático e síndrome da imunodeficiência adquirida). Para cada condição clínica presente é atribuída uma pontuação que varia de um a seis. $\mathrm{O}$ valor do índice, originado a partir do somatório desses pontos, reflete o peso das comorbidades do paciente na mortalidade, ou seja, maiores valores do índice estão associados com aumento da frequência de mortes $^{(99)}$. 


\subsubsection{Características relacionadas ao trauma}

Causa externa: variável nominal que categorizou as vítimas de acordo com o Capítulo XX (Causas externas de morbidade e de mortalidade) da CID-10 ${ }^{(1)}$. Foram observadas na casuística as categorias: Pedestre ou ciclista traumatizado em um acidente de transporte (V01-V19); Motociclista traumatizado em um acidente de transporte (V20-V29); Ocupante de um automóvel, caminhonete ou veículo de transporte pesado traumatizado em um acidente de transporte (V40-V69); Quedas (W00-W19). As causas externas, Exposição a forças mecânicas inanimadas (W20W49); Lesão autoprovocada intencionalmente por precipitação de um lugar elevado (X80); Agressão por meio de objeto cortante ou penetrante (X99); Agressão por meio de um objeto contundente (Y00); Agressão por meio de força corporal (Y04); Agressão por meios não especificados (Y09) e trauma por causa desconhecida foram reunidas nesta investigação na categoria "outras", devido à baixa frequência apresentada.

Número de lesões AIS $\geq 3$ : variável quantitativa discreta. A AIS é uma escala utilizada para descrever as lesões decorrentes de um trauma e identificar sua gravidade. A lista de lesões é apresentada no manual AIS, que fornece, para cada descrição de lesão, um identificador composto por sete números, sendo o sétimo dígito o valor referente ao escore de gravidade AIS. Nesta escala de gravidade, escore um é atribuído para lesões leves, dois para moderadas, três para sérias, quatro para graves, cinco para críticas e seis para lesões de gravidade máxima. Lesões que recebem pontuação $\geq 3$ representam potencial ameaça à vida ${ }^{(93)}$. Na atual investigação, as lesões foram codificadas segundo a última versão do manual: AIS 2005- update $2008^{(93)}$. Para descrever esta variável foram computadas todas as lesões de gravidade igual ou superior a 3 , independentemente da região corpórea.

ISS: variável quantitativa discreta que descreve a gravidade global do trauma de uma vítima, calculada a partir da análise de todas as lesões decorrentes do trauma. O ISS é um índice anatômico, com base no escore de gravidade das lesões segundo a AIS, e considera seis regiões corpóreas: cabeça ou pescoço, face, tórax, abdome ou conteúdo pélvico, extremidades ou cintura pélvica e superfície externa. As lesões das vítimas são distribuídas segundo essas seis regiões, o valor da AIS é estabelecido e, então, calcula-se o ISS. A gravidade global do trauma, conforme o ISS, é estimada pela soma do quadrado do escore AIS mais alto de três regiões diferentes do corpo e 
sua pontuação pode variar de 1 a 75 . Quanto maior o valor do escore, maior será a gravidade do trauma e, consequentemente, maior a probabilidade de morte ${ }^{(91)}$.

NISS: variável quantitativa discreta que, assim como o ISS, estima a gravidade global do trauma. O NISS é uma modificação do ISS proposta para sanar falhas apontadas ao aplicar o ISS em pacientes com múltiplas lesões localizadas na mesma região corpórea, visto que este último índice considera apenas a mais grave, ignorando a segunda e terceira lesões mais graves que, muitas vezes, encontram-se no mesmo segmento corpóreo da primeira. O NISS é obtido a partir da soma dos quadrados dos escores AIS das três lesões mais graves, independentemente da região corpórea. A pontuação do NISS também pode variar de 1 a 75; entretanto, seu cálculo não requer a separação das lesões conforme as regiões corpóreas, simplificando a estimativa do índice em relação ao $\operatorname{ISS}^{(92)}$. Desde a criação deste novo índice, pesquisas têm sido realizadas com o intuito de verificar o melhor indicador para prever diferentes desfechos dos pacientes, ISS ou NISS. Os resultados são controversos, visto que alguns estudos, realizados em UTI, mostram que o NISS é o mais apropriado para análise das variáveis tempo de internação hospitalar ${ }^{(94-95)}$, admissão na UTI ${ }^{(95)}$, necessidade de ventilação mecânica ${ }^{(96)}$ e mortalidade ${ }^{(94)}$; outro, porém, aponta melhor performance do ISS na previsão de admissão em UTI nos indivíduos com idade inferior a $65 \operatorname{anos}^{(15)}$. Mediante essas observações e o uso contínuo dos dois índices na literatura científica, optou-se por utilizar ambos os indicadores para estimar a gravidade global do trauma da casuística estudada.

Número de regiões corpóreas acometidas: variável quantitativa discreta definida pela contagem das regiões corpóreas que apresentaram alguma lesão. A divisão corpórea proposta para o cálculo do ISS (cabeça ou pescoço, face, tórax, abdome ou conteúdo pélvico, extremidades ou cintura pélvica e superfície externa) foi considerada para identificar o número de regiões e, portanto, a variação observada nesta contagem foi de 1 a 6 .

Maximum Abbreviated Injury Scale (MAIS): com este indicador descreve-se a gravidade das lesões mais sérias das vítimas de trauma com um único dígito e o seu valor corresponde ao mais alto escore da AIS em um paciente, independentemente do número de lesões ${ }^{(93)}$. O MAIS, assim como a AIS, varia de 1 a 6 pontos; porém, neste estudo, os valores observados categorizaram a casuística em três grupos: MAIS $=3$, MAIS $=4$ e MAIS $=5$. 
Localização das lesões AIS $\geq 3$ : para a categorização das vítimas segundo esta variável analisaram-se as seis regiões corpóreas descritas pelo ISS, de tal forma que a presença ou ausência de lesões AIS $\geq 3$ foi estabelecida para todos os pacientes considerando cada região corpórea isoladamente.

Região corpórea mais gravemente lesada: na análise desta variável também foram consideradas as seis regiões corpóreas do ISS separadamente. Para a categorização das vítimas segundo esta variável identificou-se o MAIS e, a seguir, as regiões corpóreas que apresentaram lesões com AIS de similar valor. Essas foram as regiões consideradas mais gravemente lesadas.

\subsubsection{Características clínicas relacionadas à internação na UTI}

Intervalo de tempo entre admissão hospitalar e UTI: variável quantitativa contínua considerada em horas.

Procedência: variável nominal que categorizou os pacientes em vindos do Pronto-Socorro, Centro Cirúrgico e outras procedências (outra UTI, unidade de internação ou outro hospital).

Tipo de admissão: variável nominal que distribuiu os pacientes em clínicos e cirúrgicos, sendo estes últimos diferenciados segundo cirurgia programada ou não.

Risco de morte segundo APACHE II: variável quantitativa contínua que neste estudo foi utilizada para descrever a gravidade do paciente nas primeiras 24 horas de internação na UTI. O APACHE II, um índice baseado na análise de populações norte-americanas e criado para estimar a gravidade do paciente de UTI, utiliza para seu cálculo um total de 12 variáveis clínicas, fisiológicas e laboratoriais padronizadas (temperatura, pressão arterial média, frequências cardíaca e respiratória, gradiente alvéolo-arterial ou pressão arterial de oxigênio consideradas conforme valor da fração inspirada de oxigênio, pH arterial, escore da Escala de Coma de Glasgow (ECGl) e valores séricos de sódio, potássio, creatinina, hematócrito e leucócitos) que recebem pontuação de zero a quatro, conforme o grau de desvio da normalidade (quanto mais alterado o valor, maior o escore). Além dessas variáveis, pontos são atribuídos à idade e presença de doença crônica. Por meio de uma equação de regressão logística feita a partir do somatório desses pontos (pontuação máxima 71) é possível calcular o risco de morte para um paciente com determinada patologia ${ }^{(65)}$, valor este considerado neste estudo. 
Risco de morte segundo SAPS II: variável quantitativa contínua vinculada à gravidade do paciente em UTI, utilizada nesta investigação tendo em vista as primeiras 24 horas de internação nesta unidade. No SAPS II, índice baseado na análise de populações europeias e norte-americanas, pontos são atribuídos a 12 variáveis fisiológicas (frequência cardíaca, pressão arterial sistólica, temperatura, pressão arterial de oxigênio dividida pela fração inspirada de oxigênio, débito urinário, ureia sérica, leucócitos, potássio sérico, sódio sérico, bicarbonato sérico, bilirrubina e ECGl), além de idade, tipo de admissão (cirúrgica programada, não programada ou clínica) e presença de doença crônica (imunodeficiência adquirida, neoplasia com metástases e neoplasia hematológica). No cálculo do SAPS II, cada variável recebe uma pontuação (que varia segundo os dados do paciente) e, no final, esses valores são somados, obtendo-se o escore total (quanto mais elevado, maior é a gravidade observada). O somatório fornece um escore que pode ser traduzido em risco de morte ${ }^{(69)}$, resultado este utilizado neste estudo.

Risco de morte segundo LODS: variável quantitativa utilizada para descrever a gravidade dos pacientes e a disfunção orgânica nas primeiras 24 horas de internação na UTI. O LODS, um índice fisiológico, é um instrumento preditivo de mortalidade com enfoque na disfunção orgânica do paciente no primeiro dia de internação na UTI. Este índice analisa 12 variáveis fisiológicas e identifica níveis de disfunção para seis sistemas orgânicos: neurológico, cardiovascular, renal, pulmonar, hematológico e hepático. O escore final pode ser convertido em probabilidade de morte e, quanto maior o número de falência de órgãos, maior o risco de óbito presente $^{(73)}$. Assim como nos índices citados anteriormente, o risco de morte identificado pelo LODS foi considerado nesta investigação.

Número de sistemas comprometidos: variável quantitativa discreta que computa o número total de sistemas comprometidos, segundo indicação do LODS, nas primeiras 24 horas de internação na UTI. Pode variar de zero a seis sistemas comprometidos (neurológico, cardiovascular, renal, pulmonar, hematológico e hepático).

Tipo de insuficiência orgânica: para categorizar as vítimas segundo esta variável analisou-se independentemente os seis sistemas orgânicos componentes do LODS e classificou-se a casuística segundo a ausência ou presença de falência nesses sistemas. 


\subsubsection{Variáveis complementares à descrição da casuística do estudo}

Tipo de trauma: variável nominal que descreveu o tipo de trauma da vítima em contuso, penetrante ou ambos.

Tempo de permanência na UTI: variável quantitativa discreta considerada em dias.

Tempo de permanência hospitalar: variável quantitativa discreta considerada em dias.

Destino após saída da UTI: variável nominal que descreveu o local para onde as vítimas foram encaminhadas após saída da UTI. Inclui as categorias: unidades de internação do IC-HCFMUSP, outros institutos do HCFMUSP, outros hospitais e Instituto Médico Legal.

Condição de saída hospitalar: variável que categorizou as vítimas em sobrevivente ou não sobrevivente na saída hospitalar.

Intervenções de enfermagem: para categorizar as vítimas segundo esta variável, com a finalidade de identificar e descrever um possível padrão de intervenções de enfermagem realizadas nesses pacientes, analisou-se independentemente os 23 itens que compõem o instrumento NAS. A investigação das atividades de enfermagem requeridas pelo paciente foi feita nos três plantões envolvidos na assistência durante as primeiras 24 horas de permanência da vítima na UTI e as intervenções foram consideradas realizadas se presentes em pelo menos um desses turnos. Para as intervenções de enfermagem classificadas conforme a complexidade (itens 1, 4, 6, 7 e 8), foi considerada a atividade de maior pontuação no NAS, conforme pesos descritos nas categorias a, b ou c. Este procedimento resultou na classificação da casuística segundo realização ou não de cada uma das intervenções de enfermagem previstas no NAS.

\subsection{Aspectos éticos}

O projeto recebeu aprovação da Comissão de Ética para Análise de Projetos de Pesquisa (CAPPesq) da Diretoria Clínica do HCFMUSP, em sessão de 16/12/2009, sob protocolo número 1220/09 (Anexo A).

O Termo de Consentimento Livre e Esclarecido - TCLE (Apêndice A) foi elaborado com a finalidade de solicitar o consentimento do paciente quanto à participação na pesquisa. Esse consentimento foi obtido com os participantes do 
estudo ou com familiares e representantes legais, nos casos em que a condição clínica do doente impedia o entendimento do termo. A inserção do paciente na pesquisa esteve sempre vinculada à assinatura do TCLE.

\subsection{Instrumentos de coleta de dados}

Durante a coleta de dados, foram aplicados quatro instrumentos, descritos a seguir.

\subsubsection{Ficha de levantamento de dados de identificação e da internação do paciente (Apêndice B)}

Os campos contemplados nessa ficha permitiram direcionar a coleta de informações do paciente no que se refere à idade, gênero, data do trauma e causa externa, bem como estimar o valor do índice de comorbidade de Charlson. O instrumento permitiu também o registro dos seguintes dados sobre a internação hospitalar: data e hora da internação no hospital e na UTI, procedência, data e hora da saída da UTI, destino depois da saída dessa unidade e data e condições de saída hospitalar. Essas informações foram coletadas no prontuário do paciente ou em registros eletrônicos.

\subsubsection{Ficha de levantamento das variáveis para o cálculo do APACHE II, SAPS II e LODS (Apêndice C)}

Esta ficha permitiu o registro de todas as informações relacionadas às variáveis necessárias para o cálculo dos índices APACHE II, SAPS II e LODS. Foram resgatados, nos prontuários ou registros computadorizados dos pacientes, dados clínicos e laboratoriais referentes às primeiras 24 horas de internação na UTI para seu preenchimento.

Nesta ficha foi anotada a variação de temperatura, frequência cardíaca, pressão arterial sistólica e média e frequência respiratória; para os demais parâmetros foi sempre registrado o valor que mais se distanciou da normalidade, conforme recomendado para aplicação dos índices ${ }^{(65,69,73)}$. Ainda seguindo essas recomendações, quando algum exame laboratorial necessário para o cálculo dos índices não foi realizado, considerou-se, para fins de pontuação, o resultado normal $^{(65,69,73)}$. Nos casos em que as vítimas foram admitidas na unidade crítica sob efeito de sedação, foi considerado o escore da ECGl obtido antes do procedimento de intubação. Se o paciente entrou no Pronto-Socorro sedado, considerou-se o valor da ECGl registrado na cena do acidente. 


\subsubsection{Formulário para aplicação do NAS (Apêndice D)}

Este foi o instrumento utilizado na coleta de dados para aplicação do NAS. O cálculo do escore total, realizado em dois momentos (primeiras e últimas 24 horas de permanência do paciente na UTI), foi feito por meio do somatório dos itens pontuados no instrumento, conforme a seguinte equação: Escore total NAS = item 1 + item $2+$ item $3+\ldots+$ item 23.

A pontuação desses itens foi considerada a partir da análise da realização ou não de cada intervenção de enfermagem descrita no NAS nos três plantões envolvidos na assistência. Uma vez realizada em pelo menos um dos plantões, a pontuação do item correspondente à atividade era considerada para o cálculo do NAS. Para as intervenções de enfermagem compostas por subitens (itens 1, 4, 6, 7 e 8) foi considerada sempre a atividade com maior pontuação, conforme pesos descritos nas categorias $\mathrm{a}, \mathrm{b}$ ou $\mathrm{c}$.

Durante a coleta de dados, as instruções para uso do NAS publicada pelos autores do instrumento ${ }^{(100)}$ orientou o preenchimento deste formulário.

\subsubsection{Ficha para registro da descrição das lesões e cálculo do ISS e NISS (Apêndice E)}

A primeira parte desta ficha foi utilizada no período de coleta de dados para transcrever as lesões decorrentes do trauma registradas no prontuário do paciente, no laudo de exames ou em fichas cirúrgicas. A segunda parte do instrumento foi empregada para o cálculo dos índices ISS e NISS e permitiu o registro das lesões distribuídas conforme a região corpórea, além do código e da gravidade dessas lesões segundo o Manual AIS 2005, update $2008^{(93)}$.

\subsection{Despesas e treinamento}

Todas as despesas com a pesquisa foram financiadas pela Reserva Técnica proveniente da bolsa de estudos fornecida à pesquisadora pela Fundação de Amparo à Pesquisa do Estado de São Paulo (FAPESP).

Para colaborar com a coleta de dados desta investigação, foram selecionadas três alunas do $3^{\circ}$ ano do curso graduação da Escola de Enfermagem da Universidade de São Paulo. Durante duas semanas, foram realizados encontros para apresentação dos instrumentos e esclarecimentos sobre sua aplicação, técnica de abordagem de pacientes e/ou família, além de formas de acesso às fontes de dados. O treinamento 
in loco iniciou-se apenas após aprovação do Comitê de Ética. Nesta fase, as alunas coletavam dados dos pacientes simultaneamente e, depois, confrontavam os resultados. Divergências, dificuldades e dúvidas eram então sanadas pela pesquisadora. Esta segunda etapa do treinamento teve duração aproximada de duas semanas e foi finalizada quando as alunas apresentaram segurança no resgate de dados e na abordagem do paciente e/ou família.

\subsection{Operacionalização da coleta dos dados}

Após aprovação da pesquisa pela CAPPesq e treinamento das alunas, iniciouse a coleta dos dados no dia $1^{\circ}$ de maio de 2010 na UTI do Trauma do ICHCFMUSP.

Por opção da pesquisadora e das alunas colaboradoras, realizou-se revezamento semanal na coleta de dados. Cada semana havia uma coletadora responsável por essa atividade, sempre supervisionada a distância ou in loco pela pesquisadora.

Diariamente, uma aluna ou a pesquisadora comparecia na unidade 20 minutos antes das passagens de plantão da equipe de enfermagem (manhã, tarde e noite), para identificar os pacientes que foram admitidos e selecionar aqueles que atendiam aos critérios de inclusão da pesquisa pela análise do censo diário, prontuários e informações fornecidas pelos profissionais da unidade.

Após selecionados os pacientes, iniciava-se o preenchimento dos instrumentos com os dados disponíveis no prontuário e, em seguida, acompanhava-se a passagem de plantão da equipe de enfermagem para completar o preenchimento do formulário NAS (Apêndice D), visto que muitas atividades de enfermagem realizadas não eram registradas na anotação e evolução do paciente. Dúvidas quanto ao tempo dispensado e número de profissionais necessários para realizar as atividades, assim como cuidados de higiene e mudança de posicionamento do paciente, suporte aos familiares e tarefas administrativas e gerenciais, entre outras, eram prontamente esclarecidas com a equipe de enfermagem.

A ficha de levantamento das variáveis para o cálculo dos índices de gravidade do paciente na UTI (Apêndice C) era preenchida com dados provenientes de resultados de exames laboratoriais e da planilha que continha informações sobre sinais vitais e balanço hídrico do paciente. 
O preenchimento dos Apêndices $\mathrm{C}$ e $\mathrm{D}$ foi realizado durante três visitas consecutivas até que todas as informações do paciente referentes às primeiras 24 horas de internação na UTI fossem resgatadas.

Além disso, a consulta à evolução médica ou de enfermagem, a descrição de cirurgias e os laudos de exames de imagem permitiram que as lesões traumáticas identificadas no paciente durante a internação hospitalar fossem inseridas no instrumento para o cálculo do ISS e NISS (Apêndice E).

Todos os pacientes do estudo eram acompanhados diariamente e, quando identificada uma programação de alta da unidade, iniciava-se a coleta dos dados para cálculo do NAS referente à saída, processo semelhante ao realizado durante a admissão na unidade crítica.

Na saída das vítimas da UTI, inclusive na vigência de óbito, completavam-se os dados do Apêndice B referentes a data e destino após saída da unidade. Para os sobreviventes, finalizava-se a aplicação do NAS com auxílio da equipe que prestou o último atendimento e registrava-se a condição de saída hospitalar após esta informação ser incluída na ficha de dados informatizados dos pacientes.

A inserção de novos pacientes na pesquisa perdurou até 31 de janeiro de 2011, ao atingir a casuística de 200 casos. Entretanto, alguns pacientes foram acompanhados até abril de 2011, período em que receberam alta da UTI.

\subsection{Processamento e análise dos dados}

O cálculo final dos índices APACHE II, SAPS II e LODS foi realizado pela pesquisadora por meio das planilhas criadas pela Société Française d'Anesthésie et de Réanimation (SFAR), disponíveis nos seguintes sites de domínio público: http://www.sfar.org/scores2/apache22.html, http://www.sfar.org/scores2/saps2.html e http://www.sfar.org/scores2/lods2.html.

Para o cálculo dos índices de gravidade do trauma, as lesões transcritas no Apêndice E foram distribuídas segundo suas regiões corpóreas. A seguir, para cada lesão, foi identificado o código AIS destacando-se o sétimo dígito na coluna referente à gravidade da lesão. Na coluna ISS registrou-se as pontuações AIS atribuídas às três lesões mais graves em segmentos corpóreos distintos. A soma dos quadrados destes valores resultou no ISS. Na coluna referente ao NISS salientou-se 
os valores da AIS das três lesões mais graves, independentemente da região corpórea. A soma do quadrado destes valores estabeleceu o NISS.

As codificações da AIS e os cálculos do ISS e NISS foram realizados por duas pesquisadoras da área de trauma. Na vigência de discordância, uma terceira pesquisadora foi consultada.

Os dados foram inseridos em uma planilha eletrônica do programa Microsoft Office Excel 2010. Para a realização das análises descritivas e inferenciais utilizou-se o software SPSS $-17^{\circledR}$.

\subsubsection{Análise descritiva}

Estatísticas descritivas foram realizadas para todas as variáveis do estudo visando à caracterização da amostra. As variáveis qualitativas foram descritas por meio de frequências absoluta e relativa (\%). Para as variáveis quantitativas contínuas e discretas foram calculados média, desvio padrão, mediana e sua variação.

Para identificar um possível padrão de intervenções de enfermagem realizadas na casuística estudada, foi inicialmente utilizado o método de agrupamento hierárquico (análise de Cluster) das vítimas, segundo as intervenções de enfermagem requeridas. $\mathrm{O}$ agrupamento hierárquico ordenou as distâncias entre as vítimas em relação a essa variável e permitiu agrupá-las em conjuntos. O resultado foi representado graficamente em um dendograma elaborado pelo método de Single Linkage. Foi estabelecido o ponto de corte que melhor identificou os grupos de vítimas com intervenções similares. A descrição do grupo que incluiu a maioria das vítimas, segundo intervenções realizadas, permitiu descrever o padrão observado, isto é, as intervenções mais frequentemente realizadas em um agrupamento com intervenções similares.

\subsubsection{Análise da adesão à distribuição normal}

$\mathrm{Na}$ análise das variáveis contínuas, primeiramente foi aplicado o teste de Kolmogorov-Smirnov para testar a hipótese de normalidade, considerando $\mathrm{p} \geq 0,05$ como distribuição normal. Para 95\% das variáveis rejeitou-se a hipótese de normalidade, optando-se assim pela utilização de testes não paramétricos em todas as análises.

\subsubsection{Análise inferencial}

A regressão logística múltipla foi utilizada para identificar os fatores associados à alta carga de trabalho de enfermagem requerida pelas vítimas de trauma. 
Em uma primeira etapa, verificou-se a associação entre as variáveis independentes do estudo e a alta carga de trabalho de enfermagem. Para comparação dos grupos (alta carga versus média/baixa carga) em relação às variáveis nominais, utilizou-se o Teste Qui-Quadrado de Pearson. O Teste Exato de Fisher foi realizado nos casos em que a frequência esperada, em pelo menos uma das caselas da tabela de contingência, foi $\leq 5$. Quanto às variáveis quantitativas discretas e contínuas, a comparação dos grupos foi feita pelo Teste de Mann-Whitney.

Para a construção do modelo de regressão logística múltipla, foram selecionadas todas as variáveis que apresentaram $\mathrm{p}<0,20$ nas análises de comparação e testadas nos dois métodos de seleção, stepwise backward e stepwise forward. Como os dois métodos apresentaram resultados semelhantes, optou-se por manter a primeira opção: stepwise backward. A capacidade preditiva do modelo foi avaliada pela Receiver Operating Characteristics Curve (Curva ROC).

A regressão linear foi utilizada para identificar o modelo para estimar a carga de trabalho de enfermagem requerida pelos sobreviventes nas últimas 24 horas de permanência na UTI, segundo o NAS. Em uma primeira etapa, as médias do NAS na alta, segundo as variáveis nominais, foram comparadas pelos Testes de MannWhitney (duas categorias) ou de Kruskal-Wallis (três ou mais categorias). Quanto às variáveis quantitativas contínuas e discretas, verificou-se a associação entre as variáveis independentes e o NAS, na alta, pelo Coeficiente de Correlação de Spearman. Identificadas as variáveis independentes que apresentaram $p<0,20$, construiu-se o modelo de regressão linear com o processo de seleção stepwise backward. Para avaliar a suposição de normalidade para o componente aleatório do modelo de regressão linear foi utilizado o gráfico normal de probabilidade (normal P-P Plot).

\subsubsection{Nível de significância}

Em todas as análises foi estabelecido o nível de significância de 5\%. 


\section{RESULTADOS}

\subsection{Caracterização das vítimas de trauma admitidas na UTI}

A casuística compôs-se de 200 vítimas de trauma admitidas na UTI no período compreendido entre $1^{\circ}$ de maio de 2010 e 31 de janeiro de 2011 . A maioria dos pacientes era do sexo masculino $(82,0 \%)$; a maior proporção de indivíduos desse gênero permitiu estabelecer uma relação masculino:feminino de 4,5:1.

Tabela 1. Estatística descritiva das variáveis idade e presença de comorbidade. São Paulo, 2010-2011

\begin{tabular}{lcccc}
\hline \multicolumn{1}{c}{ Variável } & Média (dp) & Mediana & Mín & Máx \\
\hline Idade & $40,7(18,6)$ & 36 & 18 & 86 \\
Índice de comorbidade de Charlson & $0,6(1,4)$ & 0 & 0 & 9 \\
\hline
\end{tabular}

Nos dados da Tabela 1, observa-se que a média e a mediana de idade dos pacientes foram de 40,7 e 36 anos, respectivamente. A maioria das vítimas tinha menos de 40 anos $(55,5 \%)$ e aproximadamente $18 \%$ da população era composta por idosos ( $\geq 60$ anos). Quanto à presença de comorbidade, a média do índice de Charlson foi inferior a um e somente cerca de um quarto dos pacientes (52) era portador de algum tipo de doença preexistente.

Tabela 2. Número $\left(\mathrm{n}^{\circ}\right)$ e percentual $(\%)$ de pacientes segundo causa externa e tipo de trauma. São Paulo, 2010-2011

\begin{tabular}{clcc}
\hline Variável & \multicolumn{1}{c}{ Categorias } & $\mathbf{n}^{\mathbf{0}}$ & \multicolumn{1}{c}{$\%$} \\
\hline & $\begin{array}{l}\text { Pedestre ou ciclista traumatizado em um acidente } \\
\text { de transporte (V01-V19) }\end{array}$ & 40 & 20,0 \\
& $\begin{array}{l}\text { Motociclista traumatizado em um acidente de } \\
\text { transporte (V20-V29) }\end{array}$ & 55 & 27,5 \\
Causa externa & $\begin{array}{l}\text { Ocupante de um automóvel, caminhonete ou } \\
\text { veículo de transporte pesado traumatizado em um }\end{array}$ & 20 & 10,0 \\
& $\begin{array}{c}\text { acidente de transporte (V40-V69) } \\
\text { Quedas (W00-W19) }\end{array}$ & 62 & 31,0 \\
& Outras* & 23 & 11,5 \\
Tipo de & Contuso & 189 & 94,5 \\
trauma & Penetrante & 9 & 4,5 \\
& Contuso e penetrante & 2 & 1,0 \\
\hline
\end{tabular}

* W20-W49, X80, X99, Y00, Y04, Y09 ou causa desconhecida 
Pela Tabela 2, as mais frequentes causas externas foram as quedas $(31,0 \%)$, seguidas dos acidentes com motociclistas $(27,5 \%)$ e dos atropelamentos de pedestres ou colisão de ciclistas (20,0\%). No entanto, somando-se os acidentes de transporte, observa-se que a maioria $(57,5 \%)$ foi de vítimas desse tipo de ocorrência. Em quatro casos, a causa do trauma não foi identificada. Aproximadamente $95 \%$ dos pacientes foi vítima de trauma contuso e, dentre os penetrantes, oito casos foram decorrentes de arma de fogo, dois de arma branca e um de explosivo.

Tabela 3. Estatística descritiva das variáveis relacionadas à gravidade do trauma. São Paulo, 2010-2011

\begin{tabular}{lcccc}
\hline \multicolumn{1}{c}{ Variável } & Média (dp) & Mediana & Mín & Máx \\
\hline ISS & $19,3(9,1)$ & 17 & 9 & 50 \\
NISS & $27,1(9,9)$ & 27 & 9 & 66 \\
Número de lesões AIS $\geq 3$ & $3,1(1,8)$ & 3 & 1 & 9 \\
Número de regiões corpóreas acometidas & $2,7(1,3)$ & 3 & 1 & 6 \\
\hline
\end{tabular}

Os dados da Tabela 3 mostram que, quanto à gravidade do trauma, o ISS variou de 9 a 50, com média de 19,3 e mediana de 17. A distribuição das vítimas em três grupos, ISS $<16$ (trauma leve), ISS $\geq 16$ e $<25$ (trauma moderado) e ISS $\geq 25$ (trauma grave), apresentou predomínio de pacientes com valor ISS superior a 16 pontos (59,0\%). O NISS apresentou uma variação de 9 a 66, média de 27,1 e mediana de 27. Para esse índice, prevaleceram as vítimas com NISS superior a 25 pontos $(67 \%)$ e, em 150 pacientes $(75 \%)$, a pontuação do NISS foi maior que a do ISS.

A média e a mediana do número de lesões AIS $\geq 3$ foram semelhantes $(3,1$ e 3) e a quantidade deste tipo de lesão variou de 1 a 9 . Vale salientar que $100 \%$ das vítimas apresentavam pelo menos uma lesão $\geq 3$ no cálculo da AIS. Nove pacientes apresentaram uma única lesão com valor de AIS igual a 3, totalizando escore 9 para os dois índices de gravidade do trauma.

Tendo em vista as seis regiões corpóreas consideradas para cálculo do ISS (cabeça ou pescoço, face, tórax, abdome ou conteúdo pélvico, extremidades ou cintura pélvica e superfície externa), observou-se que, em média, foram acometidas 2,7 regiões, valor próximo à mediana, 3. Houve predomínio de pacientes com uma, duas ou três regiões acometidas $(22,5 \%, 21,5 \%$ e $28 \%$, respectivamente). Um total 
de $28 \%$ dos pacientes apresentou acometimento de quatro ou mais regiões corpóreas; porém, em apenas seis vítimas (3\%), todas as regiões apresentavam algum tipo de lesão.

Tabela 4. Número $\left(\mathrm{n}^{\circ}\right)$ e percentual $(\%)$ de pacientes segundo valor do MAIS. São Paulo, 2010-2011

\begin{tabular}{lcc}
\hline MAIS & $\mathbf{n}^{\mathbf{0}}$ & $\mathbf{\%}$ \\
\hline MAIS $=3$ & 130 & 65,0 \\
MAIS $=4$ & 41 & 20,5 \\
MAIS $=5$ & 29 & 14,5 \\
\hline
\end{tabular}

Analisando o MAIS calculado por paciente, observou-se que escore igual a 3 $(65,0 \%)$ prevaleceu na amostra (Tabela 4$)$.

$\mathrm{Na}$ Tabela 5 pode-se verificar a frequência com que os pacientes apresentaram lesões AIS $\geq 3$ nas seis regiões corpóreas e também as regiões em que os pacientes tiveram as lesões mais graves, isto é, as regiões com lesões de mais alta pontuação AIS. Vale esclarecer que $15,5 \%$ da amostra apresentou mais de uma região corpórea com a pontuação máxima do paciente na escala AIS. 
Tabela 5. Análise por região corpórea do número $\left(\mathrm{n}^{\circ}\right)$ e percentual $(\%)$ de pacientes segundo a presença de lesões $A I S \geq 3$ e indicação de região corpórea mais gravemente lesada. São Paulo, 2010-2011

\begin{tabular}{|c|c|c|c|c|}
\hline \multirow[t]{2}{*}{ Região } & \multicolumn{2}{|c|}{$\begin{array}{c}\text { Localização das } \\
\text { lesões AIS } \geq 3\end{array}$} & \multicolumn{2}{|c|}{$\begin{array}{l}\text { Região corpórea mais } \\
\text { gravemente lesada }\end{array}$} \\
\hline & $\mathbf{n}^{\mathbf{o}}$ & $\%$ & $\mathbf{n}^{\mathbf{0}}$ & $\%$ \\
\hline \multicolumn{5}{|l|}{ Cabeça ou pescoço } \\
\hline Sim & 131 & 65,5 & 128 & 64,0 \\
\hline Não & 69 & 34,5 & 72 & 36,0 \\
\hline \multicolumn{5}{|l|}{ Face } \\
\hline Sim & 11 & 5,5 & 4 & 2,0 \\
\hline Não & 189 & 94,5 & 196 & 98,0 \\
\hline \multicolumn{5}{|l|}{ Tórax } \\
\hline Sim & 73 & 36,5 & 55 & 27,5 \\
\hline Não & 127 & 63,5 & 145 & 72,5 \\
\hline \multicolumn{5}{|c|}{ Abdome ou conteúdo pélvico } \\
\hline Sim & 27 & 13,5 & 22 & 11,0 \\
\hline Não & 173 & 86,5 & 178 & 89,0 \\
\hline \multicolumn{5}{|c|}{$\begin{array}{l}\text { Extremidades ou cintura } \\
\text { pélvica }\end{array}$} \\
\hline Sim & 44 & 22,0 & 30 & 15,0 \\
\hline Não & 156 & 78,0 & 170 & 85,0 \\
\hline \multicolumn{5}{|l|}{ Superfície externa } \\
\hline Sim & - & - & - & - \\
\hline Não & 200 & 100,0 & 200 & 100,0 \\
\hline
\end{tabular}

Os dados da Tabela 5 mostram que 65,5\% do pacientes tiveram lesões AIS $\geq$ 3 na região da cabeça ou pescoço e em $64 \%$ dos casos essa também foi uma das regiões corpóreas mais gravemente lesada. $\mathrm{Na}$ investigação dessas variáveis, poucas ocorrências foram registradas na região da face $(<6,0 \%)$ e houve ausência de casos de lesões em superfície externa. 
Tabela 6. Número $\left(\mathrm{n}^{\circ}\right)$ e percentual $(\%)$ de pacientes segundo procedência, tipo de admissão e destino após saída da UTI. São Paulo, 2010-2011

\begin{tabular}{clcc}
\hline Variável & \multicolumn{1}{c}{ Categorias } & $\mathbf{n}^{\mathbf{0}}$ & $\mathbf{\%}$ \\
\hline \multirow{2}{*}{ Procedência } & Pronto-Socorro & 54 & 27,0 \\
& Centro Cirúrgico & 140 & 70,0 \\
& Outras* & 6 & 3,0 \\
& Cirúrgica programada & 7 & 3,5 \\
Tipo de & Cirúrgica não programada & 133 & 66,5 \\
admissão & Clínica & 60 & 30,0 \\
& & & \\
& & 123 & 61,5 \\
Destino após & Unidades de internação do IC-HCFMUSP & 34 & 17,0 \\
saída da UTI & Outros institutos do HCFMUSP** hospitais & 5 & 2,5 \\
& Instituto Médico Legal & 38 & 19,0 \\
\hline * Outra UTI, unidade de internação ou outro hospital & \multicolumn{2}{c}{} \\
** Instituto de Ortopedia e Traumatologia (IOT) ou Hospital de Suzano & \multicolumn{2}{c}{}
\end{tabular}

Nos dados da Tabela 6, nota-se que pacientes procedentes do Centro Cirúrgico $(70,0 \%)$ e submetidos à cirurgia não programada $(66,5 \%)$ prevaleceram na amostra.

A maioria dos sobreviventes $(61,5 \%)$ foi encaminhada às Unidades de Internação da própria instituição após alta da UTI e 24 pacientes foram transferidos para o IOT com a finalidade de dar seguimento ao tratamento ortopédico. Dez vítimas foram encaminhadas ao Hospital de Suzano, referência do HCFMUSP para tratamento dos pacientes crônicos.

Neste estudo, a taxa de mortalidade das vítimas de trauma na UTI foi de 19,0\%, porém 10 pacientes evoluíram a óbito no hospital, após alta da unidade crítica, totalizando 48 mortes (24\%). 
Tabela 7. Estatística descritiva das variáveis relacionadas aos intervalos de tempo durante a internação hospitalar. São Paulo, 2010-2011

\begin{tabular}{lcccc}
\hline \multicolumn{1}{c}{ Variável } & Média (dp) & Mediana & Mín & Máx \\
\hline $\begin{array}{l}\text { Intervalo de tempo entre admissão } \\
\text { hospitalar e UTI (horas) }\end{array}$ & $29,4(58,1)$ & 15,3 & 2,0 & 502,3 \\
$\begin{array}{l}\text { Tempo de permanência na UTI (dias) } \\
\text { Tempo de permanência hospitalar (dias) }\end{array}$ & $13,6(14,6)$ & 8 & 1 & 92 \\
\hline
\end{tabular}

Observa-se na Tabela 7 que, quando considerado o intervalo de tempo entre a chegada no Pronto-Socorro e a admissão na UTI, houve uma demora média superior a um dia (29,4 horas) para o início do tratamento intensivo. A média do tempo de permanência na UTI foi 13,6 dias, e 25,5\% dos pacientes permaneceram mais de 20 dias em tratamento na unidade crítica. A média e a mediana do tempo de permanência hospitalar foram, respectivamente, de 35,9 e 16 dias, e 17,5\% dos pacientes necessitaram de hospitalização por um período superior a dois meses. Dos quatro pacientes que permaneceram por apenas um dia na instituição, um foi transferido para outro hospital e três evoluíram a óbito na UTI.

Tabela 8. Estatística descritiva do risco de morte na admissão (primeiras 24 horas) na UTI, segundo índices de gravidade dos pacientes dessa unidade. São Paulo, 20102011

\begin{tabular}{lcccc}
\hline \multicolumn{1}{c}{ Risco de morte } & Média (dp) & Mediana & Mín & Máx \\
\hline APACHE II & $25,6(19,1)$ & 21,0 & 2,9 & 92,2 \\
SAPS II & $22,9(22,6)$ & 15,3 & 0,1 & 92,5 \\
LODS & $21,1(20,1)$ & 15,0 & 3,2 & 97,6 \\
\hline
\end{tabular}

A média e a mediana do risco de morte calculadas pelos índices SAPS II $(22,9$ e 15,3$)$ e LODS $(21,1$ e 15,0$)$ foram bastante semelhantes. Nota-se na Tabela 8 valores superiores dessas medidas quando o APACHE II foi aplicado (25,6 e 21,0, respectivamente). Entretanto, quando analisados os pacientes que apresentaram alto risco de morrer (chance superior a 75\%), o APACHE II identificou um menor número dessas vítimas: 5 ante 9 apontadas pelo SAPS II e 6 pelo LODS.

Ainda no que se refere à análise dos indicadores fisiológicos de gravidade dos pacientes em UTI, constatou-se que a maioria das vítimas apresentava risco de 
morrer inferior a 25\%, conforme valores expressos pelos três índices: 116 vítimas segundo o APACHE II, 133 de acordo com o SAPS II e 142 pelo LODS.

Considerando os seis sistemas orgânicos avaliados pelos LODS (cardiológico, hematológico, hepático, neurológico, renal e pulmonar), o número médio de sistemas comprometidos foi $2,3(\mathrm{dp}=1,2)$, valor próximo à mediana $(2)$. Em 20 pacientes, nenhum sistema foi afetado e apenas cinco doentes apresentaram falência em cinco sistemas. A maior frequência foi encontrada entre os pacientes com três sistemas acometidos $(33,5 \%)$.

Os dados da Tabela 9 mostram que as insuficiências pulmonares (76,5\%) e neurológicas $(69,0 \%)$ estiveram presentes na maioria dos pacientes nas primeiras 24 horas de internação na UTI. A frequência de insuficiências hematológica e hepática na admissão da unidade crítica foi baixa nesta população $(<5,0 \%)$. 
Tabela 9. Número $\left(\mathrm{n}^{\circ}\right)$ e percentual $(\%)$ de pacientes segundo presença de insuficiências orgânicas na admissão na UTI, conforme o LODS. São Paulo, 2010-2011

\begin{tabular}{lcc}
\hline Insuficiência orgânica & $\mathbf{n}^{\mathbf{0}}$ & \% \\
\hline Cardiológica & 67 & 33,5 \\
Sim & 133 & 66,5 \\
Não & & \\
Hematológica & 8 & 4,0 \\
Sim & 192 & 96,0 \\
Não & & \\
Hepática & 9 & 4,5 \\
Sim & 191 & 95,5 \\
Não & & \\
& & \\
Neurológica & 138 & 69,0 \\
Sim & 62 & 31,0 \\
Não & & \\
Renal & & 47,0 \\
Sim & 94 & 53,0 \\
Não & 106 & \\
Pulmonar & & 76,5 \\
Sim & 153 & 23,5 \\
Não & 47 & \\
\hline
\end{tabular}


Tabela 10. Estatística descritiva dos valores do NAS na admissão e saída da UTI, considerando a casuística total, os sobreviventes e os não sobreviventes à internação nessa unidade. São Paulo, 2010-2011

\begin{tabular}{lcccc}
\hline \multicolumn{1}{c}{ NAS } & Média (dp) & Mediana & Mín & Máx \\
\hline Admissão UTI - casuística total & $71,3(16,9)$ & 69,5 & 35,9 & 131,5 \\
Admissão UTI - sobreviventes & $69,2(15,8)$ & 68,1 & 35,9 & 115,4 \\
Admissão UTI - não sobreviventes & $80,6(18,6)$ & 75,8 & 56,7 & 131,5 \\
Saída da UTI - casuística total & $57,4(28,3)$ & 47,9 & 27,9 & 151,0 \\
Saída da UTI - sobreviventes & $45,2(9,1)$ & 46,1 & 27,9 & 86,7 \\
Saída da UTI - não sobreviventes & $109,3(22,9)$ & 113,6 & 57,1 & 151,0 \\
\hline
\end{tabular}

Em relação à carga de trabalho de enfermagem mensurada nas primeiras 24 horas de permanência na UTI, identificou-se, na amostra total, média de 71,3 e mediana de 69,5. O NAS indicou que os cuidados com as vítimas da casuística deste estudo ocuparam, no mínimo, 35,9\% do tempo de um profissional de enfermagem em um plantão e, no máximo, 131,5\%. Um total de 13 pacientes $(6,5 \%)$ apresentou NAS superior a 100, requerendo, portanto, mais de um profissional de enfermagem para o seu cuidado.

Quando analisada a carga de trabalho demandada pelos pacientes na saída da unidade crítica, observa-se na Tabela 10 que tanto os valores da média do NAS $(57,4)$ quanto na mediana $(47,9)$ foram inferiores aos da admissão. Entretanto, o número de pacientes com escore NAS superior a 100 duplicou (26 casos) e todas as vítimas que demandaram esta carga de trabalho nas últimas 24 horas de permanência na UTI evoluíram a óbito na unidade.

$\mathrm{Na}$ descrição da carga de trabalho de enfermagem requerida pelos pacientes que morreram na UTI, nota-se que a média do NAS foi superior neste grupo comparada àqueles que sobreviveram, tanto nas primeiras (80,6 e 69,2, respectivamente) quanto nas últimas 24 horas de permanência na unidade crítica (109,3 e 45,2, respectivamente). 


\subsection{Identificação de um padrão de intervenções realizadas em vítimas de trauma}

na admissão em UTI

A Figura 1 e a Tabela 11 mostram a primeira fase da identificação do padrão de intervenções de enfermagem realizadas em vítimas de trauma na admissão em UTI. Nesta fase, agrupamentos de vítimas de trauma com intervenções similares foram identificados por meio do dendograma apresentado na Figura 1. 


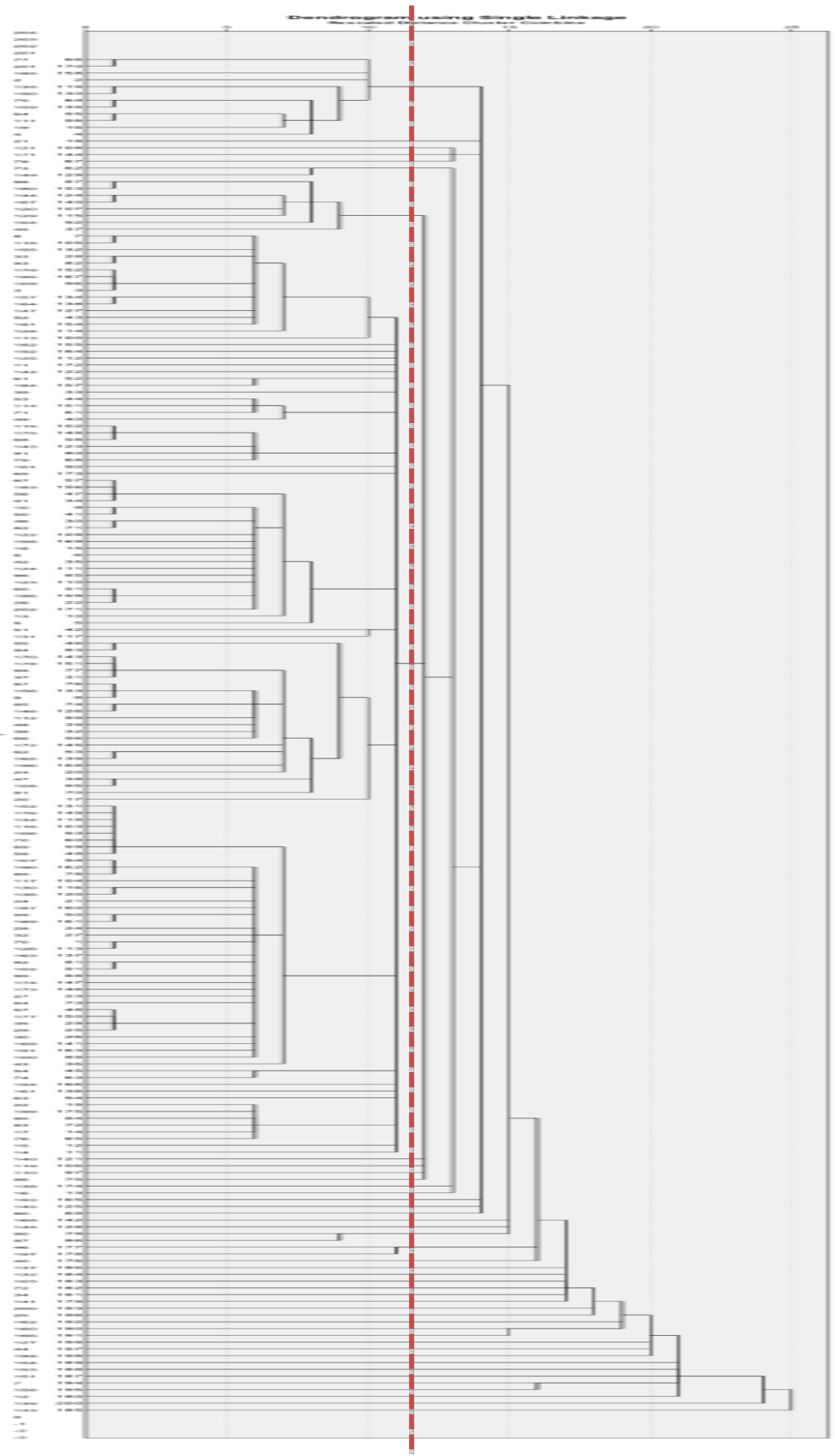

Figura 1. Dendograma das vítimas segundo intervenções de enfermagem realizadas nas primeiras 24 horas de admissão na UTI. São Paulo, 2010-2011 
A Figura 1 mostra o agrupamento hierárquico (método cluster) das vítimas segundo intervenções de enfermagem que compõem o instrumento NAS realizadas nas primeiras 24 horas de internação na UTI. Este agrupamento ordenou as distâncias da variável analisada (realização da atividade de enfermagem) entre os pacientes e permitiu agrupá-los em conjuntos, expressos no dendograma. A partir da análise do dendograma e definição do melhor ponto de corte (linha vermelha tracejada verticalmente), foi possível identificar agrupamentos das vítimas de trauma com intervenções de enfermagem similares. 
Tabela 11. Distribuição das vítimas de trauma $\left(\mathrm{n}^{\circ} \mathrm{e} \%\right)$ segundo grupos com intervenções de enfermagem similares. São Paulo, 2010-2011

\begin{tabular}{|c|c|c|}
\hline Grupos & $\mathbf{n}^{\mathbf{o}}$ & $\%$ \\
\hline Grupo 1 & 12 & 6,0 \\
\hline Grupo 2 & 1 & 0,5 \\
\hline Grupo 3 & 1 & 0,5 \\
\hline Grupo 4 & 1 & 0,5 \\
\hline Grupo 5 & 1 & 0,5 \\
\hline Grupo 6 & 2 & 1,0 \\
\hline Grupo 7 & 8 & 4,0 \\
\hline Grupo 8 & 136 & 68,0 \\
\hline Grupo 9 & 1 & 0,5 \\
\hline Grupo 10 & 1 & 0,5 \\
\hline Grupo 11 & 1 & 0,5 \\
\hline Grupo 12 & 1 & 0,5 \\
\hline Grupo 13 & 1 & 0,5 \\
\hline Grupo 14 & 1 & 0,5 \\
\hline Grupo 15 & 1 & 0,5 \\
\hline Grupo 16 & 1 & 0,5 \\
\hline Grupo 17 & 1 & 0,5 \\
\hline Grupo 18 & 1 & 0,5 \\
\hline Grupo 19 & 1 & 0,5 \\
\hline Grupo 20 & 2 & 1,0 \\
\hline Grupo 21 & 2 & 1,0 \\
\hline Grupo 22 & 1 & 0,5 \\
\hline Grupo 23 & 1 & 0,5 \\
\hline Grupo 24 & 1 & 0,5 \\
\hline Grupo 25 & 1 & 0,5 \\
\hline Grupo 26 & 1 & 0,5 \\
\hline Grupo 27 & 1 & 0,5 \\
\hline Grupo 28 & 1 & 0,5 \\
\hline Grupo 29 & 1 & 0,5 \\
\hline Grupo 30 & 1 & 0,5 \\
\hline Grupo 31 & 1 & 0,5 \\
\hline Grupo 32 & 1 & 0,5 \\
\hline Grupo 33 & 1 & 0,5 \\
\hline Grupo 34 & 1 & 0,5 \\
\hline Grupo 35 & 1 & 0,5 \\
\hline Grupo 36 & 1 & 0,5 \\
\hline Grupo 37 & 1 & 0,5 \\
\hline Grupo 38 & 1 & 0,5 \\
\hline Grupo 39 & 1 & 0,5 \\
\hline Grupo 40 & 1 & 0,5 \\
\hline Grupo 41 & 1 & 0,5 \\
\hline Grupo 42 & 1 & 0,5 \\
\hline Grupo 43 & 1 & 0,5 \\
\hline Grupo 44 & 1 & 0,5 \\
\hline
\end{tabular}


Observa-se na Tabela 11 que, a partir do ponto de corte definido, foram formados 44 grupos. Nota-se que o grupo 8 apresenta o maior número de pacientes (136) submetidos a intervenções de enfermagem similares. Trinta e oito grupos $(86,4 \%)$ foram compostos por um único indivíduo cada, revelando ausência de similaridade de intervenções realizadas nesses indivíduos perante as outras vítimas.

Considerando-se que o grupo 8 compõe a maioria dos pacientes da amostra $(68,0 \%)$ e que os demais pacientes se dispersaram em vários agrupamentos com poucos elementos, este foi o grupo selecionado para identificar o padrão de intervenções realizadas em vítimas de trauma na admissão na UTI. Na Tabela 12 observa-se a análise descritiva (frequências absolutas e relativas) dessas intervenções de enfermagem. 
Tabela 12. Número $\left(\mathrm{n}^{\circ}\right)$ e percentual $(\%)$ de pacientes do grupo $8(\mathrm{n}=136)$ segundo intervenções de enfermagem realizadas na admissão da UTI. São Paulo, 2010-2011

\begin{tabular}{l} 
Nursing Activities Score \\
\hline ATIVIDADES BÁSICAS \\
1. Monitorização e controles \\
Sinais vitais de horário, cálculo e registro do balanço hídrico \\
Presença à beira do leito e observação ou atividade contínua por 2 horas ou mai \\
Presença à beira do leito e observação ou atividade contínua por 4 horas ou mai
\end{tabular}

2. Investigações laboratoriais: bioquímicas e microbiológicas

3. Medicação, exceto drogas vasoativas

\section{Procedimentos de higiene}

Realização de procedimentos de higiene

Realização de procedimentos de higiene que durem mais do que 2 horas, em algum plantão

Realização de procedimentos de higiene que durem mais do que 4 horas em algum plantão

5. Cuidados com drenos - todos (exceto sonda gástrica), inclusive SVD

6. Mobilização e posicionamento

Realização do(s) procedimento(s) até 3 vezes em 24 horas

Realização do(s) procedimento(s) mais do que 3 vezes em 24 horas ou com 2 enfermeiros em qualquer frequência

Realização do(s) procedimento(s) com 3 ou mais enfermeiros em qualquer frequência

7. Suporte e cuidado aos familiares e pacientes

Suporte e cuidado aos familiares e pacientes que requerem dedicação exclusiva por cerca de uma hora em algum plantão

Suporte e cuidado aos familiares e pacientes que requerem dedicação exclusiva por 3 horas ou mais em algum plantão

8. Tarefas administrativas e gerenciais

Realização de tarefas de rotina

Realização de tarefas administrativas e gerenciais que requerem dedicação integral por cerca de 2 horas em algum plantão

Realização de tarefas administrativas e gerenciais que requerem dedicação integral por cerca de 4 horas ou mais de tempo em algum plantão

\section{SUPORTE VENTILATÓRIO}

9. Suporte respiratório

10. Cuidado com vias aéreas artificiais

11. Tratamento para melhora da função pulmonar. Fisioterapia torácica, espirometria estimulada, terapia inalatória, aspiração endotraqueal

\section{SUPORTE CARDIOVASCULAR}

12. Medicação vasoativa independente do tipo e dose

13. Reposição intravenosa de grandes perdas de fluidos

14. Monitorização de átrio esquerdo

15. Reanimação cardiorrespiratória nas últimas 24 horas

\section{SUPORTE RENAL}

16. Técnicas de hemofiltração. Técnicas dialíticas

17. Medida quantitativa do débito urinário

\section{SUPORTE NEUROLÓGICO}

18. Medida de pressão intracraniana

\section{SUPORTE METABÓLICO}

19. Tratamento da acidose/alcalose metabólica complicada

20. Hiperalimentação intravenosa

21. Alimentação enteral

\section{INTERVENÇÕES ESPECÍFICAS}

22. Intervenções específicas na Unidade de Terapia Intensiva

23. Intervenções específicas fora da Unidade de Terapia Intensiva

Categorias $\quad \mathbf{n}^{\mathbf{0}} \quad \%$


Com relação às intervenções de enfermagem classificadas conforme complexidade, itens $1,4,6,7$ e 8 , os resultados apontados na Tabela 12 mostram que, com frequência, as vítimas de trauma pontuaram nos itens b e c no tocante a monitorização e controles $(79,4 \%)$, procedimentos de higiene $(36,0 \%)$ e mobilização e posicionamento $(100,0 \%)$, indicando que necessitaram de cuidados além do normalmente requerido por pacientes de UTI nessas intervenções.

Quanto às demais intervenções, vale salientar que a totalidade ou quase totalidade das vítimas foram submetidas a investigações laboratoriais (item 2), medicação, exceto drogas vasoativas (item 3), cuidados com drenos (item 5), suporte respiratório (item 9) e medida quantitativa do débito urinário (item 17). Foi muito frequente $(>80 \%)$ o cuidado com vias aéreas artificiais (item 10) e o tratamento para melhora da função pulmonar (item 11). A medida de pressão intracraniana foi observada em $12,5 \%$ das vítimas e as intervenções específicas dentro e fora da UTI em $19,1 \%$ e $29,4 \%$, respectivamente.

\subsection{Fatores associados à alta carga de trabalho no primeiro dia de internação na} UTI

Para identificar indivíduos que requisitaram alta carga de trabalho de enfermagem no primeiro dia de internação em UTI, os valores do NAS foram divididos em tercis e, nessa divisão, pacientes com NAS > 75 permaneceram no terceiro tercil. Identificaram-se $69(34,5 \%)$ pacientes que requereram alta carga de trabalho, visto que se posicionaram neste último tercil. Vítimas que permaneceram no $1^{\circ}$ e $2^{\circ}$ tercis totalizaram 131 indivíduos $(65,5 \%)$ e foram classificadas entre as que necessitaram de média ou baixa carga de trabalho de enfermagem. As Tabelas 13 a 20 apresentam as comparações entre os dois grupos formados a partir dessa análise. 
Tabela 13. Comparação entre os grupos de alta e média/baixa carga de trabalho de enfermagem na admissão na UTI em relação a gênero, causa externa, procedência e tipo de admissão nessa unidade. São Paulo, 2010-2011

\begin{tabular}{|c|c|c|c|c|c|}
\hline \multirow{3}{*}{ Variável } & \multicolumn{4}{|c|}{$\begin{array}{l}\text { Carga de trabalho de } \\
\text { enfermagem (NAS) }\end{array}$} & \multirow[b]{3}{*}{$\mathbf{p}$} \\
\hline & \multicolumn{2}{|c|}{ Alta } & \multicolumn{2}{|c|}{ Média/Baixa } & \\
\hline & $\mathbf{n}^{\mathbf{o}}$ & $\%$ & $\mathbf{n}^{\mathbf{0}}$ & $\%$ & \\
\hline Gênero & & & & & \multirow{3}{*}{$0,087^{*}$} \\
\hline Masculino & 61 & 88,4 & 103 & 78,6 & \\
\hline Feminino & 8 & 11,6 & 28 & 21,4 & \\
\hline \multicolumn{6}{|l|}{ Causa externa } \\
\hline $\begin{array}{l}\text { Pedestre ou ciclista traumatizado em um } \\
\text { acidente de transporte (V01-V19) }\end{array}$ & 17 & 24,6 & 23 & 17,6 & \\
\hline $\begin{array}{l}\text { Motociclista traumatizado em um acidente } \\
\text { de transporte (V20-V29) }\end{array}$ & 17 & 24,6 & 38 & 29,0 & \\
\hline $\begin{array}{l}\text { Ocupante de um automóvel, caminhonete } \\
\text { ou veículo de transporte pesado } \\
\text { traumatizado em um acidente de transporte } \\
\text { (V40-V69) }\end{array}$ & 7 & 10,2 & 13 & 9,9 & $0,327 *$ \\
\hline Quedas (W00-W19) & 17 & 24,6 & 45 & 34,3 & \\
\hline Outras & 11 & 16,0 & 12 & 9,2 & \\
\hline \multicolumn{6}{|l|}{ Procedência } \\
\hline Pronto-Socorro & 15 & 21,7 & 39 & 29,8 & \\
\hline Centro Cirúrgico & 51 & 73,9 & 89 & 67,9 & $0,371 * *$ \\
\hline Outras & 3 & 4,4 & 3 & 2,3 & \\
\hline \multicolumn{6}{|l|}{ Tipo de admissão na UTI } \\
\hline Cirúrgica programada & 1 & 1,5 & 6 & 4,6 & \\
\hline Cirúrgica não programada & 49 & 71,0 & 84 & 64,1 & $0,502 * *$ \\
\hline Clínica & 19 & 27,5 & 41 & 31,3 & \\
\hline
\end{tabular}

* Teste de associação Qui-Quadrado de Pearson

** Teste Exato de Fisher 
Tabela 14. Medidas descritivas e comparação entre os grupos de alta e média/baixa carga de trabalho de enfermagem na admissão na UTI em relação à idade, índice de Charlson e intervalo de tempo entre admissão hospitalar e UTI. São Paulo, 20102011

\begin{tabular}{|c|c|c|c|}
\hline \multirow[t]{2}{*}{ Variáveis } & \multicolumn{2}{|c|}{$\begin{array}{l}\text { Carga de trabalho de } \\
\text { enfermagem (NAS) }\end{array}$} & \multirow[t]{2}{*}{$\mathbf{p}^{*}$} \\
\hline & Alta & Média/Baixa & \\
\hline \multicolumn{4}{|l|}{ Idade } \\
\hline Média & 40,4 & 40,9 & \multirow{4}{*}{0,567} \\
\hline Desvio padrão & 16,1 & 19,9 & \\
\hline Mediana & 38 & 34 & \\
\hline Mín-Máx & $18-82$ & $18-86$ & \\
\hline \multicolumn{4}{|c|}{ Índice de comorbidade de Charlson } \\
\hline Média & 0,6 & 0,6 & \multirow{4}{*}{0,176} \\
\hline Desvio padrão & 1,7 & 1,3 & \\
\hline Mediana & 0 & 0 & \\
\hline Mín-Máx & $0-9$ & $0-7$ & \\
\hline \multicolumn{4}{|c|}{$\begin{array}{l}\text { Intervalo de tempo entre admissão } \\
\text { hospitalar e UTI (horas) }\end{array}$} \\
\hline Média & 21,0 & 33,8 & \multirow{4}{*}{0,235} \\
\hline Desvio padrão & 33,2 & 67,3 & \\
\hline Mediana & 14,2 & 15,7 & \\
\hline Mín-Máx & $2,0-250,0$ & $2,2-502,3$ & \\
\hline
\end{tabular}

Os resultados apresentados nas Tabelas 13 e 14 mostram que os grupos comparados não diferiram entre si quando analisados em relação às variáveis gênero, causa externa, procedência, tipo de admissão na UTI, idade, índice de comorbidade de Charlson e intervalo de tempo entre admissão hospitalar e UTI. 
Tabela 15. Medidas descritivas e comparação entre os grupos de alta e média/baixa carga de trabalho de enfermagem na admissão na UTI em relação ao ISS, NISS, número de regiões corpóreas acometidas e número de lesões AIS $\geq 3$. São Paulo, 2010-2011

\begin{tabular}{|c|c|c|c|}
\hline \multirow[t]{2}{*}{ Variáveis } & \multicolumn{2}{|c|}{$\begin{array}{l}\text { Carga de trabalho de } \\
\text { enfermagem (NAS) }\end{array}$} & \multirow[t]{2}{*}{$\mathbf{p}^{*}$} \\
\hline & Alta & Média/Baixa & \\
\hline \multicolumn{4}{|l|}{ ISS } \\
\hline Média & 21,5 & 18,1 & \multirow{4}{*}{$\mathbf{0 , 0 1 2}$} \\
\hline Desvio padrão & 10,0 & 8,4 & \\
\hline Mediana & 21 & 17 & \\
\hline Mín-Máx & $9-50$ & $9-45$ & \\
\hline \multicolumn{4}{|l|}{ NISS } \\
\hline Média & 29,9 & 25,6 & \multirow{4}{*}{$\mathbf{0 , 0 0 3}$} \\
\hline Desvio padrão & 9,5 & 9,7 & \\
\hline Mediana & 27 & 27 & \\
\hline Mín-Máx & $9-66$ & $9-59$ & \\
\hline \multicolumn{4}{|c|}{ Número de regiões corpóreas acometidas } \\
\hline Média & 3,1 & 2,5 & \multirow{4}{*}{0,009} \\
\hline Desvio padrão & 1,3 & 1,3 & \\
\hline Mediana & 3 & 3 & \\
\hline Mín-Máx & $1-6$ & $1-6$ & \\
\hline \multicolumn{4}{|l|}{ Número de lesões AIS $\geq 3$} \\
\hline Média & 3,6 & 2,8 & \multirow{4}{*}{0,001} \\
\hline Desvio padrão & 1,8 & 1,8 & \\
\hline Mediana & 3 & 2 & \\
\hline Mín-Máx & $1-8$ & $1-9$ & \\
\hline
\end{tabular}

$\mathrm{Na}$ análise de variáveis que retratam a gravidade do trauma, observa-se que as diferenças entre os grupos ocorreram em relação ao ISS $(p=0,012)$, NISS $(p=0,003)$, número de regiões corpóreas acometidas $(\mathrm{p}=0,009)$ e número de lesões AIS $\geq 3$ ( $\mathrm{p}=0,001$ ) (Tabela 15). Os valores das médias dessas variáveis do grupo de alta carga de trabalho superaram os encontrados no outro grupo (média/baixa). 
Tabela 16. Comparação entre os grupos de alta e média/baixa carga de trabalho de enfermagem na admissão na UTI segundo valor do MAIS. São Paulo, 2010-2011

\begin{tabular}{|c|c|c|c|c|c|}
\hline \multirow{3}{*}{ MAIS } & \multicolumn{4}{|c|}{$\begin{array}{c}\text { Carga de trabalho de enfermagem } \\
\text { (NAS) }\end{array}$} & \multirow{3}{*}{$\mathbf{p}^{*}$} \\
\hline & \multicolumn{2}{|c|}{ Alta } & \multicolumn{2}{|c|}{ Média/Baixa } & \\
\hline & $\mathrm{n}^{\mathbf{0}}$ & $\%$ & $n^{\circ}$ & $\%$ & \\
\hline MAIS $=3$ & 41 & 59,4 & 89 & 67,9 & \\
\hline MAIS $=4$ & 17 & 24,6 & 24 & 18,3 & 0,464 \\
\hline MAIS $=5$ & 11 & 16,0 & 18 & 13,8 & \\
\hline
\end{tabular}

* Teste de associação Qui-Quadrado de Pearson

Não foi observada diferença estatisticamente significativa entre os grupos na análise relativa ao valor do MAIS $(\mathrm{p}=0,464)$. Entretanto, é interessante notar que a maioria dos pacientes, independentemente de requerer alta ou média/baixa carga de trabalho, apresentou MAIS igual a 3 (Tabela 16). 
Tabela 18. Comparação entre os grupos de alta e média/baixa carga de trabalho de enfermagem na admissão na UTI em relação à região corpórea mais gravemente lesada. São Paulo, 2010-2011

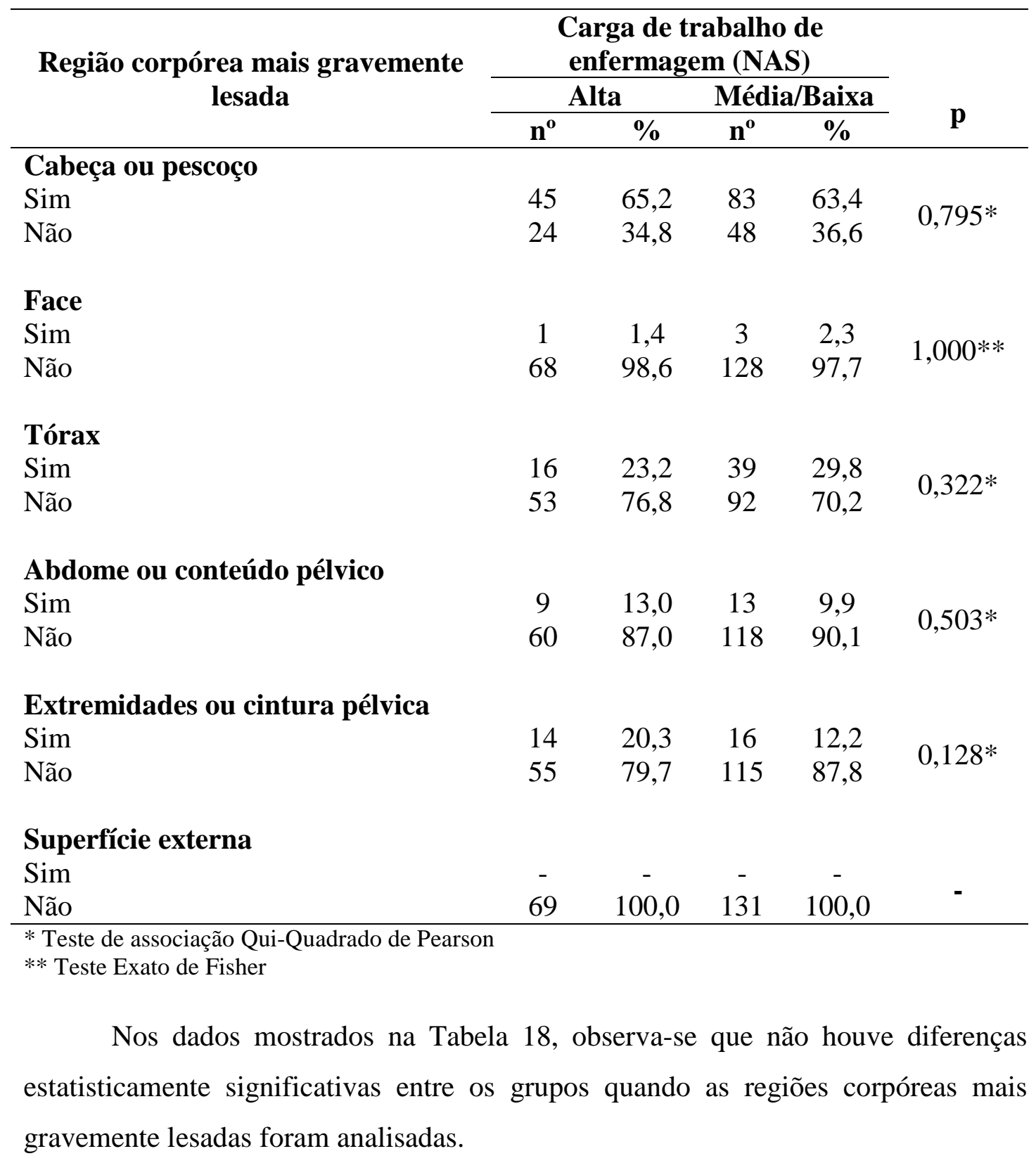


Tabela 19. Medidas descritivas e comparação entre os grupos de alta e média/baixa carga de trabalho de enfermagem na admissão na UTI em relação ao risco de morte calculado pelo APACHE II, SAPS II e LODS e número de sistemas comprometidos conforme o LODS. São Paulo, 2010-2011

\begin{tabular}{|c|c|c|c|}
\hline \multirow[t]{2}{*}{ Variáveis } & \multicolumn{2}{|c|}{$\begin{array}{c}\text { Carga de trabalho de enfermagem } \\
\text { (NAS) }\end{array}$} & \multirow[t]{2}{*}{$\mathbf{p}^{*}$} \\
\hline & Alta & Média/Baixa & \\
\hline \multicolumn{4}{|c|}{ Risco de morte APACHE II } \\
\hline Média & 32,8 & 21,7 & \multirow{4}{*}{$<0,001$} \\
\hline Desvio padrão & 21,4 & 16,6 & \\
\hline Mediana & 26,2 & 18,6 & \\
\hline Mín-Máx & $5,1-85,1$ & $2,9-92,2$ & \\
\hline \multicolumn{4}{|l|}{ Risco de morte SAPS II } \\
\hline Média & 32,7 & 17,7 & \multirow{4}{*}{$<0,001$} \\
\hline Desvio padrão & 25,7 & 19,0 & \\
\hline Mediana & 24,7 & 11,7 & \\
\hline Mín-Máx & $1,5-92,5$ & $0,1-89,7$ & \\
\hline \multicolumn{4}{|l|}{ Risco de morte LODS } \\
\hline Média & 30,0 & 16,4 & \multirow{4}{*}{$<0,001$} \\
\hline Desvio padrão & 23,4 & 16,4 & \\
\hline Mediana & 21,1 & 10,4 & \\
\hline Mín-Máx & $3,2-97,6$ & $3,2-92,0$ & \\
\hline \multicolumn{4}{|l|}{$\begin{array}{l}\text { Número de sistemas } \\
\text { comprometidos }\end{array}$} \\
\hline Média & 3 & 2 & \multirow{4}{*}{$<0,001$} \\
\hline Desvio padrão & 1,0 & 1,2 & \\
\hline Mediana & 2 & 3 & \\
\hline Mín-Máx & $0-5$ & $0-5$ & \\
\hline
\end{tabular}

Na Tabela 19 observa-se que houve fortes evidências estatísticas de diferenças entre os grupos (alta e média/baixa carga de trabalho) em relação ao número de sistemas comprometidos e risco de morte na admissão da UTI calculado pelos índices APACHE II, SAPS II e LODS ( $\mathrm{p}<0,001)$. As médias dos valores de todas as variáveis foram maiores no grupo de pacientes que demandaram alta carga de trabalho de enfermagem. 
Tabela 20. Comparação entre os grupos de alta e média/baixa carga de trabalho de enfermagem na admissão na UTI em relação ao tipo de insuficiência orgânica apresentada conforme o LODS. São Paulo, 2010-2011

\begin{tabular}{|c|c|c|c|c|c|}
\hline \multirow{3}{*}{ Tipo de insuficiência orgânica } & \multicolumn{4}{|c|}{$\begin{array}{l}\text { Carga de trabalho de } \\
\text { enfermagem (NAS) }\end{array}$} & \multirow[b]{3}{*}{$\mathbf{p}$} \\
\hline & \multicolumn{2}{|c|}{ Alta } & \multicolumn{2}{|c|}{ Média/Baixa } & \\
\hline & $\mathbf{n}^{\mathbf{o}}$ & $\%$ & $\mathbf{n}^{\mathbf{o}}$ & $\%$ & \\
\hline Cardiológica & & & & & \multirow{3}{*}{$\mathbf{0 , 0 3 0} *$} \\
\hline Sim & 30 & 43,5 & 37 & 28,2 & \\
\hline Não & 39 & 56,5 & 94 & 71,8 & \\
\hline \multicolumn{6}{|l|}{ Hematológica } \\
\hline Sim & 4 & 5,8 & 4 & 3,1 & \multirow{2}{*}{$0,451 * *$} \\
\hline Não & 65 & 94,2 & 127 & 96,9 & \\
\hline \multicolumn{6}{|l|}{ Hepática } \\
\hline Sim & 5 & 7,2 & 4 & 3,1 & \multirow{2}{*}{$0,280 * *$} \\
\hline Não & 64 & 92,8 & 127 & 96,9 & \\
\hline \multicolumn{6}{|l|}{ Neurológica } \\
\hline Sim & 59 & 85,5 & 79 & 60,3 & \multirow{2}{*}{$<0,001 *$} \\
\hline Não & 10 & 14,5 & 52 & 39,7 & \\
\hline \multicolumn{6}{|l|}{ Renal } \\
\hline Sim & 43 & 62,3 & 51 & 38,9 & \multirow{2}{*}{$\mathbf{0 , 0 0 2} *$} \\
\hline Não & 26 & 37,7 & 80 & 61,1 & \\
\hline \multicolumn{6}{|l|}{ Pulmonar } \\
\hline Sim & 66 & 95,7 & 87 & 66,4 & \multirow{2}{*}{$<0,001 *$} \\
\hline Não & 3 & 4,3 & 44 & 33,6 & \\
\hline
\end{tabular}

Observa-se na Tabela 20 que houve diferença estatisticamente significativa entre os grupos analisados (alta e média/baixa carga) em relação à presença das insuficiências cardiológica $(p=0,030)$, neurológica $(p<0,001)$, renal $(p=0,002)$ e pulmonar $(\mathrm{p}<0,001)$ e, em todos os sistemas analisados pelo LODS, a frequência da falência orgânica foi sempre maior no grupo com alta carga de trabalho de enfermagem. Vale salientar que mais de $60 \%$ dos pacientes nos dois grupos analisados apresentaram insuficiências neurológica e pulmonar; esta última acometeu quase todas as vítimas que demandaram alta carga de trabalho de enfermagem. Não menos importante, a insuficiência renal esteve presente em cerca de $62 \%$ dos pacientes deste grupo. 
Conforme estabelecido no método desta investigação, todas as variáveis independentes que apresentaram $\mathrm{p}<0,20$ nas análises estatísticas anteriormente realizadas (Tabelas 13 a 20) foram testadas durante a modelagem para identificar fatores associados à alta carga de trabalho no primeiro dia de internação na UTI. São elas: gênero, índice de comorbidade de Charlson, ISS, NISS, número de regiões corpóreas acometidas, número e localização (face e extremidades ou cintura pélvica) das lesões $\mathrm{AIS} \geq 3$, extremidades ou cintura pélvica como região corpórea mais gravemente lesada, risco de morte calculado pelos índices APACHE II, SAPS II e LODS, número de sistemas comprometidos, além da presença de insuficiências cardiológica, neurológica, renal e pulmonar.

Tabela 21. Modelo de regressão logística dos fatores associados à alta carga de trabalho de enfermagem. São Paulo, 2010-2011

\begin{tabular}{|c|c|c|c|c|c|}
\hline \multicolumn{2}{|l|}{ Variável } & B & \multicolumn{3}{|c|}{ IC $95 \%$} \\
\hline $\begin{array}{l}\text { Gênero } \\
\text { ref: feminino }\end{array}$ & Masculino & 1,05 & 2,86 & $1,09-7,49$ & $\mathbf{0 , 0 3 3}$ \\
\hline $\begin{array}{l}\text { Insuficiência pulmonar } \\
\text { ref: ausência }\end{array}$ & Presença & 1,83 & 6,23 & $1,74-22,23$ & $\mathbf{0 , 0 0 5}$ \\
\hline $\begin{array}{l}\text { Número de regiões } \\
\text { corpóreas acometidas }\end{array}$ & - & 0,29 & 1,33 & $1,05-1,70$ & $\mathbf{0 , 0 2 0}$ \\
\hline Risco de morte (SAPS II) & - & 0,02 & 1,02 & $1,01-1,04$ & $\mathbf{0 , 0 0 4}$ \\
\hline
\end{tabular}

A Tabela 21 mostra que o modelo final de regressão logística contemplou as variáveis gênero, insuficiência pulmonar, número de regiões corpóreas acometidas e risco de morte calculado pelo SAPS II como fatores associados à alta carga de trabalho de enfermagem requerida pelas vítimas de trauma na admissão da UTI. Em relação aos índices de gravidade do trauma, houve prejuízo no ajuste do modelo quando testados os valores do ISS e NISS.

A razão de chance de indivíduos do sexo masculino apresentarem alta carga de trabalho de enfermagem foi de 2,86 quando confrontados com pacientes do sexo feminino. Vítimas com insuficiência pulmonar identificada pelo LODS na admissão da UTI tiveram cerca de 6 vezes mais chance de demandar alta carga de trabalho de enfermagem do que aqueles pacientes que não apresentaram tal falência orgânica. 
Além disso, o acréscimo de uma região corpórea acometida ou de um ponto no risco de morte apontado pelo escore SAPS II aumentou a chance de o paciente demandar alta carga de trabalho de enfermagem em $33 \%$ e $2 \%$, respectivamente.

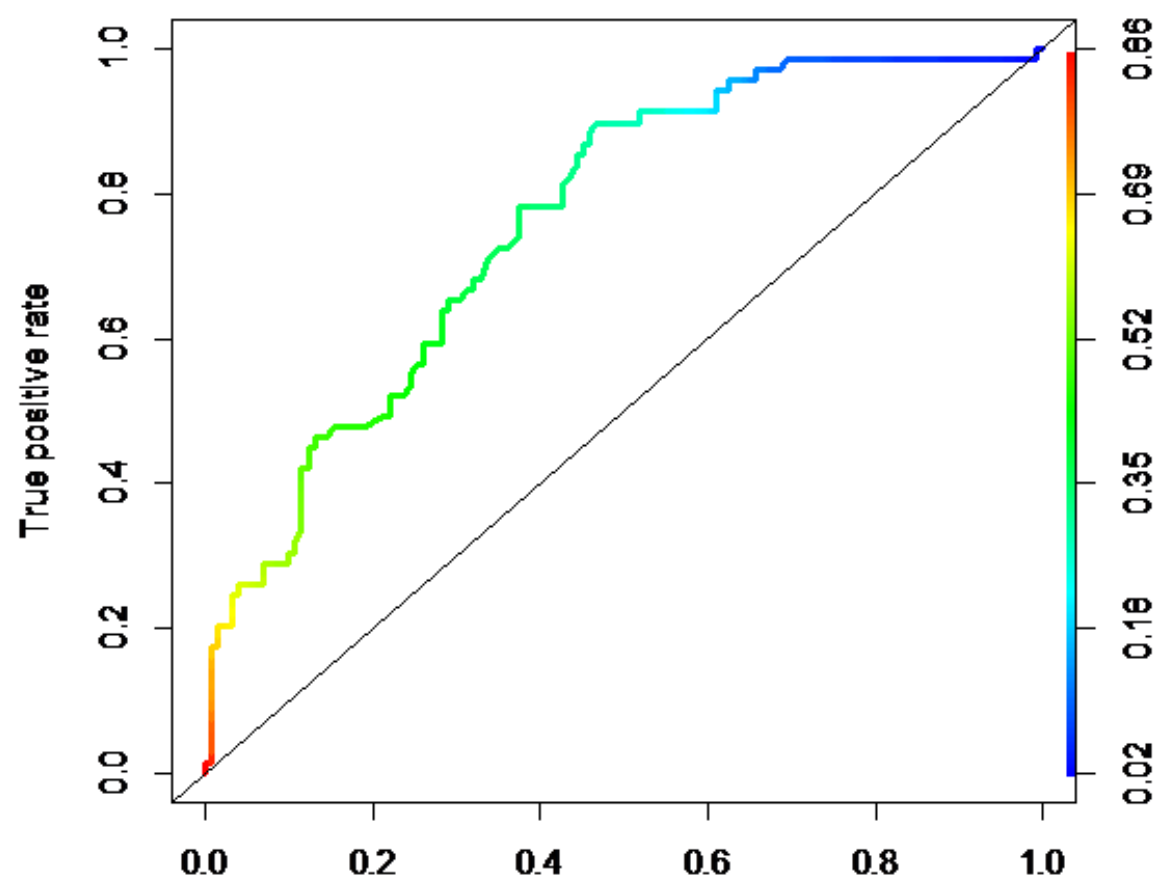

False positive rate

Figura 2. Análise da capacidade preditiva do modelo de regressão logística relacionada aos fatores associados à alta carga de trabalho de enfermagem. São Paulo, 2010-2011

A curva ROC apresentada na Figura 2 é o resultado da análise da capacidade preditiva do modelo de regressão logística relacionado aos fatores associados à alta carga de trabalho de enfermagem demandada pelas vítimas de trauma admitidas em UTI. A área sob a curva foi de 0,763 , indicando satisfatória capacidade preditiva do modelo. 


\subsection{Modelo para estimativa da carga de trabalho de enfermagem requerida pelos sobreviventes na alta da UTI}

Considerando apenas os pacientes que sobreviveram e receberam alta da UTI ( $n=162$ ), identificou-se média do NAS de 45,2\%, calculada a partir das atividades de enfermagem realizadas nas últimas 24 horas de permanência do paciente na unidade crítica. A mediana dos valores do NAS desse grupo na alta da UTI foi de 46,1\%; os valores mínimo e máximo observados foram, respectivamente, $27,9 \%$ e $86,7 \%$.

Para estabelecer um modelo para estimar a carga de trabalho requerida pelos sobreviventes na alta da UTI, as mesmas características das vítimas de trauma examinadas para identificar fatores associados à alta carga de trabalho de enfermagem na admissão na UTI foram analisadas perante a pontuação do NAS na alta dessa unidade. As Tabelas 22 a 29 apresentam os resultados dessas análises. 
Tabela 22. Medidas descritivas e comparação das médias do NAS dos sobreviventes na alta da UTI segundo gênero, causa externa, procedência e tipo de admissão nessa unidade. São Paulo, 2010-2011

\begin{tabular}{|c|c|c|c|c|}
\hline Variável & Média (dp) & Mediana & Mín - Máx & $\mathbf{p}$ \\
\hline Gênero & & & & \\
\hline Masculino & $45,5(9,4)$ & 46,1 & $27,9-86,7$ & \multirow{2}{*}{$0,339 *$} \\
\hline Feminino & $44,0(7,8)$ & 44,0 & $32,2-60,3$ & \\
\hline
\end{tabular}

\section{Causa externa}

Pedestre ou ciclista

traumatizado em um acidente de transporte (V01-V19)

Motociclista traumatizado em um acidente de transporte (V20V29)

Ocupante de um automóvel, caminhonete ou veículo de transporte pesado traumatizado em um acidente de transporte (V40-V69)

Quedas (W00-W19)

Outras

$46,1(12,7) \quad 43,8 \quad 27,9-86,7$

$45,7(8,4) \quad 46,8 \quad 27,9-70,8$

$42,1(6,3) \quad 40,1 \quad 27,9-53,6 \quad 0,263 * *$

$46,2(7,6) \quad 46,8 \quad 32,2-65,0$

$43,5(10,7) \quad 40,5 \quad 27,9-74,0$

\section{Procedência}

Pronto-Socorro

Centro Cirúrgico

Outros

$\begin{array}{clll}44,5(9,9) & 41,0 & 32,2-86,7 & \\ 45,9(8,7) & 47,4 & 27,9-74,0 & 0,459 * * \\ 50,9(15,7) & 53,9 & 34,0-64,9 & \end{array}$

Tipo de admissão na UTI

Cirúrgica programada

Cirúrgica não programada

$41,4(8,0) \quad 39,2 \quad 32,2-55,0$

$45,6(8,7) \quad 47,4 \quad 27,9-74,0 \quad 0,308^{* *}$

Clínica

$44,9(10,2) \quad 41,0 \quad 32,2-86,7$

* Teste de Mann-Whitney

** Teste Kruskal Wallis

Os dados da Tabela 22 mostram que não houve diferença estatisticamente significativa entre as médias do NAS calculado na alta da UTI segundo as variáveis gênero, causa externa, procedência e tipo de admissão na UTI. 
Tabela 23. Coeficientes de correlação entre valores do NAS dos sobreviventes na alta da UTI e as variáveis idade, índice de Charlson e intervalo entre admissão hospitalar e UTI. São Paulo, 2010-2011

\begin{tabular}{lcc}
\hline \multicolumn{1}{c}{ Variável } & $\mathbf{r}^{*}$ & $\mathbf{p}$ \\
\hline Idade & 0,112 & 0,154 \\
Índice de comorbidade de Charlson & $-0,079$ & 0,320 \\
Intervalo de tempo entre admissão hospitalar e UTI (horas) & 0,014 & 0,860 \\
\hline * Coeficiente de correlação de Spearman &
\end{tabular}

As variáveis idade, índice de comorbidade de Charlson e intervalo de tempo entre a admissão hospitalar e UTI não apresentaram correlação estatisticamente significativa com a carga de trabalho de enfermagem requerida pelos pacientes na alta dessa unidade, conforme se pode observar na Tabela 23.

Tabela 24. Coeficientes de correlação entre os valores do NAS dos sobreviventes na alta da UTI e ISS, NISS, número de regiões corpóreas acometidas e número de lesões AIS $\geq 3$. São Paulo, 2010-2011

\begin{tabular}{lcc}
\hline \multicolumn{1}{c}{ Variável } & $\mathbf{r}^{*}$ & $\mathbf{p}$ \\
\hline ISS & 0,155 & $\mathbf{0 , 0 4 9}$ \\
NISS & 0,167 & $\mathbf{0 , 0 3 4}$ \\
Número de regiões corpóreas acometidas & 0,114 & 0,147 \\
Número de lesões AIS $\geq 3$ & 0,115 & 0,146 \\
\hline
\end{tabular}

* Coeficiente de correlação de Spearman

A gravidade do trauma mensurada pelos índices ISS e NISS apresentou correlação positiva e significativa com o NAS na alta da UTI ( $p=0,049$ e p=0,034, respectivamente). Entretanto, quando analisado o número de regiões corpóreas acometidas e de lesões AIS $\geq 3$, identificou-se que não houve correlação estatisticamente significativa dessas variáveis com o valor do NAS (Tabela 24). 
Tabela 25. Medidas descritivas e comparação das médias do NAS dos sobreviventes na alta da UTI segundo valor do MAIS. São Paulo, 2010-2011

\begin{tabular}{lcccc}
\hline \multicolumn{1}{c}{ MAIS } & Média (dp) & Mediana & Mín - Máx & p* $^{*}$ \\
\hline MAIS $=3$ & $44,3(8,8)$ & 43,1 & $27,9-70,8$ & \\
MAIS $=4$ & $47,8(11,3)$ & 46,3 & $34,8-86,7$ & 0,153 \\
MAIS $=5$ & $46,8(7,0)$ & 48,2 & $32,2-58,5$ & \\
\hline
\end{tabular}

* Teste Kruskal Wallis

Tabela 26. Medidas descritivas e comparação das médias do valor do NAS dos sobreviventes na alta da UTI segundo localização das lesões AIS $\geq 3$. São Paulo, 2010-2011

\begin{tabular}{|c|c|c|c|c|}
\hline Localização das lesões AIS $\geq 3$ & Média (dp) & Mediana & Mín-Máx & p* \\
\hline $\begin{array}{l}\text { Cabeça ou pescoço } \\
\text { Sim } \\
\text { Não }\end{array}$ & $\begin{array}{c}45,7(10,2) \\
44,5(6,9)\end{array}$ & $\begin{array}{l}46,1 \\
46,1\end{array}$ & $\begin{array}{l}27,9-86,7 \\
27,9-61,4\end{array}$ & 0,770 \\
\hline $\begin{array}{l}\text { Face } \\
\text { Sim } \\
\text { Não }\end{array}$ & $\begin{array}{l}48,6(9,1) \\
45,0(9,1)\end{array}$ & $\begin{array}{l}49,3 \\
44,5\end{array}$ & $\begin{array}{l}32,2-64,9 \\
27,9-86,7\end{array}$ & 0,110 \\
\hline $\begin{array}{l}\text { Tórax } \\
\text { Sim } \\
\text { Não }\end{array}$ & $\begin{array}{c}45,8(7,4) \\
44,9(10,0)\end{array}$ & $\begin{array}{l}47,5 \\
43,8\end{array}$ & $\begin{array}{l}32,2-64,9 \\
27,9-86,7\end{array}$ & 0,237 \\
\hline $\begin{array}{l}\text { Abdome ou conteúdo pélvico } \\
\text { Sim } \\
\text { Não }\end{array}$ & $\begin{array}{l}42,7(8,1) \\
45,6(9,3)\end{array}$ & $\begin{array}{l}40,7 \\
46,1\end{array}$ & $\begin{array}{l}27,9-60,3 \\
27,9-86,7\end{array}$ & 0,122 \\
\hline $\begin{array}{l}\text { Extremidades ou cintura } \\
\text { pélvica } \\
\text { Sim } \\
\text { Não }\end{array}$ & $\begin{array}{l}45,4(7,7) \\
45,2(9,6)\end{array}$ & $\begin{array}{l}47,9 \\
43,8\end{array}$ & $\begin{array}{l}27,9-64,9 \\
27,9-86,7\end{array}$ & 0,488 \\
\hline $\begin{array}{l}\text { Superfície externa } \\
\text { Sim } \\
\text { Não }\end{array}$ & $\begin{array}{c}- \\
45,2(9,1)\end{array}$ & $\begin{array}{c}- \\
46,1\end{array}$ & $\begin{array}{c}- \\
27,9-86,7\end{array}$ & - \\
\hline
\end{tabular}


Tabela 27. Medidas descritivas e comparação das médias do NAS dos sobreviventes na alta da UTI segundo região corpórea mais gravemente lesada. São Paulo, 20102011

\begin{tabular}{|c|c|c|c|c|}
\hline $\begin{array}{l}\text { Região corpórea mais } \\
\text { gravemente lesada }\end{array}$ & Média (dp) & Mediana & Mín-Máx & $\mathbf{p}^{*}$ \\
\hline \multicolumn{5}{|l|}{ Cabeça ou pescoço } \\
\hline $\operatorname{Sim}$ & $45,6(10,2)$ & 46,1 & $27,9-86,7$ & \multirow{2}{*}{0,923} \\
\hline Não & $44,6(7,0)$ & 46,1 & $27,9-61,4$ & \\
\hline \multicolumn{5}{|l|}{ Face } \\
\hline Sim & $44,5(7,1)$ & 47,5 & $34,0-49,2$ & \multirow{2}{*}{0,922} \\
\hline Não & $45,3(9,2)$ & 46,1 & $27,9-86,7$ & \\
\hline \multicolumn{5}{|l|}{ Tórax } \\
\hline Sim & $45,4(6,8)$ & 47,5 & $32,2-61,4$ & \multirow{2}{*}{0,479} \\
\hline Não & $45,2(10,0)$ & 44,1 & $27,9-86,7$ & \\
\hline \multicolumn{5}{|l|}{ Abdome ou conteúdo pélvico } \\
\hline Sim & $45,3(8,6)$ & 40,5 & $27,9-60,3$ & \multirow{2}{*}{0,127} \\
\hline Não & $45,6(9,2)$ & 46,1 & $27,9-86,7$ & \\
\hline \multicolumn{5}{|l|}{$\begin{array}{l}\text { Extremidades ou cintura } \\
\text { pélvica }\end{array}$} \\
\hline Sim & $44,6(7,3)$ & 47,9 & $27,9-58,5$ & \multirow{2}{*}{0,857} \\
\hline Não & $45,4(9,5)$ & 44,5 & $27,9-86,7$ & \\
\hline \multicolumn{5}{|l|}{ Superfície externa } \\
\hline Sim & - & - & - & \\
\hline Não & $45,2(9,1)$ & 46,1 & $27,9-86,7$ & \\
\hline
\end{tabular}

As Tabelas 25, 26 e 27 mostram que não houve diferença estatisticamente significativa entre as médias no NAS calculado na alta da UTI e as variáveis região corpórea mais gravemente lesada, localização das lesões AIS $\geq 3$ e valor do MAIS. 
Tabela 28. Coeficientes de correlação entre os valores do NAS dos sobreviventes na alta da UTI e as variáveis número de sistemas comprometidos e risco de morte segundo APACHE II, SAPS II e LODS. São Paulo, 2010-2011

\begin{tabular}{lcc}
\hline \multicolumn{1}{c}{ Variável } & $\mathbf{r}^{*}$ & p \\
\hline Risco de morte - APACHE II & 0,142 & 0,072 \\
Risco de morte - SAPS II & 0,218 & $\mathbf{0 , 0 0 5}$ \\
Risco de morte - LODS & 0,196 & $\mathbf{0 , 0 1 2}$ \\
Número de sistemas comprometidos & 0,155 & $\mathbf{0 , 0 4 9}$ \\
\hline
\end{tabular}

* Coeficiente de correlação de Spearman

Observa-se na Tabela 28 que houve correlação estatisticamente significativa entre os valores do NAS na alta da UTI e o número de sistemas comprometidos $(\mathrm{p}=0,049)$, além do risco de morte calculado pelos índices SAPS II $(\mathrm{p}=0,005)$ e $\operatorname{LODS}(\mathrm{p}=0,012)$. 
Tabela 29. Medidas descritivas e comparação das médias do NAS dos sobreviventes na alta da UTI segundo tipo de insuficiência orgânica apresentada conforme o LODS. São Paulo, 2010-2011

\begin{tabular}{lcccc}
\hline Tipo de insuficiência orgânica & Média (dp) & Mediana & Mín-Máx & p* $^{*}$ \\
Cardiológica & & & & \\
Sim & $45,2(10,2)$ & 43,4 & $27,9-74,0$ & 0,972 \\
Não & $45,2(8,7)$ & 46,1 & $27,9-86,7$ & \\
Hematológica & & & & \\
Sim & $49,2(10,0)$ & 48,6 & $36,7-69,2$ & 0,262 \\
Não & $45,0(9,1)$ & 46,1 & $27,9-86,7$ & \\
Hepática & & & & \\
Sim & & & & \\
Não & $42,5(5,5)$ & 40,1 & $39,2-50,7$ & 0,608 \\
& $45,3(9,2)$ & 46,1 & $27,9-86,7$ & \\
Neurológica & & & & \\
Sim & & & & \\
Não & $46,3(9,8)$ & 47,4 & $27,9-86,7$ & 0,072 \\
Renal & $43,3(7,6)$ & 41,0 & $27,9-65,0$ & \\
Sim & & & & \\
Não & $45,4(8,8)$ & 46,1 & $27,9-70,8$ & 0,526 \\
Pulmonar & $45,1(9,4)$ & 44,5 & $27,9-86,7$ & \\
Sim & & & & \\
Não & $46,2(9,7)$ & 47,4 & $27,9-86,7$ & $\mathbf{0 , 0 3 5}$ \\
\hline * Teste de Mann-Whitney & $42,9(7,2)$ & 41,0 & $32,2-61,4$ & \\
\end{tabular}

A presença de insuficiência pulmonar teve associação estatisticamente significativa com a média do NAS na alta da UTI ( $\mathrm{p}=0,035)$, conforme se observa na Tabela 29. Em relação aos outros sistemas orgânicos avaliados pelo LODS, a média do NAS foi semelhante entre os que apresentaram ou não insuficiências na admissão da UTI.

Para determinar o modelo final de regressão linear simples em relação à carga de trabalho de enfermagem demandada pelos sobreviventes na alta da UTI, foram testadas todas as variáveis independentes que apresentaram um valor de $p<0,20$ nas análises estatísticas anteriormente realizadas: idade, ISS, NISS, número de regiões corpóreas acometidas, abdome ou conteúdo pélvico como região corpórea mais 
gravemente lesada, valor do MAIS, número e localização das lesões AIS $\geq 3$ (face e abdome ou conteúdo pélvico), risco de morte calculado pelos índices APACHE II, SAPS II e LODS, número de sistemas comprometidos e insuficiências neurológica e pulmonar.

Tabela 30. Regressão linear para carga de trabalho de enfermagem requerida pelos sobreviventes na alta da UTI. São Paulo, 2010-2011

\begin{tabular}{lccc}
\hline \multicolumn{1}{c}{ Variável } & $\boldsymbol{\beta}$ & Erro Padrão $(\boldsymbol{\beta})$ & p \\
\hline Intercepto & 37,171 & 2,210 & \\
Risco de morte (SAPS II) & 0,188 & 0,040 & $<\mathbf{0 , 0 0 1}$ \\
NISS & 0,193 & 0,077 & $\mathbf{0 , 0 1 3}$ \\
\hline
\end{tabular}

A regressão linear contemplou apenas as variáveis risco de morte segundo SAPS II na admissão na UTI e NISS (Tabela 30), permitindo definir a seguinte fórmula do modelo estimado:

NAS alta $=37,171+0,188$ (risco de morte na admissão segundo SAPS II) + 0,193 (NISS)

A equação indica que, mantendo-se o NISS constante, para cada ponto do escore risco de morte pelo SAPS II calculado na admissão da UTI, há um aumento de 0,188 ponto no NAS nas últimas 24 horas de internação na unidade crítica. Para cada ponto do escore NISS, há um aumento de 0,193 ponto no NAS, se considerado o valor do risco de morte pelo SAPS II constante. 


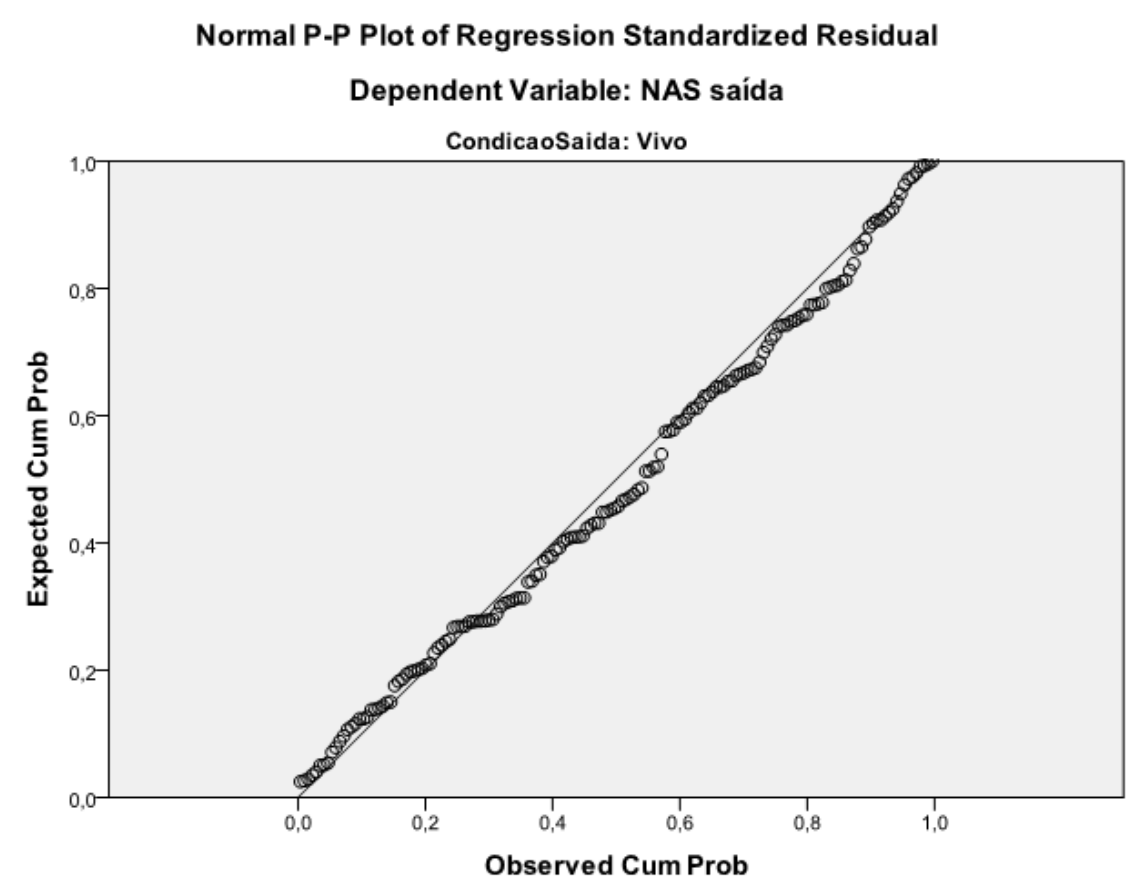

Figura 3. Análise da suposição de normalidade para o modelo de regressão linear da carga de trabalho de enfermagem. São Paulo, 2010-2011

Observa-se na Figura 3 que não há discrepâncias relevantes entre os resíduos e a curva normal padronizada teórica, indicando que o componente aleatório do modelo de regressão para estimativa da carga de trabalho de enfermagem requerida pelos sobreviventes na alta da UTI é adequado. 


\section{DISCUSSÃo}

A UTI desempenha papel decisivo na chance de sobrevida de vítimas de trauma grave e o sucesso da assistência intensiva depende das atividades desenvolvidas por uma equipe multidisciplinar treinada e capacitada e que tenha objetivos em comum ${ }^{(19)}$.

Para tanto, faz-se necessário estudos que permitam conhecer e compreender as características dessas vítimas admitidas em UTI, cujos dados poderão facilitar a implantação de políticas de saúde com enfoque na prevenção, redução de custos, assim como no gerenciamento da unidade crítica e na educação continuada dos profissionais envolvidos na assistência.

$\mathrm{Na}$ atual pesquisa, a análise do perfil sociodemográfico das vítimas de trauma admitidas na UTI evidenciou o predomínio de adultos jovens do sexo masculino, tendência mundial dos indivíduos com traumatismos.

A idade média da amostra analisada $(40,7 \pm 18,6$ anos $)$ corrobora com os resultados de estudos que abordaram este tipo de paciente na unidade crítica $^{(77,81,86,101-106)}$ e difere de pesquisas internacionais que analisaram números significativos de pacientes (amostras entre 3.778 e 223.129 indivíduos) admitidos em UTI por diversas causas e encontraram médias de idade que variaram de 56,9 a 62,4 $\operatorname{anos}^{(107-109)}$.

Na realidade brasileira, a idade média encontrada em pacientes internados na unidade crítica por diferentes causas ${ }^{(28,33,52,55,57-58,110-111)}$ também supera os achados desta investigação.

A análise dos pacientes de 11 UTI de diferentes especialidades em hospital da cidade de São Paulo mostrou que a idade média da população do estudo foi 51ะ20,6 anos. Entretanto, quando realizada a caracterização por especialidade, identificou-se valores inferiores da variável na UTI que atendia exclusivamente vítimas de trauma: idade média $43 \pm 29,1 \operatorname{anos}^{(98)}$.

Apesar dos estudos que analisam séries temporais mostrarem aumento da idade dos pacientes na UTI ${ }^{(26,112)}$ nas últimas décadas, tal achado não foi evidenciado nas vítimas de trauma, caracterizada por populações mais jovens.

Quanto ao gênero, a predominância de indivíduos do sexo masculino $(82,0 \%)$ nas vítimas de trauma em UTI corrobora com achados de outros estudos que 
analisaram este tipo de paciente ${ }^{(77,80-81,85,88,96,113-115)}$. Entretanto, em pesquisas nacionais $^{(47,52,57,110-111,116)}$ e internacionais ${ }^{(107-109)}$ que analisaram populações gerais, não é observada tal discrepância da frequência de homens perante o sexo oposto na UTI.

A relação de 4,5 homens para 1 mulher encontrada nesta investigação representa maior diferença entre a frequência de homens e mulheres do que a observada nas internações devido ao trauma e pode ser explicada pelo elevado número de vítimas, 64,0\%, que apresentaram a cabeça como a região corpórea mais gravemente lesada, uma vez que a literatura evidencia que a desproporção na relação homem/mulher é mais acentuada em vítimas com TCE, diante do maior risco de os homens apresentarem tal lesão em relação ao sexo feminino ${ }^{(117-119)}$.

A análise de dados do Sistema de Informações Hospitalares do Sistema Único de Saúde (SUS), de 1998 a 2006, mostrou que os homens são mais acometidos por trauma intracraniano que as mulheres, estabelecendo uma relação entre 4,9 e 5,3:1; outrossim, o predomínio do sexo masculino foi mais acentuado em relação aos demais traumas, que apresentaram valores de 3,4 a 3,7:1 ${ }^{(119)}$.

A importância da presença de comorbidade em vítimas de trauma vem sendo cada vez mais abordada nos estudos em virtude, principalmente, do aumento da incidência de idosos que sofrem algum tipo de lesão traumática ${ }^{(120-123)}$. Além disso, pesquisadores reforçaram tal importância ao mostrar que a presença de comorbidade impacta negativamente na sobrevida das vítimas de trauma ${ }^{(124)}$.

Neste estudo, identificou-se que $26 \%$ dos pacientes eram portadores de algum tipo de doença preexistente. Pesquisa que analisou 3.670 vítimas de trauma atendidas em hospitais da Austrália mostrou que 33,2\% dos pacientes tinham algum tipo de comorbidade $^{(124)}$. Frequência inferior foi encontrada na análise de 21.032 vítimas em Manitoba, no Canadá: 5,9\% ${ }^{(125)}$. Entretanto, quando se analisa a presença de comorbidades na população geral de pacientes de UTI, observa-se frequências mais elevadas em estudos nacionais, $53,3 \%^{(30)}, 63,6 \%^{(111)}$ e $84,0 \%{ }^{(28)}$, e internacional, $58,7 \%^{(109)}$.

A média e a mediana do índice de comorbidade de Charlson nesta investigação foram $0,6( \pm 1,4)$ e 0 , respectivamente. Não foram identificadas na literatura pesquisas que aplicassem o índice de comorbidade de Charlson em vítimas de trauma internadas em UTI. Entretanto, quando se analisa os escores do índice nas 
investigações realizadas em casuísticas mistas, que incluem pacientes não traumatizados admitidos em unidade crítica, observa-se valores da média, 1,90 $( \pm 1,94)^{(126)}$ e $1,34( \pm 2,1)^{(112)}$, e mediana, $1^{(109)}$ e $2^{(127)}$, superiores ao desta pesquisa.

As informações sobre a causa externa são importantes para a predição de alguns padrões de lesões e gravidade da vítima ${ }^{(128)}$. As maiores frequências encontradas nesta investigação foram os acidentes de transporte $(57,5 \%)$ e as quedas (31,0\%). Cotejando esses dados com a literatura, observam-se resultados semelhantes quanto a maior prevalência dos acidentes de transporte, como principal causa externa, seguida das quedas, em estudos que analisaram vítimas de trauma admitidas em $\mathrm{UTI}^{(3,77,80,83,129)}$. Outros revelaram que suicídios ${ }^{(102)}$ e assaltos ${ }^{(130)}$ suscederam os acidentes de transporte.

A análise das internações hospitalares por causas externas no Brasil, não especificamente em UTI, mostra que as quedas são mais frequentes do que os acidentes de transportes ${ }^{(131)}$. Entretanto, conforme comentado anteriormente, esta distribuição é modificada quando analisado o paciente de terapia intensiva. Tal fato pode estar relacionado à gravidade desses indivíduos decorrente do mecanismo do trauma. Para fortalecer tal premissa, cabe ressaltar que, dos acidentes de transporte, um total de 95 pacientes $(47,5 \%)$ admitidos na UTI deste estudo foi vítima de atropelamento ou acidentes que envolveram bicicletas ou motocicletas. A literatura ressalta que este tipo de vítima é mais vulnerável a lesões graves, uma vez não tem a estrutura do veículo para protegê-la, absorvendo assim toda a energia do impacto $^{(128,132)}$.

Assim como a análise da causa externa, o tipo de trauma é uma importante informação à equipe que presta assistência intensiva. No trauma penetrante, na maioria das vezes, é possível compreender a extensão das lesões mediante a análise das características da arma e localização da penetração no corpo. O mesmo não ocorre no trauma contuso, cuja identificação dessa extensão é influenciada por forças de compressão, cisalhamento e mecanismos de aceleração e desaceleração ${ }^{(128)}$.

Aproximadamente $95 \%$ dos pacientes deste estudo foi acometida pelo trauma contuso. Esse achado não difere das pesquisas que analisam vítimas na UTI que mostram prevalência do trauma contuso na população ${ }^{(88,96,101,103-104)}$.

Estudo sobre autópsias realizadas no Instituto Médico Legal em São Paulo, Brasil, mostrou que a maioria das vítimas que morreu na cena apresentava baixa 
probabilidade de sobrevida e a maior frequência desses óbitos foi decorrente de trauma penetrante ${ }^{(133)}$.

Tais resultados mostram que muitas vítimas de ferimentos penetrantes são tão graves que morrem na cena, o que implica diretamente em redução de internações hospitalares por essa causa e, consequentemente, baixa frequência desse tipo de trauma em pacientes de UTI.

Neste estudo, o intervalo médio de tempo entre a admissão hospitalar e a UTI foi de 29,4 horas $( \pm 58,1)$. Pesquisas que analisaram o impacto da demora da admissão do paciente na UTI em diferentes desfechos consideraram como ponto de corte para comparação dos grupos (admissão imediata ou tardia) tempos superiores a 120 minutos $^{(105)}$ e 6 horas $^{(134)}$. Considerando esses valores, nota-se a demora na admissão dos pacientes na UTI nesta investigação.

Tal fato parece ser uma realidade brasileira, decorrente da alta taxa de ocupação e escassez de leitos de terapia intensiva. O resultado da análise de 1.732 pacientes admitidos em 12 UTI localizadas em um hospital de São Paulo evidenciou elevado tempo médio, 2 dias, entre admissão no hospital e $\mathrm{UTI}^{(116)}$. Esta demora na admissão do paciente na unidade crítica deve ser sempre valorizada, uma vez que estudos mostram seu impacto na mortalidade hospitalar ${ }^{(134-135)}$.

Pacientes procedentes do Centro Cirúrgico (70,0\%) e aqueles submetidos à cirurgia não programada $(66,5 \%)$ prevaleceram na atual investigação. Procedimentos cirúrgicos de emergência também foram frequentes em outras pesquisas que investigaram vítimas de trauma na $\mathrm{UTI}^{(83,85,88,113,136)}$. Estudo que analisou 35.637 internações na unidade crítica reforçou tal achado ao identificar que os pacientes traumatizados foram admitidos mais frequentemente em razão de cirurgias não programadas $(54,8 \%)$ que os outros doentes $(16 \%)^{(82)}$.

A análise das admissões por trauma na UTI em um hospital na Tanzânia revelou que $68,6 \%$ das vítimas foram submetidas a procedimento cirúrgico (emergencial ou não) em algum momento da internação, com maior frequência de desbridamentos de feridas ${ }^{(130)}$.

Entretanto, quando investigados a procedência e o tipo de admissão (clínica ou cirúrgica) em UTI que não atendem exclusivamente vítimas de trauma, observamse diferenças nos resultados: pacientes procedentes do Pronto-Socorro ${ }^{(28,56,58)}$ e 
internados por causas clínicas ${ }^{(28,30,56,58,108,116,137)}$ foram mais frequentes nas amostras analisadas.

Esses achados reforçam que o trauma é uma doença cirúrgica e que o Centro Cirúrgico deve disponibilizar equipe preparada e sala cirúrgica, 24 horas por dia, para atender essas vítimas ${ }^{(138)}$, com a finalidade de garantir a sobrevida desta população.

Quanto ao tempo de permanência na UTI, a média encontrada $(13,6 \pm 14,6$ dias) foi elevada quando comparada a outras pesquisas internacionais que analisaram vítimas de trauma na unidade crítica: 4,9 dias $(\mathrm{dp}=6,0)^{(77)}, 5,5$ dias $(\mathrm{dp}=8,9)^{(83)}, 6,15$ $\operatorname{dias}(\mathrm{dp}=9,63)^{(81)}, 8,2$ dias $(\mathrm{dp}=2,5)^{(16)}$ e 10 dias $(\mathrm{dp}=11,0)^{(86)}$.

A média do tempo de permanência das vítimas de trauma na unidade crítica analisada é também considerada alta perante os resultados de estudos nacionais $^{(52,54,57,110-111)}$ e internacionais ${ }^{(62,107-108)}$ que investigaram esta variável em UTI gerais. Pesquisa que analisou 268 pacientes admitidos em UTI de diferentes especialidades mostrou que o tempo médio de permanência na casuística foi $7,7 \pm 10,4$ dias e, na UTI que atendia trauma, esta média era superior: $11 \pm 7,9$ dias ${ }^{(98)}$.

A falta de leitos de semi-intensiva, bem como a gravidade do trauma, podem ter contribuído para o prolongado tempo de internação dessas vítimas na UTI onde foi realizada esta pesquisa.

Ainda no presente estudo, a média do tempo de permanência hospitalar encontrada $(35,9 \pm 50,9$ dias) também superou os achados de outras pesquisas que acompanharam toda a internação hospitalar dos pacientes traumatizados que estiveram, em algum momento, internados em UTI: 13,81 dias $(\mathrm{dp}=12,71)^{(81)}$ e 26 $\operatorname{dias}(\mathrm{dp}=26)^{(86)}$.

Pesquisa que analisou a mortalidade e o tempo de permanência de pacientes admitidos entre os anos de 1993 e 2003 em UTI da Austrália e Nova Zelândia mostrou média de tempo de permanência no hospital de 16,4 dias $(\mathrm{dp}=19,5)^{(107)}$. Valor médio do tempo permanência hospitalar inferior ao da atual investigação também foi encontrado em estudo que analisou 5.881 pacientes submetidos a tratamento intensivo: $15,9 \pm 29,9$ dias $^{(108)}$.

Vale lembrar que o elevado tempo de permanência na UTI ou no hospital pode estar associado à baixa rotatividade de leitos e ao maior risco de ocorrência de eventos adversos, como a infecção hospitalar. Estudo realizado durante o período de 
1999 e 2006 evidenciou que a inserção de enfermeiros especialistas no atendimento à vítima de trauma na equipe melhorou a assistência e reduziu o tempo de permanência hospitalar dessas vítimas ${ }^{(139)}$. No entanto, este tipo de especialidade não é uma realidade brasileira; porém, deveria ser considerado pelos enfermeiros assistenciais e gestores de hospitais que atendem grande número de traumatizados.

Quanto à gravidade do trauma, aplicando-se o ISS nas vítimas deste estudo, identificou-se média de 19,3 (dp=9,1), mediana de 17 e variação de 9 a 50 pontos. Os valores médios encontrados corroboram com resultados na literatura de estudos que enfocaram pacientes em UTI ${ }^{(86,88-89,96,101,104,130)}$. Vale salientar que a maioria das vítimas $(59,0 \%)$ apresentou ISS superior a 16 pontos e, portanto, sofreu um trauma importante. O ISS de 16 pontos é considerado um ponto crítico, uma vez que, a partir desta faixa, ocorre aumento dos percentuais de mortes ${ }^{(140)}$.

Quanto ao NISS, os valores da média e mediana encontrados nesta pesquisa foram 27,1 $(\mathrm{dp}=9,9)$ e 27, respectivamente, e em 75,0\% das vítimas o escore NISS superou os valores do ISS. Pontuação do ISS superior ao NISS é operacionalmente inviável em razão da fórmula de cálculo dos índices.

É escasso o número de pesquisas que utilizam o NISS para calcular a gravidade de vítimas de trauma admitidas na UTI. Valores da mediana, $27^{(94)}$, e da média, $27,7 \pm 12,3^{(96)}$, do NISS são evidenciados em algumas pesquisas realizadas em UTI e retratam resultados próximos ao deste estudo.

$\mathrm{Na}$ atual investigação, $67,0 \%$ das vítimas tinham pontuação superior a 25 no cálculo do NISS, mostrando que, segundo este índice, a maioria dos pacientes na UTI apresentava trauma grave.

Pesquisas que analisaram a gravidade do trauma por meio do ISS e NISS em populações não necessariamente admitidas em UTI mostraram valores da média ou mediana dos índices inferiores aos desta pesquisa: mediana do ISS de $5^{(106)}$ ou média de $7,1^{(95)}$ e $12,49^{(141)}$, além de NISS médio de $12,8( \pm 0,8)^{(95)}$ e $16,99( \pm 17,6)^{(141)}$.

A investigação da sobrevida de vítimas de trauma grave admitidas diretamente para áreas críticas revelou que a mediana do ISS encontrada nos internados na enfermaria (19) foi inferior à dos grupos de pacientes admitidos no Centro Cirúrgico (26) e UTI $(27)^{(142)}$. Esses resultados reforçam que vítimas admitidas em UTI apresentam trauma de maior gravidade. 
Em relação ao AIS, observou-se que, em média, houve três lesões AIS $\geq 3$ por paciente e aproximadamente três regiões lesadas. Além disso, pacientes com MAIS igual a 3 prevaleceram na amostra $(65,0 \%)$.

A caracterização da população do estudo que comparou a performance de índices fisiológicos e anatômicos, bem como a combinação deles, revelou que as vítimas admitidas na UTI apresentaram média de 2,53 $( \pm 1,58)$ lesões AIS igual a $3^{(81)}$, valor próximo ao encontrado nesta pesquisa $(3,1 \pm 1,8)$.

Além disso, a alta frequência de pacientes desta investigação que apresentaram trauma contuso $(94,5 \%)$ contribuiu para o resultado relacionado ao número de regiões lesadas na amostra, uma vez que essas vítimas tiveram, em média, aproximadamente uma região corpórea a mais acometida $(2,8)$ perante aqueles que sofreram trauma penetrante $(2,0)$.

Considerando que todos os pacientes admitidos na UTI neste estudo apresentavam no mínimo uma lesão AIS igual a 3, pode-se afirmar que a indicação de tratamento intensivo foi adequada, uma vez que essa lesão é considerada séria e representa potencial ameaça à vida da vítima ${ }^{(93)}$. Pesquisa que analisou preditores precoces de morbidade e mortalidade em traumatizados tratados em UTI identificou que as lesões $\mathrm{AIS} \geq 3$ na cabeça influenciaram na ocorrência de desfechos indesejados, como falência múltipla de órgãos e mortes tardias ${ }^{(85)}$, fortalecendo a necessidade de tratamento intensivo.

Não foram encontrados na literatura estudos que analisassem o número médio de regiões corpóreas acometidas. Entretanto, pesquisa que identificou os fatores de risco precoces para sepse em vítimas de trauma contuso na UTI mostrou que 79\% dos pacientes tinham pelo menos duas regiões corpóreas acometidas ${ }^{(113)}$. Na prática clínica, observa-se que, quanto maior o número de regiões lesadas, maior a gravidade do paciente, especialmente se essas lesões representarem gravidade AIS $\geq 3$.

Um total de $65,5 \%$ dos pacientes na UTI apresentou lesões AIS $\geq 3$ na cabeça ou pescoço. Esta região foi considerada a mais gravemente lesada em 64,0\% da amostra, seguida do tórax $(27,5 \%)$.

Entre os estudos que revelaram a região corpórea mais afetada em vítimas internadas em UTI, identificou-se que, assim como nesta investigação, a região da cabeça ou pescoço prevaleceu em $95,5 \%^{(130)}$ e $52 \%^{(142)}$ da casuística. Pesquisa que analisou estratégias de proteção pulmonar na redução de falência múltipla de órgãos 
identificou que o tórax e a cabeça foram as regiões mais gravemente lesadas $(68,3 \%$ cada); entretanto, o TCE foi a principal causa de óbito precoce na UTI ${ }^{(102)}$.

A taxa de mortalidade hospitalar em decorrência de lesões por causas externas, segundo dados do SUS referentes ao período de 1998 a 2006, foi cerca de $10 \%$ em vítimas com trauma intracraniano e menor que $2 \%$ entre aquelas sem esse tipo de lesão ${ }^{(119)}$. Esses resultados mostram a importância do TCE na mortalidade das vítimas de trauma, mas também evidenciam a gravidade desse tipo de lesão e a necessidade dessas vítimas serem assistidas em unidades de cuidados intensivos.

Revisões de literatura mostram que as principais causas de TCE são os acidentes automobilísticos, em adultos, e as quedas, nos idosos. Além disso, como citado anteriormente, os homens apresentam maior risco de sofrerem TCE que as mulheres ${ }^{(117-118)}$.

Esses mecanismos de lesão foram também frequentes no atual estudo. Além disso, dos 37 idosos da pesquisa, a causa principal de internação da UTI, em 67,6\% deles, foi o trauma decorrente de quedas.

Portanto, o predomínio de vítimas de TCE na casuística estudada é consonante com as causas externas mais frequentes e a preponderância masculina nessas vítimas.

Dos 200 pacientes analisados, 38 morreram durante a permanência na UTI, representando uma taxa de mortalidade de $19,0 \%$, valor considerado superior quando comparado a diferentes estudos que analisaram desfechos em vítimas de trauma na unidade crítica ${ }^{(74,77,81,103,114)}$.

Taxas de mortalidade compatíveis ao desta investigação são encontradas em estudos que analisam pacientes internados por outras causas na UTI. Pesquisa que comparou a performance do APACHE II com o índice de comorbidade de Charlson na predição de mortalidade mostrou que, dos 3.778 pacientes analisados, 712 evoluíram a óbito na unidade crítica, representando uma taxa de mortalidade de $18,8^{(109)}$. Outro estudo evidenciou taxa de $22,5 \%$ ao analisar 1.685 pacientes internados por mais de 48 horas em UTI da França ${ }^{(143)}$.

No Brasil, alta taxa de mortalidade (29\%) foi encontrada em pesquisa que analisou a ocorrência de falência respiratória em 1.732 pacientes na $\mathrm{UTI}^{(116)}$. Valores próximos ao atual estudo foram identificados em outras pesquisas nacionais: $17,5 \%^{(55)}, 18,2 \%^{(33)}$ e $20,0 \%{ }^{(52)}$. 
A mortalidade entre vítimas de TCE é expressiva na UTI: taxas de $23,5 \%{ }^{(76)}$, $27,5 \%^{(75)}$ e $40 \%^{(129)}$. Portanto, considerando que $64,0 \%$ dos pacientes deste estudo tiveram a cabeça ou pescoço como a região mais gravemente lesada, é possível afirmar que a elevada taxa de mortalidade encontrada pode estar relacionada ao significativo número de pacientes com TCE; ademais, o grande intervalo de tempo entre a chegada ao hospital e a admissão na UTI, 29,4 horas $( \pm 58,1)$, pode ter colaborado para este resultado.

Quanto aos índices de gravidade do paciente em UTI, identificou-se média do risco de morte calculado pelo APACHE II $(25,6 \pm 19,1)$ superior ao SAPS II $(22,9 \pm 22,6)$ e ao LODS $(21,1 \pm 20,1)$ na amostra analisada. Esses valores correspondem às seguintes pontuações médias dos índices: 15,13 (APACHE II), 34,52 (SAPS II) e 4,15 (LODS). Para análise dos resultados dessas pontuações, vale lembrar que, para o APACHE II, a possibilidade de variação do escore é de 0 a 71 pontos $^{(65)}$; para o SAPS II, de 0 a $163^{(69)}$; e o valor do LODS pode variar de 0 a 22 $\operatorname{pontos}^{(73)}$.

A média do escore APACHE II encontra-se no intermédio de outros estudos sobre trauma na UTI, que mostram valores que oscilam de 12,2 a $16^{(76,88-89,114)}$. Médias do índice próximas à desta pesquisa também foram identificadas em casuísticas de UTI gerais: $19,6(\mathrm{dp}=8,6)^{(109)}, 17,10(\mathrm{dp}=9,4)^{(108)}, 15,4(\mathrm{dp}=8,5)^{(107)}$, $13,4(\mathrm{dp}=8,3)^{(50)}$ e $12,0(\mathrm{dp}=5,6)^{(110)}$, sendo as duas últimas realizadas no Brasil.

Portanto, esses achados mostram que os valores médios do APACHE II não apresentam diferenças importantes quando se analisam vítimas de trauma e demais pacientes na UTI.

Quanto ao SAPS II, assim como o APACHE II, os valores médios do escore do índice encontrado nesta pesquisa $(34,52)$ não diferiram da literatura, que mostra variações de 30 a 41,1 pontos ${ }^{(77,81,86,115,144-145)}$ nos estudos que investigam traumatizados na UTI.

A análise de 2.893 pacientes admitidos em UTI por outras causas identificou mediana do risco de morte nesses doentes, segundo SAPS II, de $10 \%{ }^{(137)}$, taxa esta inferior, porém próxima ao encontrado neste estudo $(15,3 \%)$.

Estudos nacionais, realizados com pacientes de diferentes especialidades médicas, apresentam também valores médios do risco de morte calculado pelo SAPS 
II próximos ao desta investigação: $22,79 \%(21,59)^{(59)}, 25,44 \%( \pm 24,4)^{(56)}, 25,50 \%$ $( \pm 22,12)^{(52)}$ e $28,44 \%( \pm 23,69)^{(126)}$.

Entretanto, outras pesquisas, também realizadas no Brasil, mostram valores da média do escore SAPS II $40,7 \pm 14,59^{(51)}$ e $48,3 \pm 16,6^{(55)}$ ou risco de morte, $37,8 \pm 27,8^{(54)}$, superiores.

O LODS é raramente aplicado nas vítimas de trauma. Estudo realizado em 2006 na mesma UTI desta pesquisa encontrou média do risco de morte calculado pelo LODS de $21,14 \%( \pm 22,47 \%)^{(78)}$, resultado similar ao das vítimas desta investigação, realizada após 4 anos.

Pesquisas com casuísticas mistas de pacientes de UTI mostram medianas do escore LODS iguais ao deste estudo: $3^{(116,137)}$. A mesma semelhança foi identificada em relação à média do risco de morte calculado pelo índice: $20,54 \%( \pm 17,34)^{(59)}$, $21,45 \%( \pm 18,66)^{(146)}$ e $25,13( \pm 20,98)^{(126)}$. Por conseguinte, a comparação dos resultados dessas investigações mostra que o LODS aplicado em vítimas de trauma apresenta comportamento semelhante a outros tipos de doentes em terapia intensiva.

A análise do poder preditivo do LODS e APACHE II aplicados em uma UTI neurológica mostrou que a mortalidade prevista pelo LODS foi de 7,2\% e que o índice apresentou boa calibração para vítimas de $\mathrm{TCE}^{(147)}$.

$\mathrm{Na}$ atual investigação, a média do risco de morte estimado pelo APACHE II, SAPS II e LODS na admissão das vítimas de trauma na UTI variou de 21,1 a 25,6\%, percentuais próximos à mortalidade observada durante permanência nesta unidade, 19\%. Esses resultados validam o uso desses índices em vítimas de trauma internadas em UTI para estimar sua gravidade.

A análise comparativa da capacidade preditiva dos índices de gravidade do trauma e do paciente de UTI mostrou que o SAPS II e LODS estimaram melhor a ocorrência de óbito na unidade crítica do que ISS e ISSS $^{(78)}$, reforçando a importância do uso desses índices nos pacientes de UTI com traumatismos.

A presença das insuficiências pulmonar $(76,5 \%)$ e neurológica $(69,0 \%)$ identificadas pelo LODS prevaleceram neste estudo, seguidas pela insuficiência renal (47\%). Em 20 pacientes (10,0\%), nenhum sistema foi afetado. O número médio de sistemas comprometidos foi de $2,3(\mathrm{dp}=1,2)$. 
Publicação norte-americana mostrou que a insuficiência pulmonar acometeu todas as vítimas de trauma na UTI que apresentaram falência de um ou mais órgãos ${ }^{(88)}$.

Outra pesquisa mostrou que $6 \%$ das 287 vítimas de trauma grave internadas na UTI não apresentaram falência orgânica e que 68,3\% dos pacientes apresentou TCE ou trauma torácico e, consequentemente, insuficiência dos sistemas relacionados com a localização desse tipo de lesão ${ }^{(102)}$.

O distúrbio respiratório foi o mais frequente entre 1.993 vítimas de trauma internadas em UTI em investigação que analisou o desenvolvimento de insuficiência renal nesses pacientes. A frequência de disfunção neurológica foi baixa $(22,4 \%)$, uma vez que pacientes com TCE isolado não foram inseridos na amostra ${ }^{(114)}$.

A alta frequência de insuficiência neurológica $(69,0 \%)$ nesta investigação pode ser associada ao elevado número $(65,5 \%)$ de doentes que tiveram lesões AIS $\geq$ 3 na região da cabeça ou pescoço. Este tipo de lesão em cabeça altera o escore da ECGl, influenciando a pontuação relacionada ao sistema neurológico no $\operatorname{LODS}^{(73)}$.

Pesquisa que analisou 600 pacientes internados em UTI por outras causas além das traumáticas identificou mediana de 3 insuficiências na amostra ${ }^{(146)}$, valor este superior ao encontrado na atual investigação, 2. Este mesmo estudo mostrou que as falências renais $(68,6 \%)$ e pulmonares $(50 \%)$ foram os tipos de insuficiências mais frequentes $^{(146)}$.

Dados da literatura e desta pesquisa indicam que as vítimas com traumatismos apresentam, assim como os demais pacientes de UTI, elevada frequência de insuficiências respiratória e renal. No entanto, a presença de traumas que afetam diretamente alguns sistemas, como o neurológico, têm como consequência as falências orgânicas relacionadas ao local das lesões.

Quanto à caracterização da carga de trabalho de enfermagem no primeiro dia de internação na UTI, observou-se neste estudo média NAS de 71,3\% $( \pm 16,9)$, valor mínimo de 35,9\% e máximo de $131,5 \%$.

Estudos nacionais ${ }^{(49-50,54-55,57)}$ e internacional ${ }^{(60)}$ realizados em UTI gerais encontraram médias do NAS calculadas nas primeiras 24 horas de permanência inferiores ao desta investigação: $41,42 \%$ a $69,9 \%$. A menor carga de trabalho de enfermagem foi encontrada por pesquisadores espanhóis ${ }^{(60)}$. 
A análise da carga de trabalho de enfermagem requerida por 300 pacientes internados em UTI geral e especializadas também mostrou médias do NAS inferiores ao atual estudo, independentemente do tipo de unidade: 66,54\% na UTI geral, $66,66 \%$ na UTI cardiológica e $65,18 \%$ na UTI neurológica ${ }^{(59)}$.

Apenas uma investigação que analisou estilos de liderança dos enfermeiros em unidade crítica geral mostrou NAS médio na admissão da UTI $(80,1 \% \pm 7,98)^{(53)}$ superior ao deste estudo.

Confrontando os resultados desta pesquisa com a literatura, pode-se observar que, em média, a carga de trabalho das vítimas de trauma durante as primeiras 24 horas de permanência na UTI foi superior à de outros grupos analisados.

Ademais, em publicações que apresentaram médias do NAS durante todo o período de internação na UTI, identificou-se apenas três investigações que mostraram valores superiores aos requeridos pelas vítimas de trauma desta pesquisa $^{(32,56,62)}$.

Publicação referente a quatro UTI da Noruega mostrou média NAS durante a internação de $96,24 \%( \pm 22,35)^{(62)}$. Os outros dois estudos, realizados no Brasil, abordaram populações específicas e mostraram médias do NAS pouco mais elevadas de $72,93 \%( \pm 14,47)$ na análise de idosos ${ }^{(56)}$ e $73,7 \%( \pm 16,1)$ em unidade de recuperação pós-operatória de cirurgia cardíaca ${ }^{(32)}$.

Nas últimas 24 horas de permanência na UTI, identificou-se que os pacientes demandaram, em média, $57,4 \%( \pm 28,3)$ do tempo da equipe de enfermagem. Esse valor foi superior ao encontrado em duas pesquisas que descreveram o NAS na saída da unidade: $38,86 \%{ }^{(60)}$ e $52,5 \%{ }^{(57)}$.

Tanto nas primeiras quanto nas últimas 24 horas de permanência na UTI, as vítimas não sobreviventes requereram maior carga de trabalho de enfermagem do que os sobreviventes. Além disso, o valor médio do NAS dos pacientes que morreram na unidade crítica foi maior na saída $(109,3 \%)$ que na admissão $(80,6 \%)$.

Autores que analisaram a evolução do valor diário do NAS revelaram maior média da pontuação $(75 \%)$ durante a internação na unidade crítica nos pacientes que foram a óbito em relação aos sobreviventes $(61,3 \%)^{(28)}$. A pontuação do NAS no último dia de internação na UTI foi de 65,98\%, entre os que morreram, e de 49,22\%, entre os sobreviventes, na análise de pacientes internados em quatro UTI gerais ${ }^{(148)}$. Além disso, estudo que identificou os fatores associados à carga de trabalho de 
enfermagem mostrou que a probabilidade de um paciente não sobrevivente apresentar altos valores do NAS é maior que entre os sobreviventes ${ }^{(55)}$. Esses resultados reforçam que pacientes que evoluem a óbito na UTI requerem maior carga de trabalho de enfermagem.

A ausência de estudos na literatura sobre carga de trabalho de enfermagem requerida por vítimas de trauma com a aplicação do NAS impossibilitou comparações específicas com esse grupo de pacientes.

Por meio da análise das intervenções de enfermagem realizadas nas primeiras 24 horas de internação na UTI, pelo método de Cluster, foi possível identificar um grupo de vítimas submetidas a um padrão de intervenções similares composto por 136 pacientes.

A análise descritiva deste grupo mostrou que, no tocante à realização das intervenções compostas por subitens, as vítimas de trauma pontuaram com alta frequência os itens $\mathrm{b}$ e $\mathrm{c}$ das atividades relacionadas ao item 1, monitorização e controles $(79,4 \%)$, e item 6 , mobilização e posicionamento $(100,0 \%)$, indicando que necessitaram de cuidados além do normalmente requerido por pacientes de UTI nessas intervenções.

No NAS, as atividades dos itens 1, 4, 6, 7 e 8 são apresentadas no instrumento com subitens que indicam níveis de complexidade diferentes da tarefa e expressam um tempo estimado ajustado ao necessário para sua realização. Esses subitens têm uma hierarquia de níveis exclusivos, na qual o nível "a" representa a prática de rotina da intervenção em qualquer UTI; o subitem "b" caracteriza situações em que a atividade junto ao paciente apresenta maior complexidade e ocupa mais tempo, isto é, além da rotina normal; e o "c" indica complexidade ainda maior e tempo muito mais longo para realizar a atividade ${ }^{(44,149)}$.

Publicações referentes à análise das intervenções de enfermagem realizadas em UTI gerais mostram grande variabilidade nas frequências dos subitens "b" e "c" na atividade relacionada à monitorização e controles, $13,6 \%{ }^{(33)}, 49,5 \%{ }^{(48)}, 94,4 \%{ }^{(150)}$ e $100 \%{ }^{(47)}$ e, portanto, a frequência desta atividade $(76,4 \%)$ realizada nas vítimas de trauma encontra-se no intermeio dessas pesquisas.

Entretanto, na análise do procedimento de mobilização e posicionamento (item 6), identificou-se que a totalidade das vítimas de trauma necessitou de cuidados 
além do normalmente requerido (subitens b e c) nessa atividade e a frequência de pontuação nesses subitens $(100,0 \%)$ superou o descrito em outros estudos ${ }^{(33,47-48,150)}$.

Quanto às demais intervenções de enfermagem que independem de outros profissionais, observou-se maior frequência do subitem "a" nos procedimentos de higiene (item 4), suporte e cuidado aos familiares e pacientes (item 7) e realização de tarefas administrativas e gerenciais (item 8), demonstrando que essas atividades corresponderam à prática rotineira da UTI, semelhante a outras pesquisas ${ }^{(33,47-48,150)}$.

Quanto às demais intervenções realizadas nos pacientes do grupo identificado, frequências superiores a $80 \%$ foram encontradas nas atividades de investigações laboratoriais (item 2), medicação, exceto drogas vasoativas (item 3), cuidados com drenos (item 5), suporte respiratório (item 9), cuidado com vias aéreas artificiais (item 10), tratamento para melhora da função pulmonar (item 11) e medida quantitativa do débito urinário (item 17). Essas intervenções, com exceção dos cuidados com drenos, também foram frequentemente realizadas em outras populações ${ }^{(33,47,150)}$.

Em relação ao elevado número de pacientes desta investigação que necessitaram de cuidados com drenos (99,3\%), é importante lembrar que $70 \%$ das vítimas foram submetidas a tratamento cirúrgico e, certamente, perante o tipo de cirurgia e técnica utilizada, drenos foram posicionados no intraoperatório. Além disso, deve-se levar em consideração que muitas vítimas de trauma são submetidas à drenagem de tórax para tratamento do pneumotórax, hemotórax ou outras lesões torácicas.

Não obstante, destaca-se também a frequência de pacientes desse grupo que necessitaram de medidas periódicas da pressão intracraniana (12,5\%), atividade esta não realizada ${ }^{(33,47)}$ ou presente em baixa frequência ${ }^{(48,150)}$ em outros estudos. O número considerável de pacientes com monitorização da pressão intracraniana provavelmente esteve associado à elevada frequência de vítimas que apresentaram a cabeça como região corpórea mais gravemente lesada $(64,0 \%)$, sendo a inserção do cateter uma medida capaz de monitorar a pressão intracraniana e, muitas vezes, quando locado em nível ventricular, permitir a drenagem terapêutica de liquor ${ }^{(19)}$.

Além disso, no tocante à categoria de intervenções específicas, observou-se que as frequências dessas intervenções realizadas dentro $(19,1 \%)$ e fora da UTI 
$(29,4 \%)$ nas vítimas de trauma foi superior ao encontrado em outros estudos ${ }^{(33,47-}$ $48,150)$

Vale salientar que, na avaliação e atendimento iniciais à vítima de trauma, a atenção está voltada ao diagnóstico e tratamento das lesões que implicam risco de vida ao doente. Muitas lesões de menor gravidade são posteriormente identificadas, por meio de exame físico detalhado e estudos radiológicos e laboratoriais, e então medidas são instituídas para o seu tratamento definitivo ${ }^{(128)}$. Portanto, a frequência de intervenções específicas realizadas dentro e fora da UTI nas vítimas deste estudo pode estar relacionada à identificação dessas lesões de menor gravidade.

As atividades de monitorização do átrio esquerdo (item 14) e hiperalimentação intravenosa (item 20) não foram pontuadas nesta investigação. Pesquisa que analisou o uso do cateter de artéria pulmonar em vítimas de trauma mostrou que ele reduziu de 38,6\% em 2000 para 4,2\% em 2008, e que esse cateterismo deve ser evitado como procedimento de rotina ${ }^{(104)}$.

Aconselha-se o início precoce da alimentação nas vítimas de trauma. $\mathrm{Na}$ impossibilidade de o paciente se alimentar por via oral, a via enteral é a segunda opção. A alimentação intravenosa, diante das complicações associadas à infecção, deve ser considerada apenas na impossibilidade de se utilizar o trato digestório ${ }^{(19)}$. Entretanto, a escolha pela alimentação endovenosa raramente é feita no primeiro dia de internação na UTI, o que explica a ausência de pacientes com este tipo de intervenção.

O tempo médio gasto pela equipe de enfermagem (média NAS de 71,3\%) na prestação do cuidado ao paciente deste estudo nas primeiras 24 horas de internação na UTI foi elevado perante os dados da literatura científica nacional, conforme anteriormente comentado, e ante a legislação vigente, que estabelece para uma equipe básica de enfermagem, por turno de trabalho, uma relação mínima de 1 enfermeiro para 10 leitos e a relação auxiliar ou técnico de enfermagem/paciente de $1: 2^{(21,151)}$. Tendo em vista o valor médio do NAS observado, $71,3 \%$, pode-se estimar uma proporção mínima de 1,5 profissional de enfermagem para 2 pacientes para atender as necessidades das vítimas da casuística estudada, superando, assim, o previsto nas diretrizes que embasam o funcionamento das UTI brasileiras.

Nestas circustâncias, tornou-se de especial interesse o conhecimento dos fatores associados à alta carga de trabalho de enfermagem requerida pelas vítimas de 
trauma na admissão da UTI com o intuito de fornecer informações ao enfermeiro que auxiliem no planejamento dos cuidados, dimensionamento da equipe e distribuição de tarefas.

A importância da análise dos fatores associados à alta carga de trabalho de enfermagem é reforçada por estudo de revisão de literatura que ressaltou o impacto negativo da carga de trabalho elevada na saúde dos enfermeiros, qualidade de vida no trabalho (insatisfação, estresse e altos índices de turnover) e segurança do paciente ${ }^{(152)}$. Além disso, a presença de burnout e eventos adversos também foi associada com alta demanda de cuidados requerida pelos pacientes ${ }^{(35,153)}$.

Neste estudo, optou-se por identificar os indivíduos que requereram alta carga de trabalho a partir do agrupamento das vítimas segundo os valores do NAS em tercis, diferente de outras pesquisas ${ }^{(54-56)}$ que utilizaram os valores da mediana do índice como referência para divisão dos grupos (alta e baixa carga de trabalho). Portanto, a casuística foi inicialmente dividida em três grupos de baixa, média e alta carga de trabalho de enfermagem segundo $1^{\circ}, 2^{\circ}$ e $3^{\circ}$ tercis. $\mathrm{O}$ último tercil definiu o grupo de alta carga de trabalho composto por pacientes que demandaram mais de $75,0 \%$ do tempo de um profissional de enfermagem em um plantão e que foi confrontado com as demais vítimas, reunidas em um único grupo que requisitou baixa/média carga de trabalho de enfermagem.

Nos estudos que analisaram os fatores associados à alta carga de trabalho mensurada pelo $\operatorname{NAS}^{(54-56)}$ e utilizaram a mediana como base para a divisão dos grupos, os valores dessa referência foram inferiores ao encontrado nesta investigação: $66,4 \%{ }^{(55)}, 68 \%{ }^{(54)}$ e $71,1 \%{ }^{(56)}$.

Na comparação dos grupos (alta e média/baixa carga) no primeiro dia de admissão em UTI, identificou-se diferença estatisticamente significativa em relação às seguintes variáveis: gravidade do trauma (ISS e NISS), número de regiões corpóreas acometidas, número e localização (extremidades ou cintura pélvica) de lesões AIS $\geq 3$, risco de morte segundo APACHE II, SAPS II e LODS, número de sistemas orgânicos comprometidos e presença de insuficiências cardiológica, neurológica, renal e pulmonar.

A alta carga de trabalho de enfermagem esteve associada a maiores pontuações nos indicadores de gravidade do paciente de UTI e do trauma, independentemente do instrumento de mensuração utilizado, evidenciando uma 
estreita relação entre a gravidade e a carga de trabalho de enfermagem no primeiro dia de internação na UTI. Observou-se maior número de lesões AIS $\geq 3$ e de sistemas comprometidos no grupo com alta demanda de trabalho, assim como a frequência de lesão AIS $\geq 3$ em extremidades ou cintura pélvica e de insuficiências cardiológica, neurológica, renal e pulmonar também foi maior nesse grupo.

A análise multivariada evidenciou, no modelo final, as variáveis risco de morte segundo SAPS II, presença de insuficiência pulmonar, número de regiões corpóreas acometidas e gênero.

Nesse modelo, o SAPS II foi o índice de gravidade do paciente em UTI de melhor ajuste; em relação ao trauma, o ISS e o NISS não se ajustaram ao modelo e foram superados pela variável número de regiões corpóreas acometidas como fator de risco de alta carga de trabalho de enfermagem no primeiro dia de internação em UTI. A insuficiência pulmonar se destacou entre as demais, que apresentaram associação na análise bivariada e a sua presença aumentou em 6,23 vezes a chance de alta carga de trabalho requerida pelas vítimas de trauma. $\mathrm{O}$ gênero, que de forma isolada não se associou à alta carga, na análise conjunta das variáveis permaneceu no modelo final. Vale salientar que, conforme resultado da área sob a curva ROC, foi satisfatória a capacidade preditiva deste modelo.

A análise prospectiva de 200 pacientes admitidos em quatro UTI localizadas em São Paulo mostrou que as variáveis tempo de internação, mortalidade, SAPS II e TISS-28 associaram-se com alta carga de trabalho de enfermagem. Cada dia de internação na UTI aumentou em $7 \%$ a probabilidade de o paciente demandar alta carga. Além disso, a mortalidade na unidade crítica (OR 2,65), o escore do TISS-28 superior a 23 pontos (OR 5,45) e os valores do SAPS II $\geq 46,5$ pontos (OR 2,78) aumentaram a possibilidade de o paciente necessitar alta demanda de cuidados da equipe de enfermagem ${ }^{(55)}$.

Em outro estudo, o tempo de permanência na UTI também foi um fator significativamente associado à elevada carga de trabalho de enfermagem no primeiro dia de internação; a permanência superior a 6 dias na unidade crítica aumentou cerca de 2 vezes a chance de o paciente exigir maior tempo de assistência de enfermagem $^{(54)}$.

$\mathrm{Na}$ análise da casuística formada por 71 idosos (> 60 anos), os preditores de alta carga de trabalho de enfermagem foram a idade, o tipo de internação e a 
gravidade. Pacientes com idade entre 70 e 79 anos apresentaram maior chance de requerer alta carga perante aqueles da faixa entre 60 e 69 anos, principalmente quando admitidos por motivos cirúrgicos e apresentavam alta gravidade, definida pelo SAPS II superior a 38 pontos. Vale salientar que, nesse estudo, além de todos os pacientes serem idosos, a carga de trabalho de enfermagem foi mensurada durante toda a permanência do paciente na $\mathrm{UTI}^{(56)}$.

Observa-se que, em dois ${ }^{(55-56)}$ dos três estudos citados anteriormente ${ }^{(54-56)}$, a gravidade mensurada pelo SAPS II esteve associada à alta demanda de cuidados requerida pelos pacientes. Nesta investigação, o acréscimo de um ponto no risco de morte calculado pelo índice aumentou a chance de o paciente demandar alta carga em $2 \%$.

O SAPS II é um índice que vem sendo cada vez mais aplicado em UTI e analisado em face da demanda de cuidados de enfermagem. Pesquisa que verificou os fatores independentes associados à carga de trabalho de enfermagem em UTI geral e especializadas mostrou que o SAPS II fez parte do modelo final de estimativa desta carga nas três unidades investigadas. Os resultados mostraram que, mantendo as outras variáveis que compuseram os modelos constantes, para cada aumento de um ponto do risco de morte calculado pelo SAPS II, houve um aumento de 0,184 ponto do escore NAS na UTI geral, 0,257 ponto na UTI cardiológica e 0,163 ponto na UTI neurológica ${ }^{(59)}$.

Tendo em vista que o TISS-28 antecedeu o NAS na medida da carga de trabalho, vale comentar a análise de 6.903 pacientes internados em UTI cirúrgica localizada na Alemanha que evidenciou correlação moderada $(r=0,42)$ e significativa $(\mathrm{p}<0,001)$ entre TISS-28 e SAPS II. Além disso, o TISS-28 foi significativamente maior nos pacientes que permaneceram por mais de duas semanas na UTI e evoluíram a óbito na unidade ${ }^{(144)}$.

Correlação positiva e significativa $(r=0,68, p<0,0001)$ entre TISS-28 e SAPS II também foi evidenciada na pesquisa que analisou 89 pacientes em UTI, cujos resultados reforçaram a relação entre gravidade do paciente e número de intervenções terapêuticas realizadas ${ }^{(154)}$.

Não foram encontrados na literatura estudos que analisassem a correlação entre instrumentos de medidas de carga de trabalho e gravidade de vítimas de trauma. Entretanto, os resultados das pesquisas anteriormente descritas mostram a 
relação entre carga de trabalho de enfermagem e gravidade dos pacientes internados em UTI mensurada pelo SAPS II e corroboram com os achados desta investigação, na qual o índice foi um fator preditor de elevada demanda de cuidados de enfermagem requerida pelos vítimas de trauma.

Identificou-se também nesta pesquisa que o acréscimo de uma região corpórea acometida aumentou em $33 \%$ a chance de o paciente demandar alta carga de trabalho de enfermagem.

A análise da ocorrência de fibrilação atrial em pacientes traumatizados durante internação na UTI mostrou que, das 293 vítimas analisadas, 16 apresentaram tal arritmia e os fatores de risco encontrados na regressão logística múltipla foram: uso de catecolaminas, SAPS II $\geq 30$, três ou mais regiões corpóreas acometidas, idade $\geq 40$ anos e presença de síndrome da resposta inflamatória sistêmica. Além disso, a carga de trabalho de enfermagem mensurada pelo OMEGA foi significativamente diferente e superior nos pacientes que apresentaram fibrilação atrial do que aqueles sem tal $\operatorname{arritmia}^{(86)}$.

$\mathrm{Na}$ prática clínica, observa-se que o aumento do número de regiões acometidas acarreta, além da maior necessidade de monitorização contínua à beira do leito e do tempo dispensado nos procedimentos de higiene e curativos, maior quantitativo de profissionais de enfermagem envolvidos na mobilização e no posicionamento do paciente, fazendo com que pontuações nessas atividades sejam direcionadas para os subitens b (além do normal) e c (muito além do normal), gerando valores elevados do NAS na soma final da pontuação das atividades.

Pacientes com insuficiência pulmonar apresentaram cerca de 6 vezes mais chance de demandar alta carga de trabalho de enfermagem perante as vítimas que não apresentaram tal distúrbio orgânico.

Conforme descrito anteriormente, o falência pulmonar esteve presente em $100 \%$ dos pacientes na UTI que apresentaram um ou mais sistemas orgânicos acometidos conforme pesquisa que investigou a ocorrência de falência múltipla de órgãos em vítimas de trauma ${ }^{(88)}$. Dos 243 pacientes analisados em um hospital na Espanha, 65\% necessitaram de ventilação mecânica durante o atendimento da sala de emergência e, portanto, foram admitidos na UTI do trauma com alterações pulmonares $^{(105)}$. 
Análise de 287 pacientes com trauma grave submetidos a tratamento intensivo mostrou que 55,4\% tiveram contusão pulmonar, mas a presença desta lesão não se associou significativamente com mortalidade ${ }^{(102)}$.

Outra investigação evidenciou que a contusão pulmonar associada ao TCE alterou a troca gasosa dos pacientes na UTI, mas não acentuou a morbidade e mortalidade das vítimas quando comparadas aos doentes com TCE isolado ${ }^{(155)}$.

Corroborando com esses achados, dos 1.993 pacientes traumatizados admitidos na UTI, 45,2\% apresentaram disfunção respiratória, seguida da coagulopatia $(44,1 \%)$. Entretanto, na análise de regressão logística, apenas a presença de insuficiência renal (OR 29,5) e escore APACHE II $\geq 25$ (OR 34,6) geraram impacto na mortalidade dos pacientes na terapia intensiva ${ }^{(114)}$.

Esses resultados mostram que a presença de insuficiência pulmonar não está correlacionada com a mortalidade das vítimas de trauma. Entretanto, a necessidade de ventilação mecânica está diretamente associada à ocorrência de infecção. Pesquisa que investigou processos infecciosos em vítimas de trauma em tratamento intensivo mostrou que a pneumonia foi a infecção mais comum (49\%) e que, dos 40 pacientes que desenvolveram infecção nosocomial, $90 \%$ foram submetidos à ventilação mecânica em algum momento da internação na UTI ${ }^{(89)}$.

Quando se analisa pacientes admitidos em unidade crítica por diversas causas, pesquisas revelam que insuficiências renais prevalecem, seguidas das pulmonares, conforme identificadas pelo sistema $\operatorname{LODS}^{(143,146)}$. Na investigação dos desfechos na UTI, a disfunção pulmonar apresentou associação estatisticamente significante com a mortalidade na unidade ${ }^{(146)}$.

Embora as vítimas de trauma apresentem comportamento diferente dos outros tipos de pacientes na UTI em relação à mortalidade associada à falência pulmonar, os estudos citados anteriormente mostram que esta disfunção é altamente frequente nesses pacientes.

Nesta investigação, tal disfunção orgânica gerou impacto na carga de trabalho de enfermagem. Na prática clínica, a assistência de enfermagem prestada aos pacientes com disfunção pulmonar é voltada à vigilância do paciente, sendo muitas vezes necessário monitorização contínua à beira do leito por mais tempo em virtude de agitação do paciente, risco de extubação acidental e desconforto do doente durante a realização da ventilação não invasiva. 
Além disso, pacientes intubados e com sedação contínua necessitam de maior número de profissionais de enfermagem para a realização da atividade de mobilização e posicionamento. Intervenções de suporte ventilatório, que englobam oxigenoterapia, ventilação assistida, cuidado com vias aéreas artificiais e tratamento para melhora da função pulmonar, entre outras, são altamente frequentes nessas vítimas.

Em síntese, todas essas intervenções de enfermagem citadas, ao serem pontuadas no instrumento NAS, conferem aumento da demanda de cuidados de enfermagem na soma final dos pontos do escore.

Em relação ao gênero, o resultado do atual estudo mostrou que a chance de homens apresentarem alta carga de trabalho de enfermagem foi cerca de 3 vezes maior em relação ao sexo oposto.

Resultado semelhante foi encontrado em uma pesquisa na qual o sexo feminino foi um fator protetor para o aumento da carga de trabalho de enfermagem analisada em uma UTI cardiológica. As mulheres admitidas nesta unidade tinham uma redução de 2,996 pontos no escore NAS quando comparadas aos homens ${ }^{(59)}$.

Não existem estudos que investiguem comparativamente o gênero segundo a demanda de cuidados de enfermagem requerida por vítimas de trauma. Entretanto, resultados de algumas investigações serão comentados, considerando que a mortalidade, assim como a gravidade, tem a associação com a carga de trabalho de enfermagem requerida pelos pacientes ${ }^{(55-56,144,154)}$.

Pesquisa que analisou 621 pacientes que morreram após 48 horas do evento traumático identificou, na regressão logística, que as variáveis ECG1 $<8$, ISS $>25$, trauma penetrante, sexo masculino, pneumonia e transfusão sanguínea acima de 15 unidades foram preditores independentes para mortalidade dessas vítimas, tendo sido a chance de pacientes de sexo masculino morrerem aproximadamente $2 \%$ maior do que as mulheres ${ }^{(156)}$.

Outro estudo que investigou 20.261 vítimas admitidas em três Centros de Trauma nos Estados Unidos concluiu que homens jovens ( $<50$ anos) tiveram probabilidade $27 \%$ maior de morrer do que as mulheres jovens $(<50$ anos $)$ que apresentavam gravidade do trauma semelhante ${ }^{(157)}$.

Corroborando com os achados dos estudos anteriores, pesquisa que investigou o impacto de comorbidades no tempo e na localização das mortes de 
6.839 vítimas de trauma contuso mostrou que, das 463 mortes ocorridas na casuística analisada, 45,8\% ocorreram na UTI, sendo a frequência de óbitos na unidade crítica dos pacientes do sexo masculino significativamente maior que as mulheres $(\mathrm{p}<0,005)^{(158)}$.

Em relação à associação entre mortalidade e carga de trabalho de enfermagem em UTI, algumas pesquisas analisaram a mortalidade de pacientes após alta da UTI e evidenciaram que esses doentes consumiram maior carga de trabalho no último dia de permanência na unidade crítica comparados aos sobreviventes à internação hospitalar ${ }^{(159-160)}$. Essa necessidade de investigar a relação entre desfechos que ocorreram após alta da UTI e as características apresentadas pelo paciente durante a permanência na unidade crítica é desencadeada pela preocupação da equipe em atender as demandas do paciente em outras unidades e manter a mesma qualidade da assistência intensiva no período após a alta da UTI.

Nesse propósito, identificou-se nesta investigação um modelo de estimativa da carga de trabalho de enfermagem na alta da UTI. Na análise inicial, os resultados mostraram que os valores do NAS na alta se correlacionaram positiva e significativamente com a gravidade do trauma mensurada pelo ISS e NISS, risco de morte calculado pelos índices SAPS II e LODS na admissão da UTI, bem como número de sistemas comprometidos conforme o LODS nesse período. Diferença significativa foi encontrada entre as médias do NAS requerido pelos sobreviventes na saída da UTI segundo a presença de insuficiência pulmonar na admissão nessa unidade.

No modelo final, apenas o SAPS II e o NISS exerceram influência sobre a carga de trabalho de enfermagem desses pacientes. Para cada ponto do risco de morte calculado pelo SAPS II na admissão da UTI, houve um aumento de 0,188 ponto no NAS nas últimas 24 horas de internação na unidade crítica. Para o NISS, esse aumento do NAS foi 0,193 ponto, considerando o aumento de cada ponto do índice de gravidade do trauma.

Foram encontradas duas pesquisas que exploraram a carga de trabalho de enfermagem requerida por pacientes nas últimas 24 horas de permanência na UTI perante diferentes desfechos ${ }^{(52,57)}$.

Dos 600 pacientes internados em 4 UTI gerais, identificou-se que 20\% morreram durante a permanência na unidade. Dos sobreviventes, os resultados da 
análise do destino após alta da UTI mostraram que os valores da NAS calculados nas primeiras e últimas 24 horas de permanência na unidade foram mais elevados nos doentes encaminhados para unidades semi-intensivas do que naqueles transferidos para unidades de internação. $\mathrm{Na}$ análise de regressão múltipla, os fatores relacionados ao encaminhamento desses pacientes para unidades semi-intensivas foram idade e SAPS II. Pacientes com 60 anos ou mais tiveram 1,65 vez mais chance de ser encaminhados à unidade semi-intensiva do que doentes com menos de 60 anos. Além disso, cada ponto do risco de morte calculado pelo SAPS II na admissão da UTI aumentou a chance de o paciente ser encaminhado a esta unidade em $2 \%{ }^{(57)}$.

Outro estudo investigou os fatores associados a óbito e readmissão na UTI e identificou que valores do NAS, SAPS II e LODS mais elevados no último dia de internação na unidade estiveram associados à mortalidade e que pacientes que permaneceram mais tempo internados tiveram mais chance de morrer na UTI. Entretanto, as pontuações mais altas do NAS e LODS calculadas na admissão do paciente e apontadas como fator de risco de óbito na análise univariada foram fatores protetores para a ocorrência de óbito na UTI quando analisados conjuntamente com as demais variáveis. Antecedentes de hepatite aumentaram a chance de readmissão na terapia intensiva, ao passo que a maior pontuação NAS identificada na alta da UTI diminuiu esse risco ${ }^{(52)}$.

Esses resultados mostraram a importância de estimar a carga de trabalho de enfermagem na saída do paciente da UTI, uma vez que representou variável de destaque em relação aos desfechos analisados.

Nota-se também nesses estudos a importância do SAPS II na identificação dos fatores associados ao óbito ${ }^{(52)}$ ou unidade de destino ${ }^{(57)}$ na análise de pacientes internados em UTI por causas diversas.

Nesta investigação, o SAPS II esteve associado à alta carga de trabalho de enfermagem na admissão na UTI e contemplou o modelo de estimativa do NAS dos sobreviventes na alta da unidade crítica. Diante desses resultados e da facilidade de sua aplicação, os enfermeiros de terapia intensiva que atendem pacientes traumatizados devem considerar a possibilidade de utilizá-lo como um dos parâmetros de sua prática.

O NISS associou-se significativamente com alta carga de trabalho de enfermagem na admissão da UTI, mas não foi contemplado na regressão por 
prejudicar o ajuste do modelo final deste estudo. Entretanto, na análise dos sobreviventes, o índice mostrou sua importância na estimativa da carga de trabalho dessas vítimas na saída da UTI.

Pesquisas que aplicaram o NISS em pacientes internados em UTI objetivaram, principalmente, testar a performance do índice perante o ISS ${ }^{(15,94-96)}$ ou outros índices de gravidade ${ }^{(78)}$, com resultados conflitantes.

O NISS apresentou melhor desempenho na análise das variáveis tempo de internação hospitalar ${ }^{(94-95)}$, admissão na $\mathrm{UTI}^{(95)}$, necessidade de ventilação mecânica $^{(96)}$ e mortalidade ${ }^{(94)}$ em relação ao ISS. Entretanto, outra pesquisa apontou melhor performance do ISS na previsão de admissão em UTI nos indivíduos com idade inferior a 65 anos $^{(15)}$.

Os resultados da comparação entre índices de gravidade do trauma (ISS e NISS) e índices de gravidade do paciente (SAPS II e LODS) evidenciaram que ISS e NISS não mostraram boa capacidade discriminatória para ocorrência de óbito na UTI, diferentemente do SAPS II e LODS, que apresentaram melhor performance para estimar esta variável ${ }^{(78)}$.

Revisão bibliográfica sobre os 10 anos de utilização do NISS mostrou evidências favoráveis ao índice; porém, ressaltou que a comunidade científica continua resistente na substituição do ISS pelo NISS ${ }^{(161)}$.

Algumas pesquisas realizadas em UTI sugerem a combinação de índices de gravidade do trauma e do paciente na predição de mortalidade das vítimas de trauma ${ }^{(81-82)}$.

Estudo que analisou 5.538 pacientes internados em terapia intensiva mostrou que a performance para prognosticar resultados do Trauma and Injury Severity Score (TRISS) e SAPS II foi ruim quando os índices foram analisados isoladamente. Entretanto, a combinação dos índices, denominada TRISS-SAPS, melhorou o ajuste de risco, sendo indicada para avaliar a vítima grave na UTI e acompanhar sua evolução $^{(82)}$.

Outra pesquisa também mostrou que a combinação do TRISS com o SAPS II aumentou a acurácia na predição de mortalidade de pacientes com ISS > 16 $\operatorname{pontos}^{(81)}$.

Não foram encontrados estudos que analisassem a combinação de índices de gravidade para previsão da carga de trabalho de enfermagem requerida pelas vítimas 
de trauma em UTI. Porém, os resultados da atual pesquisa apontam para a combinação do NISS e SAPS II para essa finalidade.

A possibilidade de estimar a carga de trabalho de enfermagem dos pacientes que terão alta da UTI contribui para o estabelecimento de parâmetros facilitadores à equipe das unidades que receberão a vítima, no sentido de dimensionar corretamente o pessoal de enfermagem e garantir a qualidade da assistência prestada.

$\mathrm{Na}$ aplicação dos resultados desta investigação algumas limitações devem ser consideradas: a amostra incluiu pacientes de uma única instituição, centro de referência para o atendimento às vítimas de trauma, trazendo restrições para a generalização dos resultados. Ademais, ausência de unidade semi-intensiva na instituição pode ter influenciado os valores do NAS na alta da UTI e ter resultado em menores escores se comparados com hospitais que contam com este tipo de unidade.

Deve-se ainda considerar que a carga de trabalho de enfermagem não é pautada exclusivamente nos cuidados requeridos pelo paciente, uma vez que pode ser influenciada pela condição emocional e pessoal do profissional e pelo ambiente de trabalho no qual ele está inserido, fatores esses não analisados nesta pesquisa.

Os resultados desta pesquisa, na medida em que analisa fatores associados à alta carga de trabalho na UTI e identifica um padrão de intervenções de enfermagem realizadas e um modelo estimativo da demanda de cuidados requerida pelas vítimas de trauma sobreviventes, trazem valiosas contribuições não somente à enfermagem intensiva, mas também para a equipe que dará continuidade aos cuidados às vítimas após a alta da unidade crítica. Além disso, novas perspectivas de análise e adequação dos recursos humanos podem ser repensadas.

Portanto, este estudo contribuirá para prática clínica das equipes que prestam assistência às vítimas de trauma, fornecendo subsídios que auxiliarão no planejamento da assistência com vistas a um padrão de excelência no atendimento e melhoria da sobrevida e qualidade de vida do traumatizado. 


\section{CONCLUSÕES}

A análise dos dados desta investigação, realizada com uma amostra de 200 vítimas de trauma admitidas na UTI, permitiu as seguintes conclusões:

\subsection{Quanto à caracterização das vítimas}

Houve predomínio de pacientes do sexo masculino (82,0\%), procedentes do Centro Cirúrgico $(70,0 \%)$ e submetidos à cirurgia não programada $(66,5 \%)$. As médias da idade e do índice de comorbidade de Charlson foram 40,7 (dp=18,6) e 0,6 $(\mathrm{dp}=1,4)$, respectivamente. O trauma contuso prevaleceu na amostra $(94,5 \%)$ e a mais frequente causa externa foi o acidente de transporte $(57,5 \%)$, com destaque para o envolvimento de motociclistas $(27,5 \%)$ e pedestres ou ciclistas $(20,0 \%)$. As quedas perfizeram $31,0 \%$ da casuística.

Com relação à gravidade do trauma, verificou-se média de 19,3 (dp=9,1) para o ISS e 27,1 $(\mathrm{dp}=9,9)$ para o NISS. O valor médio do número de lesões AIS $\geq 3$ foi $3,1(\mathrm{dp}=1,8)$ e de regiões corpóreas acometidas, $2,7(\mathrm{dp}=1,3)$. Pacientes com MAIS igual a $3(65,0 \%)$ prevaleceram na amostra. A região da cabeça e pescoço foi a mais frequente, tanto na análise da localização das lesões AIS $\geq 3(65,5 \%)$ quanto na identificação da região corpórea mais gravemente lesada $(64,0 \%)$.

$\mathrm{Na}$ análise da gravidade do paciente de UTI, identificou-se que a média do risco de morte calculado pelo APACHE II foi 25,6\% (dp=19,1); pelo SAPS II, 22,9\% $(\mathrm{dp}=22,6)$; e pelo LODS, 21,1\% ( $\mathrm{dp}=20,1)$. A maioria das vítimas apresentou insuficiência pulmonar $(76,5 \%)$ e/ou neurológica $(69,0 \%)$, conforme identificado pelo LODS.

Referente à carga de trabalho de enfermagem, maiores valores médios do NAS foram identificados na admissão da UTI $(71,3)$ perante a demanda de cuidados requerida pelos pacientes da saída da unidade $(57,4)$. Os valores do NAS calculado entre os pacientes que morreram na UTI foram superiores aos sobreviventes, tanto nas primeiras (médias de 80,6 e 69,2, respectivamente) quanto nas últimas 24 horas de permanência na unidade (médias de 109,3 e 45,2, respectivamente).

A permanência na UTI foi, em média, de 13,6 dias $(\mathrm{dp}=14,6)$, e o tempo de internação hospitalar médio alcançou 35,9 dias $(\mathrm{dp}=50,9)$. O intervalo de tempo entre a admissão no hospital e na UTI foi de 29,4 horas $(\mathrm{dp}=58,1)$. Um total de 38 vítimas 
$(19,0 \%)$ evoluiu a óbito na unidade e, dos sobreviventes, a maioria $(61,5 \%)$ foi encaminhada às Unidades de Internação da instituição.

\subsection{Quanto ao padrão de intervenções de enfermagem realizadas na admissão das vítimas de trauma em UTI}

A análise do dendograma permitiu estabelecer 44 agrupamentos e identificar um grupo com 136 vítimas (68\% da casuística) submetidas a intervenções de enfermagem similares. Este foi o grupo que apontou o padrão de intervenções realizadas em vítimas de trauma nas primeiras 24 horas de permanência na UTI.

Com relação às intervenções de enfermagem classificadas conforme complexidade em sua execução (monitorização e controles; procedimentos de higiene; mobilização e posicionamento; suporte e cuidado aos familiares e pacientes e tarefas administrativas e gerenciais), verificou-se que as vítimas de trauma necessitaram frequentemente de cuidados além do normalmente requerido por pacientes de UTI nas intervenções monitorização e controles (79,4\% das vítimas), procedimentos de higiene (36,0\% das vítimas) e mobilização e posicionamento (100,0\% das vítimas).

Quanto às demais intervenções, vale salientar que a totalidade ou quase totalidade das vítimas foram submetidas a investigações laboratoriais; medicação, exceto drogas vasoativas; cuidados com drenos; suporte respiratório e medida quantitativa do débito urinário. Foi muito frequente (> $80 \%$ dos casos) o cuidado com vias aéreas artificiais e o tratamento para melhora da função pulmonar.

\subsection{Quanto à identificação dos fatores associados à alta carga de trabalho no primeiro dia de internação na UTI}

Houve diferença estatisticamente significante entre os grupos analisados (alta e média/baixa carga) em relação às seguintes variáveis: ISS, NISS, número de regiões corpóreas acometidas, localização (extremidades ou cintura pélvica) e número das lesões AIS $\geq 3$, risco de morte calculado pelos índices APACHE II, SAPS II e LODS, número de sistemas comprometidos, além da presença de insuficiências cardiológica, neurológica, renal e pulmonar conforme o LODS.

$\mathrm{Na}$ determinação dos fatores associados à alta carga de trabalho de enfermagem no primeiro dia de internação na UTI, as variáveis gênero, presença de 
insuficiência pulmonar, número de regiões corpóreas acometidas e risco de morte calculado pelo SAPS II foram as que permitiram o melhor ajuste do modelo de regressão logística. Indivíduos do sexo masculino e aqueles com insuficiência pulmonar tiveram maior chance de demandar alta carga de enfermagem perante as vítimas do sexo feminino e sem falência deste sistema. A probabilidade de ocorrer alta carga de trabalho foi $2 \%$ maior para cada aumento de um ponto no valor do risco de morte segundo SAPS II. Além disso, o acréscimo de uma região corpórea lesada aumentou em 33\% a chance da vítima requerer alta carga de trabalho de enfermagem.

A análise da capacidade preditiva deste modelo de regressão logística pela curva ROC resultou em área sob a curva de 0,763 , indicando satisfatória capacidade preditiva.

\subsection{Quanto ao modelo para estimar a carga de trabalho de enfermagem requerida pelos sobreviventes na alta da UTI}

Houve significativa correlação entre os valores do NAS dos sobreviventes na alta da UTI e as variáveis ISS, NISS, risco de morte calculado pelos índices SAPS II e LODS e número de sistemas comprometidos conforme o LODS. Além disso, a presença de insuficiência pulmonar também se associou de forma estatisticamente significativa com a média do NAS.

As variáveis NISS e risco de morte segundo SAPS II contemplaram o modelo final da regressão linear, permitindo definir a seguinte fórmula para estimar a carga de trabalho de enfermagem requerida pelos sobreviventes na alta da UTI:

NAS alta $=37,171+0,188$ (risco de morte na admissão segundo SAPS II) $+0,193$

O gráfico normal de probabilidade indicou que o componente aleatório do modelo de regressão para estimar a carga de trabalho de enfermagem requerida pelos sobreviventes na alta da UTI foi adequado. 


\section{REFERÊNCIAS}

1. Brasil. Ministério da Saúde. Datasus. CID -10 - Classificação estatística internacional de doenças e problemas relacionados à saúde. Causas externas de morbidade e de mortalidade [texto na Internet]. Brasília; 2012 [citado 2012 jan 10]. Disponível em: http://www.datasus.gov.br/cid10/v2008/cid10.htm

2. Brasil. Ministério da Saúde. Datasus. Informações de saúde. Estatísticas de mortalidade. Óbitos por ocorrência segundo causas externas no Brasil [texto na Internet]. Brasília; 2012 [citado 2012 jan 10]. Disponível em: http://www.tabnet.datasus.gov.br/cgi/tabcgi.exe?simp/cnv/obtuf.def.

3. Gross T, Schüepp M, Attenberger C, Pargger H, Amsler F. Outcome in polytraumatized patients with and without brain injury. Acta Anaesthesiol Scand. In press 2012.

4. Khan F, Amatya B, Hoffman K. Systematic review of multidisciplinary rehabilitation in patients with multiple trauma. Br J Surg. 2012;99(Supl 1):88-96.

5. Brasil. Ministério da Saúde. Datasus. Informações de saúde. Estatísticas de mortalidade. Óbitos por ocorrência por faixa etária segundo causas externas no Brasil [texto na Internet]. Brasília; 2012 [citado 2012 jan 10]. Disponível em: http://tabnet.datasus.gov.br/cgi/tabcgi.exe?sim/cnv/ext10uf.def

6. Acosta JA, Yang JC, Winchell RJ, Simons RK, Fortlage DA, HollingsworthFridlund P, et al. Lethal injuries and time to death in a Level I Trauma Center. J Am Coll Surg. 1998;186(5):528-33.

7. Muñoz Céspedes JM, Paúl Lapedriza N, Pelegrín Valero C, Tirapu Ustarroz J. Factores de pronóstico en los traumatismos craneoencefálicos. Rev Neurol. 2001;32(4)351-64.

8. Miller RS, Patton M, Graham RM, Hollins D. Outcomes of trauma patients who survive prolonged lengths of stay in the Intensive Care Unit. $\mathrm{J}$ Trauma. 2000;48(2):229-34. 
9. Vazquez Mata G, Rivera Fernandez R, Perez Aragon A, Gonzalez Carmona A, Fernandez Mondejar E, Navarrete Navarro P. Analysis of quality of life in polytraumatized patients two years after discharge from an intensive care unit . J Trauma. 1996;41(2):326-32.

10. Jorge MHPM, Koizumi MS. Gastos governamentais do SUS com internações hospitalares por causas externas: análise no Estado de São Paulo, 2000. Rev Bras Epidemiol. 2004;7(2):228-38.

11. Morris JA Jr, Sanchez AA, Bass SM, MacKenzie EJ. Trauma patients return to productivity? J Trauma. 1991;31(6):827-33.

12. Holtslag HR, Post MW, van der Werken C, Lindeman E. Return to work after major trauma. Clin Rehabil. 2007;21(4):373-83.

13. Livingston DH, Tripp T, Biggs C, Lavery RF. A fate worse tha death? Long-term outcome of trauma patients admitted to the surgical intensive care unit. J Trauma. 2009;67(2):341-8.

14. Brenneman FD, Redelmeier DA, Boulanger BR, McLellan BA, Culhane JP. Long-term outcomes in blunt trauma: who goes back to work? J Trauma. 1997;42(5):778-81.

15. Tamim H, Al Hazzouri AZ, Mahfoud Z, Atoui M, El-Chemaly S. The Injury Severity Score or the New Injury Severity Score for predicting mortality, intensive care unit admission and length of hospital stay: experience from a university hospital in a developing country. Injury. 2008;39(1):115-20.

16. Lavoie A, Moore L, LeSage N, Liberman M, Sampalis JS. The Injury Severity Score or the New Injury Severity Score for predicting intensive care unit admission and hospital length of stay? Injury.2005; 36(4):477-83.

17. Domingues CA, Sousa RMC, Nogueira LS, Poggetti RS, Fontes B, Muñoz D. The role of the New Trauma and Injury Severity Score (NTRISS) for survival prediction. Rev Esc Enferm USP. 2011;45(6):1350-55.

18. Ong AW, Omert LA, Vido D, Goodman BM, Protetch J, Rodriguez A, et al. Characteristics and outcomes of trauma patients with ICU lengths of stay 30 days and greater: a seven-year retrospective study. Crit Care. 2009;13(5):R154.

19. Pereira Júnior GA, Coletto FA, Martins MA, Marson F, Pagnano RCL, Dalri MCB, et al. O papel da Unidade de Terapia Intensiva no manejo do trauma. Medicina (Ribeirão Preto). 1999;32(4):419-37. 
20. Park CA, McGwin G Jr, Smith DR, May AK, Melton SM, Taylor AJ, et al. Trauma-specific intensive care units can be cost effective and contribute to reduced hospital length of stay. Am Surg. 2001;67(7):665-70.

21. Brasil. Ministério da Saúde. Portaria no 3432 de 12 de agosto de 1998. Estabelece critérios de classificação entre diferentes Unidades de Tratamento Intensivo - UTI. Brasília; 1998 [citado 2011 set 14]: Diponível em: http://dtr2001.saude.gov.br/sas/PORTARIAS/PORT98/GM/PRT-3432.pdf

22. Moerer O, Plock E, Mgbor U, Schmid A, Schneider H, Wischnewsky MB, et al. A German national prevalence study on the cost of intensive care: an evaluation from 51 intensive care units. Crit Care. 2007;11(3):R69.

23. Havill JH, Caspari M, McConnell H, Alexander M, Montgomery C. Charging for intensive care using direct nursing hours as the cost marker. Anaesth Intensive Care. 1997;25(4):372-7.

24. Telles SCR, Castilho V. Custo de pessoal na assistência de enfermagem em Unidade de Terapia Intensiva. Rev Latino Am-Enfermagem. 2008;15(5):1005-9.

25. Fugulin FMT, Lima AFC, Castilho V, Bochembuzio L, Costa JA, Castro L, et al. Custo da adequação quantitativa de profissionais de enfermagem em Unidade Neonatal. Rev Esc Enferm USP. 2011:45(spe):1582-8.

26. Jakob SM, Rothen HU. Intensive care 1980-1995: change in patient characteristics, nursing workload and outcome. Intensive Care Med. 1997;23(11):1165-70.

27. Aiken LH, Clarke SP, Sloane DM, Sochalski J, Silber JH. Hospital nurse staffing and patient mortality, nurse burnout and job dissatisfaction. JAMA. 2002;288(16):1987-93.

28. Gonçalves LA, Garcia PC, Toffoleto MC, Telles SCR, Padilha KG. Necessidades de cuidados de enfermagem em Terapia Intensiva: evolução diária dos pacientes segundo o Nursing Activities Score (NAS). Rev Bras Enferm. 2006;59(1):56-60.

29. Padilha KG, Sousa RMC, Garcia PC, Bento ST, Finardi EM, Hatarashi RHK. Nursing workload and staff allocation in an intensive care unit: a pilot study according to Nursing Activities Score (NAS). Intensive Crit Care Nurs. 2010;26(2):108-13.

30. Inoue KC, Matsuda LM. Dimensionamento de pessoal de enfermagem em Unidade de Terapia Intensiva para adultos. Acta Paul Enferm. 2010;23(3):379-84. 
31. Queijo AF, Padilha KG. Instrumento de medida da carga de trabalho de Enfermagem em Unidade de Terapia Intensiva: Nursing Activities Score (NAS). Rev Paul Enferm. 2004;23(2):114-22.

32. Ducci AJ, Zanei SSV, Whitaker IY. Carga de trabalho de enfermagem para quantificar proporção profissional de enfermagem/paciente em UTI cardiológica. Rev Esc Enferm USP.2008;42(4):673-80.

33. Conishi RMY, Gaidzinski RR. Nursing Activities Score (NAS) como instrumento para medir carga de trabalho de enfermagem em UTI adulto. Rev Esc Enferm USP. 2007;41(3):346-54.

34. Gaidzinski RR. Dimensionamento de pessoal de enfermagem em instituições hospitalares [tese livre-docência]. São Paulo: Escola de Enfermagem, Universidade de São Paulo; 1998.

35. Frade Mera MJ, Vinagre Gaspar R, Zaragoza García I, Viñas Sánchez S, Antúnez Melero E, Álvarez González S, et al. Síndrome de burnout em distintas Unidades de Cuidados Intensivos. Enferm Intensiva. 2009;20(4):131-40.

36. Saulnier F, Duhamel A, Descamps JM, de Pouvourville G, Durocher A, Blettery $\mathrm{B}$, et al. Indicateur simplifé de la charge en soins spécifique à la réanimation: le PRN réa. Réan Urg. 1995;4(5):559-69.

37. Comission d'Évaluation de la Société de Réanimation de Langue Française. Utilisation de Lindice de gravité simpliflié et du systéme OMEGA. Réan Soins Intens Méd Urg. 1986;2:219-21.

38. Italian Multicenter Group of ICU research (GIRTI). Time Oriented Score System (TOSS): a method for direct and qualitative assessment of nursing workload for ICU patients. Intensive Care Med. 1991;17(6):340-5.

39. Cullen DJ, Civetta JM, Briggs BA, Ferrara LC. Therapeutic Intervention Scoring System: a method for quantitative comparison of patient care. Crit Care Med. 1974;2(2):57-60.

40. Keene AR, Cullen DJ. Therapeutic Intervention Scoring System: update 1983. Crit Care Med. 1983;11(11):1-3.

41. Miranda DR, de Rijk A, Schaufeli W. Simplified Therapeutic Intervention Scoring System: the TISS-28 itens - results from a multicenter study. Crit Care Med. 1996;24(1):64-73. 
42. Miranda DR, Moreno R, Iapichino G. Nine equivalents of nursing manpower use score (NEMS). Intensive Care Med.1997;23(7):760-5.

43. Vincent JL, Moreno R. Clinical review: scoring systems in the critically ill. Crit Care. 2010;14(2):207.

44. Miranda DR, Nap R, Rijk A de, Schaufeli W, Iapichino G. Nursing activities score. Crit Care Med. 2003;31(2):374-82.

45. Queijo AF, Padilha KG. Nursing Activities Score (NAS): adaptação transcultural e validação para a língua portuguesa. Rev Esc Enferm USP. 2009;43(esp):1018-25.

46. Brasil. Ministério da Saúde. Resolução RDC n. 7, de 24 de fevereiro de 2010. Dispõe sobre os requisitos mínimos para funcionamento de Unidades de Terapia Intensiva e dá outras providências [legislação na Internet]. Brasília; 2010 [citado 201218 fev]. Disponível em: http://www.ccih.med.br/arqs_legislacao/RDC-072010-UTI-ANVISA.pdf?MOD=AJPERES

47. Ciampone JT, Gonçalves LS, Maia FOM, Padilha KG. Necessidades de cuidados de enfermagem e intervenções terapêuticas em Unidade de Terapia Intensiva: estudo comparativo entre pacientes idosos e não idosos. Acta Paul Enferm. 2006;19(1):2835.

48. Sousa RMC, Padilha KG, Nogueira LS, Miyadahira AMK, Oliveira VCR. Carga de trabalho de enfermagem requerida por adultos, idosos e muito idosos em Unidade de Terapia Intensiva. Rev Esc Enferm USP. 2009;43(esp 2):1284-91.

49. Coelho FUA, Queijo AF, Andolhe R, Gonçalves LA, Padilha KG. Carga de trabalho de enfermagem em Unidade de Terapia Intensiva de cardiologia e fatores clínicos associados. Texto \& Contexto Enferm. 2011;20(4):735-41.

50. Nogueira LS, Santos MR, Mataloun SE, Moock M. Nursing Activities Score: comparação com o índice APACHE II e a mortalidade em pacientes admitidos em Unidade de Terapia Intensiva. Rev Bras Ter Intensiva. 2007;19(3):327-30.

51. Cremasco MF, Wenzel F, Sardinha FM, Zabei SSV, Whitaker IY. Úlcera por pressão: risco e gravidade do paciente e carga de trabalho de enfermagem. Acta Paul Enferm. 2006;19(esp 70 anos):897-902.

52. Silva MCM, Sousa RMC, Padilha KG. Fatores associados ao óbito e a readmissão em Unidade de Terapia Intensiva. Rev Latino Am-Enfermagem. 2011;19(4);911-9. 
53. Balsanelli AP, Cunha ICKO, Whitaker IY. Estilos de liderança de enfermeiros em Unidade de Terapia Intensiva: associação com perfil pessoal, profissional e carga de trabalho. Rev Latino Am-Enfermagem. 2009;17(1);28-33.

54. Gonçalves LA, Padilha KG. Fatores associados à carga de trabalho de enfermagem em Unidade de Terapia Intensiva. Rev Esc Enferm USP. 2007;41(4):645-52.

55. Padilha KG, Sousa RM, Queijo AF, Mendes AM, Miranda DR. Nursing activities score in the intensive care unit: analysis of the related factors. Intensive Crit Care Nurs. 2008;24(3):197-204.

56. Sousa CR, Gonçalves LA, Toffoleto MC, Leão K, Padilha KG. Preditores da demanda de trabalho de enfermagem para idosos em Unidade de Terapia Intensiva. Rev Latino Am-Enfermagem. 2008;16(2);218-23.

57. Silva MCM, Sousa RMC, Padilha KG. Destino do paciente após alta da Unidade de Terapia Intensiva: unidade de internação ou intermediária? Rev Latino AmEnfermagem. 2010;18(2);224-32.

58. Ducci AJ, Padilha KG. Nursing Activities Score: estudo comparativo da aplicação retrospectiva e prospectiva em unidade de terapia intensiva. Acta Paul Enferm. 2008;21(4):581-7.

59. Queijo AF. Estudo comparativo da carga de trabalho de enfermagem em Unidades de Terapia Intensiva Geral e Especializadas, segundo o Nursing Activities Score (NAS) [tese]. São Paulo: Escola de Enfermagem, Universidade de São Paulo; 2008.

60. Adell AB, Campos RA, Rey MC, Bellmunt JQ, Rochera ES, Muñoz JS, et al. Nursing Activity Score (NAS). Nuestra experiencia con un sistema de cómputo de cargas de enfermería basado en tiempos. Enferm Intensiva. 2005;16(4):164-73.

61. Adell AB, Campos RA, Bou MY, Bellmunt JQ, García CG, Canuto MS, et al. Cargas de trabajo asistencial en pacientes críticos. Estudio comparativo NEMS frente a NAS. Enferm Intensiva. 2006;17(2):67-77.

62. Stafseth SK, Solms D, Bredal IS. The characterisation of workloads and nursing staff allocation in intensive care units: a descriptive study using the Nursing Activities Score for the first time in Norway. Intensive Crit Care Nurs. 2011;27(5):290-4. 
63. Andrei AM, Moura Júnior DF, Almeida FP, Lagudis S. Índices prognósticos em terapia intensiva. In: Knobel E. Condutas no paciente grave. 3 ed. São Paulo: Atheneu; 2006. p.2055-71.

64. Knaus WA, Zimmerman JE, Wagner DP, Draper EA, Lawrence DE. APACHE acute physiology and chronic health evaluation: a physiologically based classification system. Crit Care Med. 1981;9(8):591-7.

65. Knaus WA, Draper EA, Wagner DP, Zimmerman JE. APACHE II: a severity of disease classification system. Crit Care Med. 1985;13(10):818-29.

66. Knaus WA, Wagner DP, Draper EA, Zimmerman JE, Bergner M, Bastos PG, et al. The APACHE III prognostic system: risk prediction of hospital mortality in critically ill hospitalized adults. Chest. 1991;100(6):1619-36

67. Zimmerman JE, Kramer AA, McNair DS, Malila FM. Acute Physiology and Chronic Health Evaluation (APACHE) IV: hospital mortality assessment for today's critically ill patients. Crit Care Med. 2006;34(5):1297-310.

68. Le Gall J-R, Loirat P, Alperovitch, et al. A simplified acute physiology score for ICU patients. Crit Care Med. 1984;12:975-7.

69. Le Gall J-R, Lemeshow S, Saulnier F. A new simplified acute physiology score (SAPS II) based on a European/North American Multicenter Study. JAMA. 1993; 270(24):2957-63.

70. Moreno RP, Metnitz PG, Almeida E, Jordan B, Bauer P, Campos RA, et al. SAPS 3 - From evaluation of the patient to evaluation of the intensive care unit. Part 2: development of a prognostic model for hospital mortality at ICU admission. Intensive Care Med. 2005;31(10):1345-55.

71. Lemeshow S, Teres D, Pastides H, Avrunin JS, Steingrub JS. A method for predicting and mortality of ICU patient: using objectively derives weights. Crit Care Med. 1985;13(7):519-25.

72. Lemeshow S, Teres D, Klar J, Avrunin JS, Gehlbach SH, Rapoport J. Mortality Probability Models (MPM II) based on an international cohort of intensive care unit patients. JAMA. 1993;270(20):2478-86.

73. Le Gall J-R, Klar J, Lemeshow S, Saulnier F, Alberti C, Artigas A, et al. The logistic organ dysfunction system: a new way to assess organ dysfunction in the Intensive Care Unit. JAMA.1996; 276(10):802-8. 
74. Rutledge R, Fakhry S, Rutherford E, Muakkassa F, Meyer A. Comparison of APACHE II, Trauma Score, and Injury Severity Score as predictors of outcome in critically injured trauma patients. Am J Surg. 1993;166(3):244-7.

75. Cho DY, Wang YC. Comparison of the APACHE III, APACHE II and Glasgow Coma Scale in acute head injury for prediction of mortality and functional outcome. Intensive Care Med. 1997;23(1):77-84.

76. Hyam JA, Welch CA, Harrison DA, Menon DK. Case mix, outcomes and comparison of risk prediction models for admissions to adult, general and specialist critical care units for head injury: a secondary analysis of the ICNARC Case Mix Programme Database. Crit Care. 2006;10(suppl 2:S):1-11.

77. Ulvik A, Wentzel-Larsen T, Flaatien H. Trauma patients in the intensive care: short-and long-term survival and predictors of 30-day mortality. Acta Anaesthesiol Scand.2007;51(2):171-7.

78. Nogueira LS, Sousa RMC, Domingues CA. Gravidade das vítimas de trauma, admitidas em Unidades de Terapia Intensiva: estudo comparativo entre diferentes índices. Rev Latino Am-Enfermagem. 2009;17(6):1037-42.

79. Dossett LA, Redhage LA, Sawyer RG, May AK. Revisiting the validity of APACHE II in the trauma ICU: improved risk stratification in critically injured adults. Injury. 2009:40(9):993-8.

80. Dalgiç A, Ergüngör FM, Becan T, Elhan A, Okay O, Yüksel BC. The revised Acute Physiology and Chronic Health Evaluation System (APACHE II) is more effective than the Glasgow Coma Scale for prediction of mortality in headinjured patients with systemic trauma. Ulus Travma Acil Cerrahi Derg. 2009;15(5):453-8.

81. Fueglistaler P, Amsler F, Schüepp M, Fueglistaler-Montali I, Attenberger C, Pargger H, et al. Prognostic value of Sequential Organ Failure Assessment and Simplified Acute Physiology II score compared with trauma scores in the outcome of multiple-trauma patients. Am J Surg. 2010;200(2):204-14.

82. Reiter A, Mauritz W, Jordan B, Lang T, Põlzl A, Pelinka L, et al. Improving risk adjustment in critically ill trauma patients: the TRISS-SAPS score. J Trauma. 2004;57(2):375-80. 
83. Wang SH, Wei TS, Chen CP. Prognostic analysis of patients with blunt chest trauma admitted to an Intensive Care Unit. J Formos Med Assoc. 2007;106(6):44451.

84. Wu J, Sheng L, Ma Y, Gu J, Zhang M, Gan J, et al. The analysis of risk factors of impacting mortality rate in severe multiple trauma patients with posttraumatic acute respiratory distress syndrome. Am J Emerg Med. 2008;26(4):419-24.

85. Brattström O, Granath F, Oldner A. Early predictors of morbidity and mortality in trauma patients treated in the intensive care unit. Acta Anaesthesiol Scand. 2010;54(8):1007-17.

86. Seguin P, Laviolle B, Maurice A, Leclercq C, Mallédant Y. Atrial fibrillation in trauma patients requiring intensive care. Intensive Care Med. 2006;32(7):398-404.

87. Ma YF, Sheng L, Gu J, Zhang M, Jiang GY. Analysis of clinical risk factors associated with mortality of severely multiple trauma patients with acute lung injury. Chin Med J. 2009;122(6):701-5.

88. Durham RM, Moran JJ, Mazuski JE, Shapiro MJ, Baue AE, Flint LM. Multiple organ failure in trauma patients. J Trauma. 2003;55(4):608-15.

89. Hurr H, Hawley HB, Czachor JS, Markert RJ, McCarthy MC. APACHE II and ISS scores as predictors of nosocomial infections in trauma patients. Am J Infect Control. 1999;27(2):79-83.

90. Pereira Júnior GA, Scarpelini S, Basile Filho A, Andrade JI. Índices de trauma. Medicina (Ribeirão Preto). 1999;32(4):237-50.

91. Baker SP, O`neill B, Haddon W, Long WB. The injury severity score: a method for describing patients with multiple injuries and evaluating emergency care. J Trauma. 1974;14(3):187-96.

92. Osler T, Baker SP, Long W. A modification of the injury severity score that both improves accuracy and simplifies scoring. J Trauma.1997;43(6):922-5.

93. ASSOCIATION FOR THE ADVANCEMENT OF AUTOMOTIVE MEDICE AAAM. The Abbreviated Injury Scale (AIS): 2005, update 2008. Des Plaines, Illions, 2008.

94. Harwood PJ, Giannoudis PV, Probst C, Van Griensven M, Krettek C, Pape HC. Which AIS based scoring system is the best predictor of outcome in orthopaedic blunt trauma patients? J Trauma. 2006;60(2):334-40. 
95. Balogh ZJ, Varga E, Tomka J, Süveges G, Tóth L, Simonka JÁ. The new injury severity score is a better predictor of extended hospitalization and intensive care unit admission than the injury severity score in patients with multiple orthopaedic injuries. J Orthop Trauma. 2003;17(7):508-12.

96. Honarmand A, Safavi M. The new Injury Severity Score: a more accurate predictor of need ventilator and time ventilated in trauma patients than the Injury Severity Score. Ulus Travma Acil Cerrahi Derg. 2008;14(2):110-7.

97. Lefering R, Zart M, Neugebauer EA. Retrospective evaluation of the simplified Therapeutic Intervention Scoring System (TISS-28) in a surgical Intensive Care Unit. Intensive Care Med. 2000;26(12):1794-802.

98. Padilha KG, Sousa RM, Kimura M, Miyadahira AM, da Cruz DA, Vattimo MF, et al. Nursing workload in Intensive Care Units: a study using the Therapeutic Intervention Scoring System-28 (TISS-28). Intensive Crit Care Nurs. 2007;23(3):162-9.

99. Charlson ME, Pompei P, Ales KL, MacKenzie CR. A new method of classifying prognostic comorbidity in longitudinal studies: development and validation. J Chronic Dis. 1987;40(5):373-83.

100. Miranda DR, Nap R, Rijk A, Schaufeli W, Iapichino G. Nursing activities score: instructions for use. Article additional to Reis Miranda et al. 2003. Crit Care Med.2003;31(2). In Critical Care Medicine, on line 2004.

101. Trottier V, McKenney MG, Beninati M, Manning R, Schulman CI. Survival after prolonged length of stay in a trauma intensive care unit. $\mathbf{J}$ Trauma. 2007;62(1):147-50.

102. Laudi S, Donaubauer B, Busch T, Kerner T, Bercker S, Bail H, et al. Low incidence of multiple organ failure after major trauma. Injury. 2007;38(9):1052-8.

103. Desarrollo de una herramienta de comunicación para la seguridad del paciente (Briefing). Experiencia em uma unidad de cuidados intensivos de trauma y emergencias. Fernández MC, Fuentes CG, Fernández MAA, Vázquez DT, Aznárez SB, Riera JASI. Med Intensiva. In press 2012.

104. Barmparas G, Inaba K, Georgiou C, Hadjizacharia P, Chan LS, Demetriades D, et al. Swan-Ganz cateter use in trauma patients can be reduced without negatively affecting outcomes. World J Surg. 2011;35(8):1809-17. 
105. Serviá L, Badia M, Baeza I, Montserrat N, Justes M, Cabré X, et al. Time spent in the emergency department and mortality rates in severely injured patients admitted to the intensive care unit: an observational study. J Crit Care. 2012;27(1):58-65.

106. Leung KK, Ho W, Tong KH, Yuen WK. Outcome of severely injured trauma patients at a designated trauma center in the Hong Kong Special Administrative Region. Chin Med J. 2010;123(10):1251-4.

107. Moran JL, Bristow P, Solomon PJ, George C, Hart GK, Australian and New Zealand Intensive Care Society Database Management Committee (ADMC). Mortality and length-of-stay outcomes, 1993-2003, in the binational Australian and New Zealand intensive care unit adult patient database. Crit Care Med. 2008;36(1):46-61.

108. Martin CM, Hill AD, Burns K, Chen LM. Characteristics and outcomes for critically ill patients with prolonged intensive care stays. Crit Care Med. 2005;33(9):1922-7.

109. Quach S, Hennessy DA, Faris P, Fong A, Quan H, Doig C. A comparison between the APACHE II and Charlson Index Score for predicting hospital mortality in critically ill patients. BMC Health Serv Res. 2009;9:129.

110. Oliveira ABF, Dias OM, Mello MM, Araújo S, Dragosavac D, Nucci A, et al. Fatores associados à maior mortalidade e tempo de internação prolongado em unidade de terapia intensiva de adultos. Rev Bras Ter Intensiva. 2010;22(3):250-6.

111. Japiassú AM, Cukier MS, Queiroz AGCN, Gondim CRN, Penna GLA, Almeida GF, et al. Fatores preditores precoces de reinternação em unidade de terapia intensiva. Rev Bras Ter Intensiva. 2009;21(4):353-8.

112. Williams TA, Ho KM, Dobb GJ, Finn JC, Knuiman MW, Webb SA. Changes in case-mix and outcomes of critically ill patients in an Australian tertiary intensive care unit. Anaesth Intensive Care. 2010;38(4):703-9.

113. Flores JM, Jiménez PI, Rincón MD, Márquez JA, Navarro H, Arteta D, et al. Early risk predictors factors for sepsis in patients with severe blunt trauma. Injury. 2001;32(1):5-12.

114. Ala-Kokko T, Ohtonen P, Laurila J, Martikainen M, Kaukoranta P. Development of renal failure during the initial $24 \mathrm{~h}$ of intensive care unit stay correlates with hospital mortality in trauma patients. Acta Anaesthesiol Scand. 2006;50(7):828-32. 
115. Magret M, Amaya-Villar R, Garnacho J, Lisboa T, Díaz E, Dewaele J, et al. Ventilator-associated pneumonia in trauma patients is associated with lower mortality: results from EU-VAP Study. J Trauma. 2010;69(4):849-54.

116. Franca SA, Toufen C Jr, Hovnanian AL, Albuquerque AL, Borges ER, Pizzo VR, et al. The epidemiology of acute respiratory failure in hospitalized patients: a Brazilian prospective cohort study. J Crit Care. 2011;26(3):330.e1-8.

117. Abelson-Mitchell N. Epidemiology and prevention of head injuries: literature review. J Clin Nurs. 2008;17(1):46-57.

118. Bruns J Jr, Hauser WA. The epidemiology of traumatic brain injury: a review. Epilepsia. 2003;44 Supl 10:2-10.

119. Rodrigues AS, Sousa RMC. Hospitalização por traumatismos intracranianos em relação às demais lesões por causas externas no Brasil. In: $15^{\circ}$ Simpósio Internacional de Iniciação Científica - SIICUSP; 2007 nov 28-29; Ribeirão Preto, São Paulo, Brasil.

120. Moore L, Lavoie A, Le Sage N, Bergeron E, Emond M, Liberman M, et al. Using information on preexisting conditions to predict mortality from traumatic injury. Ann Emerg Med. 2008;52(4):356-364.

121. McGwin G Jr, MacLennan PA, Fife JB, Davis GG, Rue LW. Preexisting conditions and mortality in older trauma patients. J Trauma. 2004;56(6):1291-6.

122. Grossman MD, Miller D, Scaff DW, Arcona S. When is an elder old? Effect of preexisting conditions on mortality in geriatric trauma. J Trauma. 2002;52(2):242-6.

123. Taylor MD, Tracy JK, Meyer W, Pasquale M, Napolitano LM. Trauma in the elderly: intensive care unit resource use and outcome. J Trauma. 2002;53(3):407-14.

124. Gabbe BJ, Magtengaard K, Hannaford AP, Cameron PA. Is the Charlson comorbidity index useful for predicting trauma outcomes? Acad Emerg Med. 2005;12(4):318-21.

125. Cameron CM, Purdie DM, Kliewer EV, McClure RJ. Differences in prevalence of pre-existing morbidity between injured and non-injured populations. Bull World Health Organ. 2005;83(5):345-52.

126. Toffoletto MC. Fatores associados aos eventos adversos em Unidade de Terapia Intensiva [tese]. São Paulo: Escola de Enfermagem, Universidade de São Paulo; 2008. 
127. Christensen S, Johansen MB, Christiansen CF, Jensen R, Lemeshow S. Comparison of Charlson comorbidity index with SAPS and APACHE scores for prediction of mortality following intensive care. Clinical Epidemiology. 2011;3:20311.

128. American College of Surgeons. Advanced Trauma Life Support - Student Course Manual. $8^{\text {a }}$ ed. Chicago: American College of Surgeons; 2008.

129. Sousa RMC, Ferreira Júnior AA, Ikemori SY, Souza FF, Souza RC. Vítimas de trauma crânio-encefálico internadas em unidade de terapia intensiva e enfermaria de hospital de referência da Baixada Santista. Acta Paul Enferm. 2004;17(2):201-10.

130. Chalya PL, Gilyoma JM, Dass RM, Mchembe MD, Matasha M, Mabula JB, et al. Trauma admissions to the Intensive care unit at a reference hospital in Northwestern Tanzania. Scand J Trauma Resusc Emerg Med. 2011;19:61.

131. Brasil. Ministério da Saúde. Datasus. Informações de saúde. Morbidade hospitalar do SUS por causas externas e local de internação [texto na Internet]. Brasília; 2012 [citado 2012 jan 10]. Disponível em: http://tabnet.datasus.gov.br/cgi/tabcgi.exe?sih/cnv/fiuf.def.

132. Chandran A, Sousa TR, Guo Y, Bishai D, Pechansky F. Road traffic deaths in Brazil: rising trends in pedestrian and motorcycle occupant deaths. Traffic Inj Prev. 2012;13(Supl 1):11-6.

133. Wilson JL, Herbella FAM, Takassi GF, Moreno DG, Tineli AC. Lesões fatais em trauma numa grande metrópole brasileira: um estudo de autópsias. Rev Col Bras Cir. 2011;38(2):122-6.

134. Chalfin DB, Trzeciak S, Likourezos A, Baumann BM, Dellinger RP; DELAYED study group. Impact of delayed transfer of critically ill patients from the emergency department to the intensive care unit. Crit Care Med. 2007;35(6):147783.

135. Cardoso LT, Grion CM, Matsuo T, Anami EH, Kauss IA, Seko L, et al. Impact of delayed admission to intensive care units on mortality of critically ill patients: a cohort study. Crit Care. 2011;15(1):R28.

136. Suay RN, Cela EB, Zozaya IJ, Barbará AHA, Ortega CG, Labajo JDG, et al. Even more critical medicine: a retrospective analysis of casualties admitted to the intensive care unit in the Spanish Military Hospital in Herat (Afeghnistan). Med Intensiva. 2011;35(3):157-65. 
137. Metnitz PG, Lang T, Valentin A, Steltzer H, Krenn CG, Le Gall JR. Evaluation of the logistic organ dysfunction for the assessment of organ dysfunction and mortality in critically ill patients. Intensive Care Med. 2001;27(6):992-8.

138. Committee on trauma. American College of Surgeons. Resources for optimal care of the injured patient 2006. Chicago: American College of Surgeons; 2006.

139. Jarrett LA, Emmett M. Utilizing trauma nurse practitioners to decrease length of stay. J Trauma Nurs. 2009;16(2):68-72.

140. Gennari TD, Koizumi MS. Determinação do nível de gravidade do trauma. Rev Saúde Pública. 1995;29(5):333-41.

141. Whitaker IY, Gennari TD. The difference between ISS and NISS in a series of trauma patients in Brazil. Annu Proc Assoc Adv Automot Med. 2003;47:301-9.

142. Parke TR, Henry J, Grant PT, Kennedy RL. Increased survival after serious injury in patients admitted directly to critical care areas from the accident and emergency department. Injury. 1998 Nov;29(9):697-703.

143. Timsit JF, Fosse JP, Troché G, De Lassence A, Alberti C, Garrouste-Orgeas M, et al. Calibration and discrimination by daily Logistic Organ Dysfunction scoring comparatively with daily Sequential Organ Failure Assessment scoring for predicting hospital mortality in critically ill patients. Crit Care Med. 2002;30(9):2003-13.

144. Muehler N, Oishi J, Specht M, Rissner F, Reinhart K, Sakr Y. Serial measurement of Therapeutic Intervention Scoring System-28 (TISS-28) in a surgical Intensive Care Unit. J Crit Care. 2010;25(4):620-7.

145. Beloeil H, Mazoit JX, Benhamou D, Duranteau J. Norepinephrine kinetics and dynamics in septic shock and trauma patients. Br J Anaesth. 2005;95(6):782-8.

146. Padilha KG, Sousa RMC, Silva MCM, Rodrigues AS. Disfunções orgânicas de pacientes internados em Unidades de Terapia Intensiva segundo o Logistic Organ Dysfunction System. Rev Esc Enferm USP. 2009;43(Esp 2):1250-5.

147. Kim TK, Yoon JR. Comparison of the predictive power of the LODS and APACHE II scoring Systems in a Neurological Intensive Care Unit. J Int Med Res. 2012;40(2):777-86.

148. Silva MCM. Fatores relacionados com a alta, óbito e readmissão em Unidade de Terapia Intensiva [tese]. São Paulo: Escola de Enfermagem, Universidade de São Paulo; 2007. 
149. Gonçalves LA, Padilha KG, Sousa RMC. Nursing Activities Score (NAS): a proposal for practical application in intensive care units. Intensive Crit Care Nurs. 2007;23(6):355-61.

150. Gonçalves LA. Fatores associados à carga de trabalho de enfermagem em Unidade de Terapia Intensiva de adultos no primeiro dia de internação [dissertação]. São Paulo: Escola de Enfermagem, Universidade de São Paulo; 2006.

151. Brasil. Ministério da Saúde. Resolução RDC n. 26, de 11 de maio de 2012. Altera a resolução RDC n. 07, de 24 de fevereiro de 2010, que dispõe sobre os requisitos mínimos para funcionamento de Unidades de Terapia Intensiva e dá outras providências [legislação na Internet]. Brasília; 2010 [citado 201218 fev]. Disponível em:

http://bvsms.saude.gov.br/bvs/saudelegis/anvisa/2012/rdc0026_11_05_2012.html

152. Carayon P, Alvarado CJ. Workload and patient safety among critical care nurses. Crit Care Nurs Clin North Am. 2007;19(2):121-9.

153. Cohen MM, O'Brien-Pallas LL, Copplestone C, Wall R, Porter J, Rose DK. Nursing workload associated with adverse events in the postanesthesia care unit. Anesthesiology. 1999;91(6):1882-90.

154. Yee Kwok WW, Chun Chau JP, Pau Le Low L, Thompson DR. The reliability and validity of the therapeutic activity index. J Crit Care. 2005;20(3):257-63.

155. Leone M, Albanèse J, Rousseau S, Antonini F, Dubuc M, Alliez B, et al. Pulmonary contusion in severe head trauma patients: impact on gas exchange and outcome. Chest. 2003;124(6):2261-6.

156. Mostafa G, Huynh T, Sing RF, Miles WS, Norton HJ, Thomason MH. Genderrelated outcomes in trauma. J Trauma. 2002;53(3):430-4.

157. Wohltmann CD, Franklin GA, Boaz PW, Luchette FA, Kearney PA, Richardson JD, Spain DA. A multicenter evaluation of whether gender dimorphism affects survival after trauma. Am J Surg. 2001;181(4):297-300.

158. Bamvita JM, Bergeron E, Lavoie A, Ratte S, Clas D. The impact of premorbid conditions on temporal pattern and location of adult blunt trauma hospital deaths. J Trauma. 2007;63(1):135-41.

159. Iapichino G, Morabito A, Mistraletti G, Ferla L, Radrizzani D, Reis Miranda D. Determinants of post-intensive care mortality in high-level treated critically ill patients. Intensive Care Med. 2003;29(10):1751-6. 
160. Moreno R, Miranda DR, Matos R, Fevereiro T. Mortality after discharge from intensive care: the impact of organ system failure and nursing workload use at discharge. Intensive Care Med. 2001;27(6):999-1004.

161. Nogueira LS, Domingues CA, Campos MA, Sousa RMC. Ten years of the New Injury Severity Score: is it a possible change? Rev Latino Am-Enfermagem. 2008;16(2):314-9. 


\section{APÊNDICES}

\section{Apêndice A}

HOSPITAL DAS CLÍNICAS DA FACULDADE DE MEDICINA DA UNIVERSIDADE DE

SÃO PAULO - HCFMUSP

Termo de Consentimento Livre e Esclarecido (TCLE)

Dados de identificação do sujeito da pesquisa ou responsável legal

1. Nome:

Documento de identidade $\mathrm{n}^{\circ}$

Sexo:

$\mathrm{M}$

$\mathrm{F}$

Data de nascimento: 1

Endereço: $\mathrm{N}^{\mathrm{o}}$ Apto Bairro:

Cidade: CEP: Tefefone:

2. Responsável legal:

Natureza (grau de parentesco, tutor, curador etc): Sexo: $\mathrm{M}$ $\mathrm{F}$

Documento de identidade $\mathrm{n}^{\mathrm{o}}$ Data de nascimento:

Endereço: $\mathrm{N}^{\mathrm{o}}$ Apto Bairro:

Cidade: CEP: Tefefone:

\section{Dados sobre a pesquisa}

1. Título do protocolo de pesquisa: "Vítimas de trauma admitidas em Unidade de Terapia Intensiva: características e fatores associados à carga de trabalho de enfermagem"

2. Pesquisadora executante: Lilia de Souza Nogueira; pesquisador responsável: Dr. Renato Sérgio Poggetti

3. Avaliação do risco da pesquisa: -

4. Duração da pesquisa: 6 meses

Eu discuti com a Enf ${ }^{a}$ Lilia de Souza Nogueira sobre a minha decisão em participar deste estudo. Ficaram claros para mim os objetivos do estudo, os procedimentos a serem realizados, as garantias do anonimato e da possibilidade de obter esclarecimentos sempre que achar necessário. Ficou claro também que minha participação é isenta de despesas e que tenho garantia do acesso a tratamento hospitalar quando necessário. Concordo voluntariamente em participar deste estudo e estou ciente de que poderei retirar o meu consentimento a qualquer momento, antes ou durante o mesmo, sem penalidades ou prejuízo ou perda no meu atendimento neste Serviço.

Assinatura do paciente/representante legal

$$
\begin{aligned}
& \text { Assinatura da testemunha (para casos de } \\
& \text { pacientes analfabetos, semianalfabetos, } \\
& \text { portadores de deficiência auditiva ou visual) }
\end{aligned}
$$

Declaro que obtive de forma apropriada e voluntária o Consentimento Livre e Esclarecido deste paciente ou representante legal para a participação neste estudo. 


\section{Apêndice A - continuação \\ HOSPITAL DAS CLÍNICAS DA FACULDADE DE MEDICINA DA UNIVERSIDADE DE SÃO PAULO}

O objetivo deste estudo é caracterizar pacientes admitidos em Unidade de Terapia Intensiva (UTI) e identificar os fatores associados à carga de trabalho de enfermagem. Os participantes serão as vítimas de trauma admitidas nesta UTI do hospital no período de maio de 2010 a janeiro de 2011, através da coleta de dados dos registros feitos nos prontuários.

A sua participação é voluntária, sendo garantida a liberdade de não participar ou retirar seu consentimento a qualquer momento, não implicando qualquer prejuízo na continuidade de seu tratamento na Instituição. Você terá o direito de ser mantido atualizado sobre os resultados parciais da pesquisa ou de resultados que sejam de conhecimento dos pesquisadores, caso seja de seu interesse.

Todas as informações obtidas serão analisadas em conjunto com as de outros pacientes, sendo garantido que não será divulgada a identificação de nenhum deles. Os pesquisadores firmam o compromisso de utilizar os dados obtidos somente para a elaboração de trabalhos científicos.

Não haverá despesas pessoais, nem compensação financeira relacionada à sua participação. Neste estudo, você não será submetido a nenhuma intervenção ou procedimento, além daqueles que fazem parte do seu tratamento. Em qualquer etapa desta pesquisa, você poderá ter acesso aos profissionais responsáveis pela pesquisa para esclarecimento de eventuais dúvidas: Enfermeira Lilia de Souza Nogueira, pesquisadora executante, no endereço Av. Dr. Enéas de Carvalho Aguiar, 419, Departamento ENC, telefone 9131-0447, email: lilianogueira@usp.br ou Dr. Renato Sérgio Poggetti, pesquisador responsável, no endereço Rua Dr. Ovídio Pires de Campos, 471, telefone: 3069-7125. Se você tiver alguma consideração ou dúvida sobre a ética da pesquisa, entre em contato com o Comitê de Ética em Pesquisa (CEP), Rua Ovídio Pires de Campos, 225, $5^{\circ}$ andar, telefone: 3069-6442, ramais 16, 17, 18 ou 20, fax: 3069-6442, ramal 26, e-mail: cappesq@ hcnet.usp.br.

Eu discuti com a Enf ${ }^{a}$ Lilia de Souza Nogueira sobre a minha decisão em participar deste estudo. Ficaram claros para mim os objetivos do estudo, os procedimentos a serem realizados, as garantias do anonimato e da possibilidade de obter esclarecimentos sempre que achar necessário. Ficou claro também que minha participação é isenta de despesas e que tenho garantia do acesso a tratamento hospitalar quando necessário. Concordo voluntariamente em participar deste estudo e estou ciente que poderei retirar o meu consentimento a qualquer momento, antes ou durante o mesmo, sem penalidades ou prejuízo ou perda no meu atendimento neste Serviço.

Assinatura do paciente/representante legal Assinatura da testemunha (para casos de pacientes
analfabetos, semianalfabetos, portadores de

Declaro que obtive de forma apropriada e voluntária o Consentimento Livre e Esclarecido deste paciente ou representante legal para a participação neste estudo.

Enf $^{a}$ Lilia de Souza Nogueira

Data: 
Apêndice B

Ficha de levantamento de dados de identificação e da internação do paciente

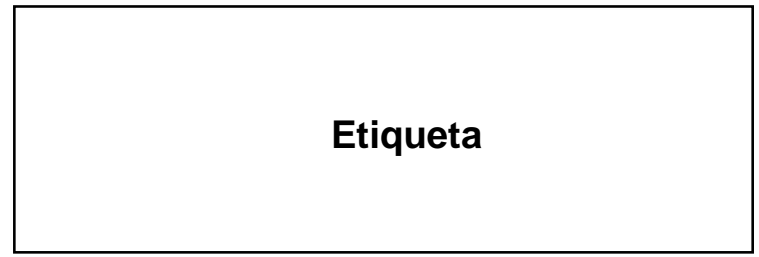

DADOS DE ADMISSÃO

Iniciais do nome:

Idade:

Gênero: ( ) F ( ) M

Data do trauma:

Causa externa:

Índice de comorbidade de Charlson

\begin{tabular}{|c|c|}
\hline Comorbidade (categoria diagnóstica) & Pontuação \\
\hline Infarto do miocárdio & $1(\mathrm{r})$ \\
\hline Insuficiência cardíaca congestiva & $1(\mathrm{r})$ \\
\hline Doença vascular periférica & $1(\mathrm{)})$ \\
\hline Doença cerebrovascular & $1(\mathrm{)}$ \\
\hline Demência & $1(\mathrm{)})$ \\
\hline Doença pulmonar crônica & $1(\mathrm{)})$ \\
\hline Doença do tecido conjuntivo & $1(\mathrm{)}$ \\
\hline Úlcera péptica & $1(\mathrm{)})$ \\
\hline Doença crônica do fígado ou cirrose & $1(\mathrm{)})$ \\
\hline Diabetes sem complicações & $1(\mathrm{)}$ \\
\hline Hemiplegia ou paraplegia & 2() \\
\hline Doença renal severa ou moderada & 2() \\
\hline Diabetes com complicações & 2() \\
\hline Tumor & 2() \\
\hline Leucemia & 2() \\
\hline Linfoma & 2() \\
\hline Doença do fígado severa ou moderada & 3() \\
\hline Tumor maligno metastático & $6($ ) \\
\hline Síndrome da imunodeficiência adquirida & $6($ ( ) \\
\hline Total de pontos & \\
\hline
\end{tabular}

\section{DADOS DE INTERNAÇÃO}

Data de internação hospitalar:

Hora:

Data de internação na UTI:

Hora:

Procedência: ( ) PS ( ) CC ( ) outra UTI ( ) UI ( ) Outros

Data e destino após saída da UTI:

Hora:

( ) Semi ( ) unidade de internação(UI) ( ) óbito ( ) transferência

Data e condições de saída hospitalar:

( ) sobrevivente

( ) não sobrevivente 
Apêndice C

Ficha de levantamento das variáveis para o cálculo do APACHE II, SAPS II e LODS

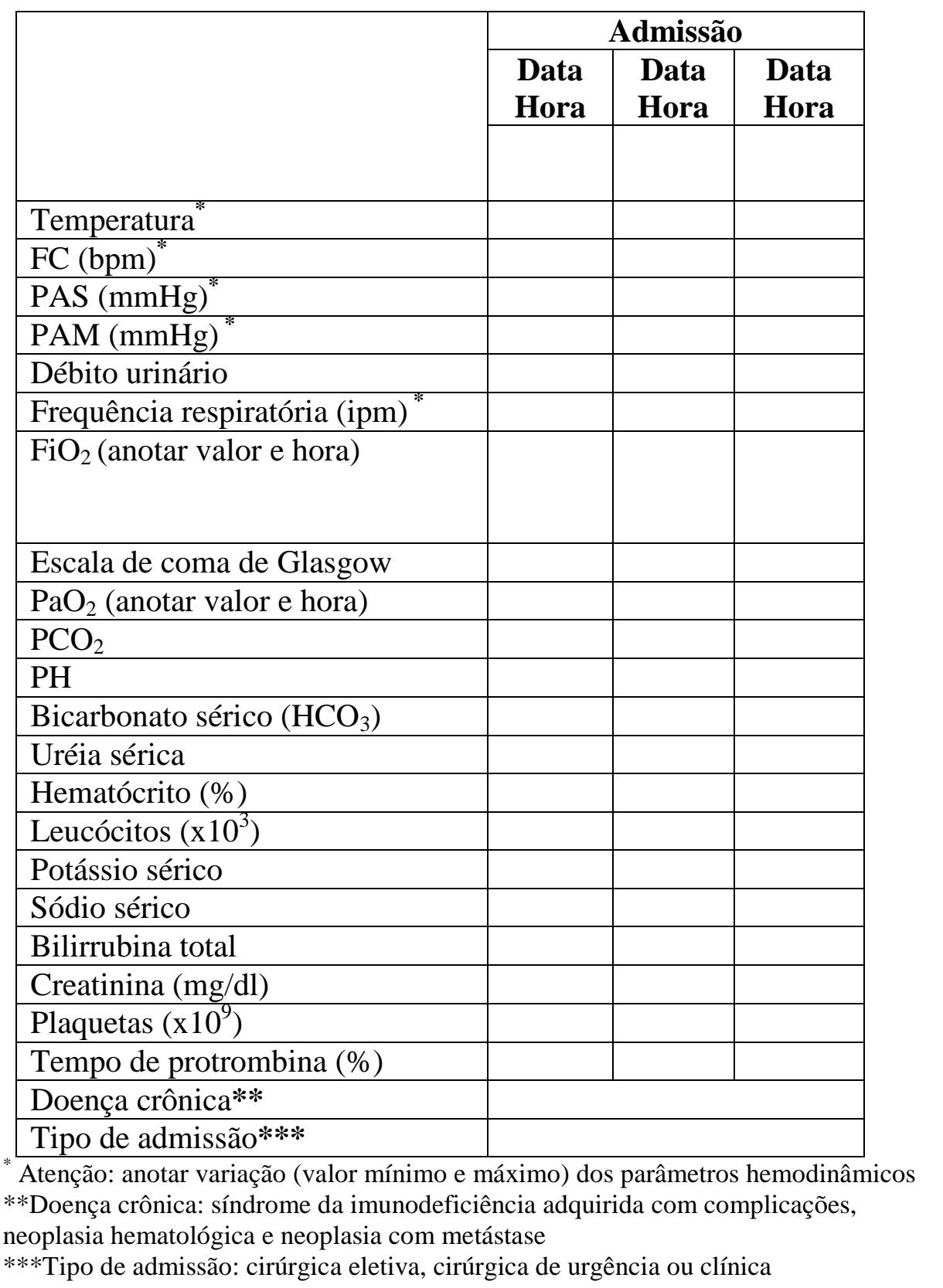




\section{Apêndice D}

\section{Formulário para aplicação do NAS}

\begin{tabular}{|c|c|c|c|}
\hline \multirow{4}{*}{ Nursing Activities Score } & \multirow[b]{4}{*}{ Ponto } & \multirow{2}{*}{$\begin{array}{c}\text { Admissão } \\
\text { Data }\end{array}$} & \multirow{2}{*}{$\begin{array}{l}\text { Saída } \\
\text { Data } \\
\end{array}$} \\
\hline & & & \\
\hline & & Turno & Turno \\
\hline & & & \\
\hline ATIVIDADES BÁSICAS & & & \\
\hline $\begin{array}{l}\text { 1 - MONITORIZAÇÃO E CONTROLES } \\
\text { 1a. Sinais vitais horários, cálculo e registro regular do balanço hídrico }\end{array}$ & 4,5 & & \\
\hline $\begin{array}{l}\text { 1b. Presença à beira do leito e observação ou atividade contínua por } 2 \\
\text { horas ou mais em algum plantão por razões de segurança, gravidade ou } \\
\text { terapia, tais como: ventilação mecânica não invasiva, desmame, agitação, } \\
\text { confusão mental, posição prona, procedimentos de doação de órgãos, } \\
\text { preparo e administração de fluidos ou medicação, auxílio em } \\
\text { procedimentos específicos }\end{array}$ & 12,1 & & \\
\hline $\begin{array}{l}\text { 1c. Presença à beira do leito e observação ou atividade contínua por } 4 \\
\text { horas ou mais em algum plantão por razões de segurança, gravidade ou } \\
\text { terapia, tais como os exemplos acima }\end{array}$ & 19,6 & & \\
\hline $\begin{array}{l}2 \text { - INVESTIGAÇÕES LABORATORIAIS: bioquímicas e } \\
\text { microbiológicas }\end{array}$ & 4,3 & & \\
\hline 3 - MEDICAÇÃO, exceto drogas vasoativas & 5,6 & & \\
\hline $\begin{array}{l}\text { 4- PROCEDIMENTOS DE HIGIENE } \\
\text { 4a. Realização de procedimentos de higiene tais como: curativo de } \\
\text { feridas e cateteres intravasculares, troca de roupa de cama, higiene } \\
\text { corporal do paciente em situações especiais (incontinência, vômito, } \\
\text { queimaduras, feridas com secreção, curativos cirúrgicos complexos com } \\
\text { irrigação), procedimentos especiais (ex: isolamento), etc }\end{array}$ & 4,1 & & \\
\hline $\begin{array}{l}\text { 4b. Realização de procedimentos de higiene que durem mais do que } 2 \\
\text { horas, em algum plantão }\end{array}$ & 16,5 & & \\
\hline $\begin{array}{l}\text { 4c. Realização de procedimentos de higiene que durem mais do que } 4 \\
\text { horas em algum plantão }\end{array}$ & 20,0 & & \\
\hline $\begin{array}{l}5 \text { - CUIDADOS COM DRENOS - Todos (exceto sonda gástrica), } \\
\text { inclusive SVD }\end{array}$ & 1,8 & & \\
\hline $\begin{array}{l}\text { 6- MOBILIZAÇÃ̃ E POSICIONAMENTO incluindo } \\
\text { procedimentos tais como: mudança de decúbito, mobilização do paciente, } \\
\text { transferência da cama para cadeira, mobilização do paciente em equipe } \\
\text { (ex: paciente imóvel, tração, posição prona) } \\
\text { 6a. Realização do(s) procedimento(s) até } 3 \text { vezes em } 24 \text { horas }\end{array}$ & 5,5 & & \\
\hline $\begin{array}{l}\text { 6b. Realização do(s) procedimento(s) mais do que } 3 \text { vezes em } 24 \text { horas } \\
\text { ou com } 2 \text { enfermeiros em qualquer frequência }\end{array}$ & 12,4 & & \\
\hline $\begin{array}{l}\text { 6c. Realização do(s) procedimento(s) com } 3 \text { ou mais enfermeiros em } \\
\text { qualquer frequência }\end{array}$ & 17,0 & & \\
\hline $\begin{array}{l}7 \text { - SUPORTE E CUIDADOS AOS FAMILIARES E PACIENTES } \\
\text { incluindo procedimentos tais como telefonemas, entrevistas, } \\
\text { aconselhamento. Frequentemente, o suporte e cuidado, sejam aos } \\
\text { familiares ou aos pacientes permitem equipe continuar com outras } \\
\text { atividades de enfermagem (ex: comunicação com o paciente durante } \\
\text { procedimentos de higiene, comunicação com os familiares enquanto } \\
\text { presente à beira do leito observando o paciente) } \\
\text { 7a. Suporte e cuidado aos familiares e pacientes que requerem dedicação } \\
\text { exclusiva por cerca de uma hora em algum plantão tais como: explicar } \\
\text { condições clínicas, lidar com a dor e angústia, lidar com circunstâncias } \\
\text { familiares difíceis. }\end{array}$ & 4,0 & & \\
\hline $\begin{array}{l}\text { 7b. Suporte e cuidado aos familiares e pacientes que requerem dedicação } \\
\text { exclusiva por } 3 \text { horas ou mais em algum plantão tais como: morte, } \\
\text { circunstâncias trabalhosas (ex: grande número de familiares, problemas } \\
\text { de linguagem, familiares hostis) }\end{array}$ & 32,0 & & \\
\hline
\end{tabular}


Apêndice D (continuação)

\section{Formulário para aplicação do NAS}

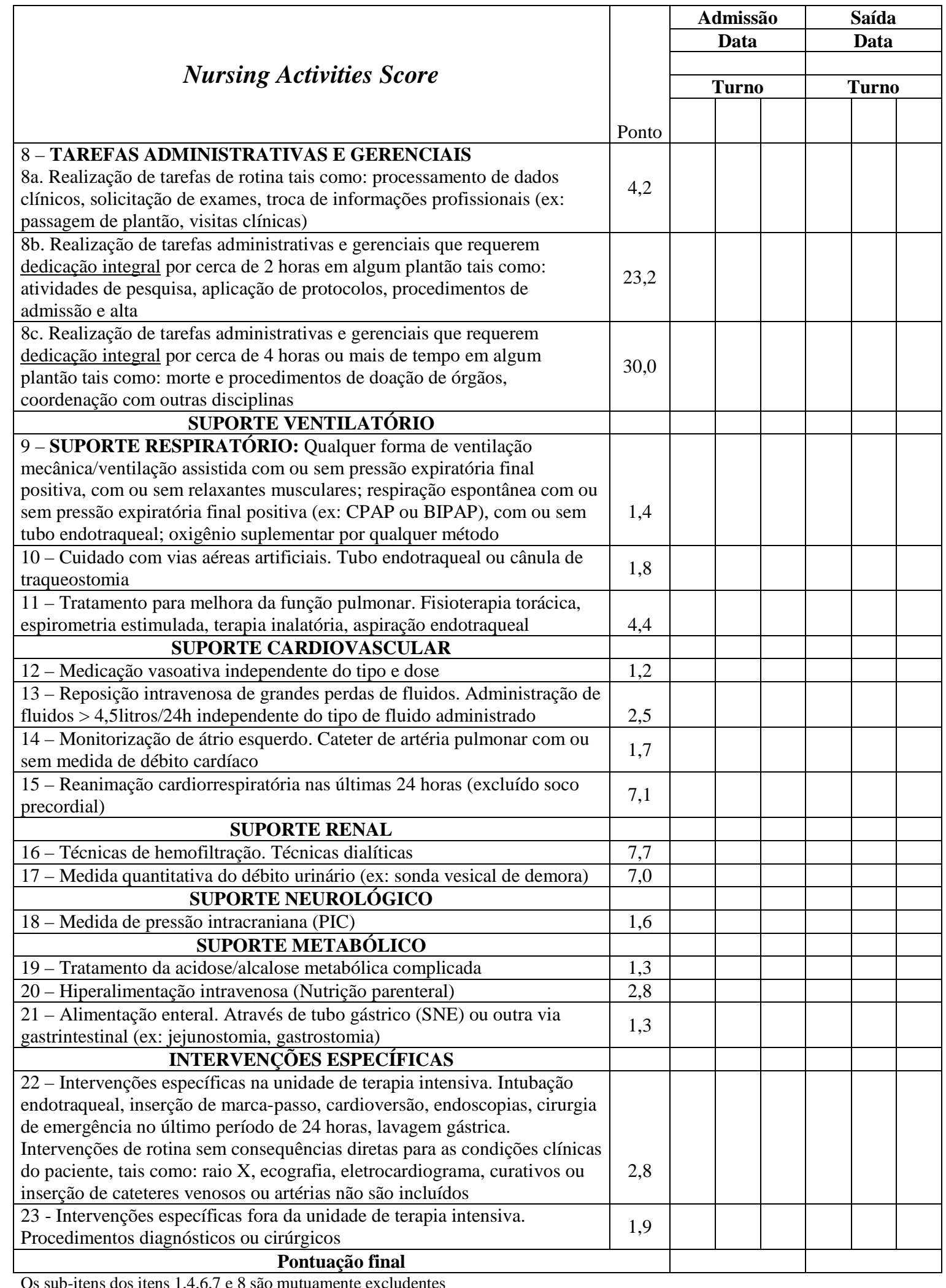


Apêndice E

Ficha para registro da descrição das lesões e cálculo do ISS e NISS

\begin{tabular}{|l|}
\hline DESCRIÇÃO DAS LESÕES \\
\hline \\
\hline \\
\hline \\
\hline \\
\hline \\
\hline \\
\hline \\
\hline
\end{tabular}

\begin{tabular}{|c|c|c|c|c|c|}
\hline \multicolumn{6}{|c|}{ Cálculo do ISS e NISS } \\
\hline $\begin{array}{c}\text { Região } \\
\text { Corpórea }\end{array}$ & $\begin{array}{l}\text { Descrição } \\
\text { das lesões }\end{array}$ & $\begin{array}{c}\text { Código } \\
\text { AIS }\end{array}$ & $\begin{array}{c}\text { Gravidade } \\
\text { da lesão }\end{array}$ & ISS & NISS \\
\hline Cabeça ou pescoço & & & & & \\
\hline Face & & & & & \\
\hline Tórax & & & & & \\
\hline $\begin{array}{l}\text { Abdome ou } \\
\text { conteúdo pélvico }\end{array}$ & & & & & \\
\hline $\begin{array}{l}\text { Extremidades ou } \\
\text { cintura pélvica }\end{array}$ & & & & & \\
\hline Superfície externa & & & & & \\
\hline Total & & & & & \\
\hline
\end{tabular}




\section{ANEXO}

Anexo A

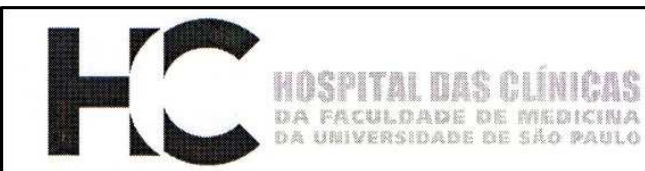

\section{APROVAÇÃO}

A Comissão de Ética para Análise de Projetos de Pesquisa CAPPesq da Diretoria Clínica do Hospital das Clínicas e da Faculdade de Medicina da Universidade de São Paulo, em sessão de 16/12/2009, APROVOU $O$ Protocolo de Pesquisa $n^{\circ}$ 1220/09, intitulado: "ESTUDO COMPARATIVO ENTRE ÍNDICES DE GRAVIDADE E CARGA DE TRABALHO DE ENFERMAGEM EM VÍTIMAS DE TRAUMA ADMITIDAS EM UNIDADE DE TERAPIA INTENSIVA", apresentado pelo Departamento de CIRURGIA, inclusive Termo de Consentimento Livre e Esclarecido.

Cabe ao pesquisador elaborar e apresentar à CAPPesq, os relatórios parciais e final sobre a pesquisa (Resolução do Conselho Nacional de Saúde n 196, de 10/10/1996, inciso IX.2, letra "c").

Pesquisador (a) Responsável: PROF. DR. RENATO SÉRGIO POGGETI Pesquisador (a) Executante: LILIA DE SOUZA NOGUEIRA

Orientador (a): PROFA. DRA. REGINA MARCIA CARDOSO DE SOUSA CAPPesq, 17 de Dezembro de 2009

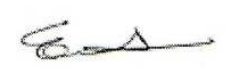

PROF. DR. EDUARDO MASSAD Presidente Comissão de Ética para Análise de Projetos de Pesquisa

Comissão de Ética para Análise de Projetos de Pesquisa do HCFMUSP e da FMUSP Diretoria Clínica do Hospital das Clínicas da Faculdade de Medicina da Universidade de São Paulo Rua Ovídio Pires de Campos, 225, $5^{\circ}$ andar - CEP 05403010 - São Paulo - SP Fone: 01130696442 Fax: 01130696492 e-mail: cappesq@hcnet.usp.br/ secretariacappesq2@hcnet.usp.br 